\title{
Pastoral Modernism: An American Poetics
}

\author{
Jennifer Tai-Chen Chang \\ Washington, DC
}

M.F.A., University of Virginia, 2002

B.A. University of Chicago, 1998

\begin{abstract}
A Dissertation presented to the Graduate Faculty of the University of Virginia for the Degree of

Doctor of Philosophy
\end{abstract}

Department of English Language and Literature

University of Virginia

May, 2017

Committee:

Jahan Ramazani, Director Michael Levenson, Reader Elizabeth Fowler, Reader Claire Lyu, External Reader 


\section{PASTORAL MODERNISM: AN AMERICAN POETICS}

TABLE OF CONTENTS

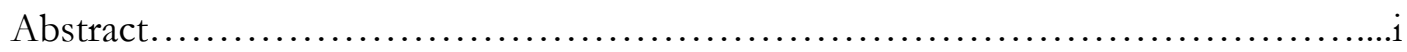

Acknowledgments.......................................................ii

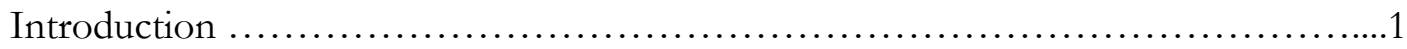

1. William Carlos Williams and the Democratic Invitation of Pastoral...............26

2. Pastoral and the Problem of Place in Claude McKay's Harlem Shadows.............73

3. The Pisan Cantos an the Modernity of Pastoral: Discourse, Locality, Race..........115

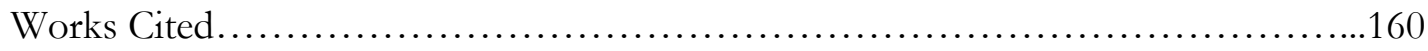




\begin{abstract}
Pastoral Modernism: An American Poetics uncovers the re-emergence of an ancient literary mode as a vehicle for both poetic innovation and cultural investigation in three exemplary America modernist poets: William Carlos Williams, Claude McKay, and Ezra Pound. In the first half of the twentieth century, the United States experienced dramatic demographic changes due to global migration, immigration, and the Great Migration, which effectively relocated black life from the country to the city. Further, the expansion of cities, as physical locations and cultural centers, not only diminished their distance from the countryside, but also altered rural topographies into suburban and commuter towns. This dissertation argues that by turning to the pastoral mode American modernist poets documented these shifting demographics and topographies, revealing the integrality of place to cultural and social identity. William Carlos Williams's pastorals—from his early short lyric poems to later world-building epics—reflect on how new populations of immigrant and blacks created political fissures in his small town of Rutherford, NJ, while necessitating a reconsideration of American space and cultural identity within the formal context of modernist poetics. For Williams, questions of cultural topography come to inform the typography and lineation of his poems. While the poems of Claude McKay's Harlem Shadows are largely set in New York City, the Jamaican-born inscribes Diasporic history into his pastoral lyrics by observing the confluences of weather and geography in the islands of Manhattan and Jamaica and, moreover, expresses a critique of American life, exposing tropes of nature as capitalist commodities. McKay illuminates how the social and emotional distances that pastoral historically tracks as geographical distances become absorbed into the very experience of modernity for marginalized individuals, whether they are in the city or the country. The final chapter turns to Ezra Pound's Pisan Cantos, in which his fusing of pastoral and poetic experimentation encompass a surprising, yet unintentional, transnational and multicultural American community. In reading Pound's pastoralism as a foil to Williams's and
\end{abstract}


McKay's embrace of American potentialities and their inevitable culmination, this final chapter posits the future of culture as balancing the accidents and intentions of both history and poetic design. How do poems reflect and, at the same time, remake our world? Pastoral Modernism: An American Poetics investigates how modernist poets attempt to innovatively answer this question in their pastoral writing. 


\section{ACKNOWLEDGMENTS}

Writing is solitary, but words and thoughts are, at their best, born of social exchange. Many people contributed to the critical imaginary of this dissertation, and I owe each a debt of gratitude that I can never adequately repay. At UVA, Steve Arata's course on late Victorian literature impressed upon me the remarkable sociality of Thomas Hardy's natural environments, and it was the opportunity to consider the forests of The $W$ oodlanders as a space of community formation that spawned my first thoughts about the culture of nature. Steve kept his door open to me long after I was his student, and I will always be grateful to his willingness to talk more about writing, Joseph Conrad, and the weird joys of academia. It was not until I audited Elizabeth Fowler's seminar on environmental thought and early modern literature that I began to see the capaciousness of pastoral as a literary mode.

Studying poetry with her has been transformative to how I read, write, and think about what poems do and can be. Her example is a touchstone in my life as a poet-scholar, and her participation in the final stretch of my dissertation has been a true gift.

Jahan Ramazani never made the project of writing a dissertation feel impossible or unimportant, and for this my gratitude is only outmatched by my sense of fortune in having so excellent and steadfast a dissertation director. The precision of his critique, his enviably lucid thinking, and, above all, his passionate faith in poetry's power to connect us to each other have been an inspiration to me as a scholar, teacher, and writer. I'm grateful to Michael Levenson for his persistent enthusiasm in this project. His generous responses to drafts emboldened me to trust my critical instincts and make more vigorous claims, and his exemplary work as a pedagogue continues to inform my faith in the humanities classroom as a space for community. I'm grateful, too, to Clare Lyu for agreeing to serve as the external reviewer of this dissertation and for doing so with such eloquence and acumen. 
Many hours were spent standing in Jim Miller's doorway at GW, talking about Claude McKay and the Harlem Renaissance, conversations that informed the revision of my second chapter. Although Jim passed away before I could show him the final version, I will be forever grateful for his voice, his career advice ("Stop raising your hand at department meetings!'), and his dazzling wit, which made me adore him and love our profession, despite everything.

I had the enormous luck of serving on the judging committee for the Kingsley and Kate Tufts Poetry Prizes at the Claremont Graduate School with Charles Altieri, whose work I had long admired and who became a most wonderful interlocutor. Charlie's tireless exuberance for aesthetics and poetry and his unnecessarily ardent support for my critical and creative work gave me the much needed push to finish two longstanding projects, including this dissertation.

All along the way, many friends took walks with me, offered to read countless revisions, housed me on research and conference trips, and nurtured my thinking about poetry, pastoral, race, and modernism. Thank you to Brian Glavey, Julia Hansen, Mai-Linh Hong, Jenny Johnson, Rowena Kennedy-Epstein, Aimee Nezhukumatathil, Cecily Parks, David Lee Rubin, Jolie Sheffer, and Lisa Russ Spaar. At GW, Daniel DeWispelare, D. Gilson, Robert McRuer, Ayanna Thompson, and Gayle Wald have been amazing colleagues and cheerleaders. I am especially grateful to Gabriel Haley for reading the earliest drafts and to David Francis and Madigan Haley for reading some of the last. Thank you to Jim Cocola, whose collaborations on MLA and MSA panels sharpened my conceptualization of pastoral. Cherene Sherrard-Johnson took a chance on my ideas on Claude McKay for her Companion to the Harlem Renaissance (Blackwell-Wiley 2016), and her fine editorial eye made the chapter significantly better. Nathan Hensley at Georgetown invited me to join his department's 
Environmental Humanities Symposium, which led to me think more about Empson and the modernity of "some." Towards the end, a fortuitous reunion with my undergraduate professor, Robert van Hallberg, reminded me why I was pursuing a Ph.D. and reinforced the need to finish, and I'm immensely grateful to him for sparking my initial curiosity in The Cantos. Through the years, this dissertation benefited from the counsel of librarians at the Beinecke Rare Book and Manuscript Library, the Schomburg Center for Research in Black Culture, The Poetry Collection at the University of Buffalo, and the Harry Ransom Center at UT-Austin. In particular, Jim Maynard at Buffalo and the very endearing librarian with the Ezra Pound tattoo at the Ransom Center provided indispensable guidance in the archive.

The first conversation I had about my dissertation was with my classmate Evan Rhodes. I wanted to see his prospectus and learn more about his research. Little did I know then that I would have the last conversation about my dissertation with him, nor that it would be a family celebration of sorts. There has been no greater friend to my heart and my thoughts. To Evan, I owe my humblest and most enduring gratitude for patiently waiting as I tried to find the best words in their best order. 


\title{
Pastoral Modernism: An American Poetics
}

\author{
Introduction
}

\section{The Nature of Modernity}

Ezra Pound's directive "Make it new" is perhaps the chestnut of modernism, but the language of this phrase reflects our conventional understanding of a cultural movement and moment that was, at heart, a call to innovation. It would seem strange then to reorient modernism, particularly American modernism, by focusing on a literary mode that began with Theocritus (circa 310-250 B.C.), caught the fancy of Renaissance courtesans, and abounds with Romanticist associations. However, as James Longenbach and Rebecca Beasley have emphasized, the "it" that must be made new is often, in fact, quite old, and numerous modernist poets found cause to make the timeworn mode of pastoral new. ${ }^{1}$ Pastoral began as "short poems of rural life (descriptive, narrative, amatory) often in dialogue for and supposedly uttered by simple rustics," but as a literary mode focused on "herdsmen and their lives," it has been at once a social form and an expression of the ethos or attitudes of a culture. ${ }^{2}$ That pastoral re-emerges quietly yet tenaciously in the work of twentieth-century American writers is remarkable for underscoring how pastoral absorbs persistent questions about person and place in the context of social, cultural, and political milestones that would irrevocably alter the way we perceive and write about American experience. The challenge of re-writing America, as a culture and a place, lay in re-imagining the aesthetic potential for pastoral. Writers as stylistically divergent as Claude McKay and Gertrude Stein, as formally inventive as Ezra Pound and Zora Neale Hurston, as

\footnotetext{
${ }^{1}$ Beasley, 19-31; Longenbach (1987), 3-28.

${ }^{2}$ Williamson, 568; Alpers, $\mathrm{x}$.
} 
idiosyncratic as Eugene O’Neill and Djuna Barnes contributed to the innovations of pastoral due in no small part to consequences of modernity such as urbanization, global migration, and two world wars. While much could be written about each of the above authors and their relationships to the mode and, indeed, to each other, my dissertation Pastoral Modernism: $A n$ American Poetics focuses on three American modernist poets - William Carlos Williams, Claude McKay, and Ezra Pound - who repurposed and revitalized pastoral in response to changes in topography, demographics, and cultural identity in the United States in the first half of the twentieth century.

The earliest examples of pastoral in western literature feature idealized visions of rural life wherein shepherds tend to their herds amidst unblemished nature. From Theocritus to Christopher Marlowe, classical and Renaissance poets took the perspectives of the aristocratic court, establishing an imaginative engagement with social and geographical distances that would grant pastoral a capaciousness of form and content that has proven endlessly adaptive to the concerns of subsequent eras. More than a measure between the country and the city, that distance would articulate the Romantic imaginary of an acculturated self, yearning for the freedom of inspiration, and then later mediate the nostalgic strains of the Victorian period, when the advent of industrialization threatened the bucolic rhythms associated with family life. ${ }^{3}$ Poets of these periods would continue to write of rural life, figuring like Wordsworth's shepherd Michael or Tennyson's northern farmer as emblematic of an innocence only nature and poverty could nurture; however, they wrote not from intimate experience but from an obeisance to literary precedence and the distance of their own privilege. Their pastorals engaged fictions of the countryside meant to uphold the cultural values of the city, preserving a hazy faith in the innocence of nature and its tenders

\footnotetext{
${ }^{3}$ Barrell and Bull, 1-9, 427-33.
} 
while highlighting the sophisticated observations of those at the center of civilized society. By the twentieth century, with the countryside in evanescence, distance arguably becomes contingent on sociological and psychological conditions. Boundaries between the city and the country were eroding, and migration and increased mobility meant that the distances between people could no longer be understood as strictly geographical. Between 1900 and 1914, nearly 13 million immigrants arrived in the United States, a number that exceeded immigration arrivals of the previous three decades. ${ }^{4}$ The Great Migration also reorganized the demographic map of the United States: from 1910s to the 1970s, an estimated 6 million African Americans moved from rural regions to the urban and industrial centers, where segregation and Jim Crow laws were far less severe and economic opportunities presumed more plentiful. ${ }^{5}$ Such large-scale population shifts fed directly into the formation of neighborhoods like Harlem, Yorktown, and Little Italy in New York City, just to name a few examples.

This history of pastoral is, to be sure, too swiftly charted, but the literature on the history and theory of pastoral is plentiful and impressively varied in methodological approach, including distinguished contributions from Paul Alpers, William Empson, Leo Marx, Daniel Halperin, Annabel Patterson, and Raymond Williams, among numerous others. My investigation into three exemplary modernist poets of pastoral will highlight how pastoral has been historically manifest as a fraught social form, evoking what Anne-Lise François has observed of pastoral as a "justifiably maligned genre in which you point to poor people and say how good they have it." While François's assessment is not inaccurate and William Empson has also flagged the "involuntary falsity" of pastoral, it overlooks the

\footnotetext{
${ }^{4}$ Parker, 16.

${ }^{5}$ U. S. Census Bureau; Wilkerson, 8-15.

${ }^{6}$ François, xx. Author's emphasis.
} 
potential for pastoral to interrogate the very cultural values and social distances it would seem to maintain and by which Raymond Williams justifies pastoral's enduring critical significance. ${ }^{7}$ To that end, pastoral cannot help but expose the world it depicts, however unintentionally and however imagined. Although pastoral as a literary term often brings fields to mind, the history of the mode indicates that the form has always been more social than environmental, focused on the dynamics between people within a particular space and not necessarily on places deemed "natural."

And yet, the pastorals borne of modernity do not preclude nature, just as any environment, however urban or constructed, invariably expresses the natural, what is not man-made and never wholly eradicable. The first poetics of the twentieth century to galvanize modernism was Imagism, and while it transformed the pages of little magazines from Harriet Monroe's Poetry to Dora Marsden's The New Freewoman, later The Egoist, based in Chicago and London respectively, the foundational thought of Imagism grew out of an encounter with nature.

In 1906, a twenty-three year old T. E. Hulme left behind his studies at the University of London to play vagabond in Canada. A gifted student of mathematics, he sought adventure, hopping trains, picking up odd jobs, and wandering the wilds of the New World. It was there, in the western prairie, that he saw for the first time a vastness of land that was thrillingly real yet quantitatively "incomprehensible." "The experience led him to abandon math and university life for good and to then turn to writing poems. It was a decision he would later explain rather obliquely in his unfinished work on poetics Cinders: "Formerly, one liked theories because they reduced the world to a single principle. Now the same reason

\footnotetext{
${ }^{7}$ Empson, 8; Williams (1973), 1-8, 272-306.

${ }^{8}$ Beasley, 2-4.
} 
disgusts us. The flats of Canada are incomprehensible on any single theory."' Two years later, Hulme would deliver a groundbreaking statement on literary modernism to an unsuspecting club audience in London. "A Lecture on Modern Poetry” includes a sole elusive mention of the image of the Canadian prairie that he could not dislodge from his mind: "Speaking of personal matters, the first time I ever felt the necessity or inevitableness of verse, was in the desire to reproduce the peculiar quality of feeling which is induced by the flat spaces and wide horizons of western Canada." ${ }^{\prime 10}$ Whether the newly arrived Pound was in attendance is unknown; however, Hulme's claim that out of the visible objects of the real world poetry must spring was as influential to Pound as French symbolism in formulating the tenets of Imagism. The two would become friends, part of a larger group of young writers who met regularly to eat together and talk of "the image and vers libre, with Hulme's voice dominating." ${ }^{11}$ For Hulme, as for Pound, it was in the "direct treatment of the object," and especially the natural object, that poetry could best capture the truth of the human condition. "The natural object is the proper and perfect symbol," Pound claimed in 1909. ${ }^{12}$ That this was a poetry free of the hallucinatory effects of meter and rhyme and bound instead to the concreteness of an image - and, indeed, the concreteness of encounter and observation - suggests a proto-ecological perspective that privileges realism and the symbiosis between the human and non-human. ${ }^{13}$

Although Hulme was utterly transformed by the Canadian prairie, he did not stay far afield. He returned, instead, to the metropolis, bringing with him a new vision for modern poetry from the hinterlands. In this, Hulme repeats the pattern of many writers of pastoral

\footnotetext{
${ }^{9}$ Hulme, 10-11.

${ }^{10}$ Hulme, 53.

${ }^{11}$ Moody, 96.

${ }^{12}$ Moody, 225.

${ }^{13}$ Phillips, 6-7.
} 
before and after him, demonstrating how a green thought in a green shade persists even under the harsh glare of city lights. In the introduction to The Penguin Book of English Pastoral Verse, Burrell and Bull explain that "[p]astoral had been from the outset an urban interpretation of rural matters," but it is worth discerning how nature gets figured and even abstracted into an expression we might too readily misread as acculturated. Consider that Hulme's urban perspective on the prairie is rendered as a "peculiar quality of feeling," which a surface reading suggests an experience of Shelleyan sublimity, as if the Canadian flats were just another Mont Blanc. But that "peculiar quality of feeling" describes, too, the young poet's recognition of incongruity between twentieth century contemporaneity and the timelessness of a natural environment that had so far been untouched by modernity. Hulme was standing on the precipice of monumental change; by 1917, three years after volunteering as an artilleryman for the British Army, he would be struck dead by a loose shell in West Flanders, one of many literary and artistic luminaries who would not survive the Great War. A perhaps more productive way to understand Hulme's transformative experience is as a tension made visible, settling finally on the poetic effort towards materiality that Imagism sought to perform. If Hulme felt a "peculiar quality of feeling" when facing the Canadian prairie, then he also seems to have read in the prairie both an image and a model for the future of culture. A future that eschewed the received forms of math and the old poetry. A future that resonated with impossibility yet stood as a stark materiality before him. His response was to write and talk about poems in London, a location of modernism where such futures could be realized.

What Hulme saw in the Canadian prairies was an aesthetic modernity, a plan for the future-of poetry and of place-that this dissertation attempts to unearth. For, it is out of the collision between modernism's now and the planetary time of nature that pastoral arises, 
an ancient form that urges us to see what is not yet present, that invests in "an often desperate belief in future improvement." ${ }^{\prime 14}$ Raymond Williams has argued that scholars of modernist studies ought to look beyond conventional locations like London and New York and find modernism in the hinterlands. ${ }^{15}$ Williams is right, no doubt, but he failed to consider how the hinterlands — as culture, memory, and peculiar qualities of feeling-found ways to insinuate themselves into modernism's presumed metropolitanism. That modernist poetry was born of the colluding imaginations of the New World and the natural world might be easily overlooked, dismissed as a curious anecdote, were it not for the modernist pastoral.

Although Hulme's work will not figure in this dissertation, the story of his vision for modern poetry informs and resonates with poets who experimented with tradition and, at the same time, straddled the boundaries between the real and the imagined in their writing. That this tradition is pastoral reinforces our understanding of the mode as mediating between the real worlds we live in and the worlds we dream about and long for. Such a distance is measured by thought, history, and language, but it is above all a distance that the three poets in question seek to somehow diminish. In Pastoral Modernism, both the real and imagined worlds can denote specific locations like New Jersey, Harlem, Jamaica, and Pisa, as well as more abstract territory such as, in the words of Randolph Bourne, the very real, if much contested, "trans-national America" or a paradisical memory of home, be it Jamaica or Idaho. ${ }^{16}$ Determining where the real world resides in relation to the imagined is the interpretive challenge modernist pastorals can pose to readers and, moreover, explains the occasional difficulty in recognizing a poem by a modernist like Wallace Stevens or Ezra

\footnotetext{
${ }^{14}$ Burrell and Bull, 6.

${ }^{15}$ Williams (1989), 47.

${ }^{16}$ Bourne (1964), 107.
} 
Pound as pastoral. When William Carlos Williams asks in his poem, “The Wanderer," "How shall I be a mirror to this modernity," I would propose that one answer is by writing pastoral. The very difficulties pastoral modernism submits us to-the uncertainty in identifying a person, the flux and instability of places - reflects modernity as we've come to understand it in the twentieth century. It's more than coincidence, then, that the collection “The Wanderer" appears in, the 1917 AlQue Quiere!, includes three poems titled "Pastoral," which I'll explore in depth in the first chapter.

Consequently, Pastoral Modernism seeks to uncover modernism’s various elsewheres, places imagined by poets of pastoral that might be unreachable, or just out of reach, yet nevertheless represent a necessary destination. "Elsewhere" renames pastoral's locus amoenus, the "delightful place" in which shepherds and other rustics dwelled and for which modernism's pastoralists long to return or arrive at. ${ }^{17}$ While these elsewheres could be found in Raymond Williams's hinterlands, they more often than not stood in close proximity to the city, or the dominant cultural locus cities represent. William Carlos Williams could walk to elsewhere, the poor neighborhoods of Rutherford, New Jersey, where he lived and which itself stood as an elsewhere relative to that better known location of modernism, New York City. Beyond geography, though, Williams's observations of town life reflected his own marginalization as both an artist amongst country folk and the son of immigrants, and what he imagines through writing pastoral are communities that can embrace a cosmopolitanism of mind and people. Claude McKay's poems articulate how racial experience in the United States makes any location in the city or the country feel like an elsewhere, and his acute longing for a home he would never return to intensifies his desire for a place of belonging anywhere. Pound's elsewhere is historical, fragmentary, heterogeneous, and often

\footnotetext{
${ }^{17}$ Williamson, 569.
} 
unintentionally visionary. Writing of his postwar captivity in Italy in The Pisan Cantos, the poet reveals the inherent transnationalism of twentieth century American space and identity, suggesting not only the modernity of elsewhere but the potential of pastoral to revise our more rigid conceptions of who we are and the role of place in shaping our cultural and social identities. In each instance I've noted here, the question of identity, like the question of futurity, finds answers in the contours of place - how places are made, imagined, and complicated by those who move through it.

Pastoral has historically reflected on the integrality of people and places: shepherds defined the country as much as the country was defined by shepherds. However, as modernism and modernity irrevocably altered individual consciousness (who we are) and topography (where we are), the rhetorical demands of pastoral shift. Elsewhere can no longer be found solely in the country. Modernism's pastoralists can no longer be merely shepherds or introspective poets, just as the aristocratic perspective has become retrograde. Renaissance poets imagined shepherds as freely and painfully amorous, while Romantic poets once positioned themselves as pastoralists - consider Marlowe's nymphs or a Londonbound Wordsworth pining for fields of daffodils. While modernist poets might assume the positions that their predecessors took, profligate with longing and self-conscious of their displacement, their subjectivities are distinctly marked by ideology and cultural identity. Their marginalizations are neither imagined nor exaggerated, but express the politics and poetics of belonging within modernity.

The attention to pastoral by modernist poets was also aesthetic, and this dissertation considers how responses to modernity as reflected in the innovations made to pastoral specifically reveal the priorities and practices of American modernist poetics. In reading pastoral writing as critical to the development of American modernist poetics, I want to 
demonstrate how a preoccupation with one's place in society and space becomes, too, a preoccupation with the place of the poem both on the page and in the culture: a field. Pastoral modernism, I argue, anticipates postwar concerns like multiculturalism, environmentalism, and urban development, even as the modernist poets this dissertation investigates largely excused themselves from activist action. However, if the modernist pastoral imagination is at all interventionist, that intervention aims not for environmental justice or ecological correction but for a vision of an equitable social space the might better inform the place that the United States was in the process of becoming.

\section{Locating Pastoral Elsewhere}

When we write about modernism, we are always, in a sense, writing about distance. Like our conceptions of place and space, distance encompasses both a measurable fact and an abstract concept. Distance maps the flâneur's ever-broadening circuit of the metropolis and assumes the transnational networks that animate modernity. It enunciates the conflict between the individual and "the sovereign powers of society," describing modern man's essential alienation in the age of the machine. ${ }^{18}$ Distance in modernism is also temporal; for, modernist artists, writers, and thinkers have, at once, an irreverent eye on the past and a determined eye trained on the future. The measure of distance between the country and the city is, accordingly, quantifiable and qualitative - each a destination and point of departure, each focusing a form of individual and/or collective longing. Locating elsewhere in modernist pastorals also measures a distance, allowing us to better to see what social, cultural, and aesthetic divides the poet seeks to traverse within the imaginative work of pastoral writing.

${ }^{18}$ Simmel, 324. 
That the categories of the country and the city were no longer stable or consistent by the twentieth century reflects Georg Simmel's explanation of the city as a "totality of effects which transcend their immediate sphere." ${ }^{, 19}$ While Simmel is making a broader claim about how the individual consciousness conditions the life of the city, his central insight that place coalesces human experiences (or "human sensoriums") rather than adhering to any cartography is especially illuminating to the innovative possibilities in writing pastoral. After all, the country, too, is a "totality of effects," one that reaches beyond physical boundaries. Moreover, Simmel's conception of place resonates with Lawrence Buell's ecocritical delineation of "place-sense," which collects an individual's experiences of all places into a kind of "palimpsest," as much historical as psychological, and determines how any one place is understood. ${ }^{20}$ One's place-sense may be loco-descriptive, but it is neither cartographical nor geographical because it projects individual consciousness and experiences onto place.

Walt Whitman's “This Compost” expresses the conflicted place-sense at the root of the American pastoral imagination. In it, he details a place-sense of America that is at once personal and historical, seeing through the natural beauty, the "still woods I loved," to a history of colonization, slavery, and war, or the "corruptions" to which he refers in one of the poem's last lines: "I am terrified at the Earth, it is that calm and patient, / It grows such sweet things out of such corruptions." ${ }^{21}$ Whitman's speaker's place-sense ultimately reaches beyond the limits of nation- "Is not every continent work'd over and over with sour dead?"- ending with the global imaginary of this terrifying Earth. In recognizing the persistence of nature's deceptive beauty, Whitman implores our keenest attentions to the invisible human suffering (personal and historical) our places can foster, reflecting a place-

\footnotetext{
${ }^{19}$ Ibid, 335.

${ }^{20}$ Buell, 73.

${ }^{21}$ Whitman, 307-9.
} 
sense that belongs not only to an individual but also to a collective, and that is not only American but also transnational. "This Compost" therefore establishes the history of American place as prone to a process of abstraction, one that enables pastoral in particular to constitute a place (a specific geographical location) and a space ("a site activated by movements, actions, narratives, and signs"). ${ }^{22}$ In other words, the place of America as Whitman describes it in "The Compost" is mappable, an edge of land by a forest, but it is also a space of history and culture, a battlefield, an example of man's violence to civilization and the environment, a past that cannot be reconciled by nature. It is this process of abstraction that permits the discourse of pastoral to engage culture and history as dynamically as it engages form and rhetoric.

But the modernity of pastoral ultimately lies in the pastoralist, whose determining consciousness, as suggested by Simmel and Buell, invokes larger questions about the consequences of human habitation and how place and person can be mutually altering. Wallace Stevens's “Anecdote of the Jar” offers a compelling example of this:

I placed a jar in Tennessee, And round it was, upon a hill. It made the slovenly wilderness Surround that hill.

The wilderness rose up to it, And sprawled around, no longer wild. The jar was round upon the ground And tall and of a port in air.

It took dominion everywhere. The jar was gray and bare. It did not give of bird or bush. Like nothing else in Tennessee. ${ }^{23}$

\footnotetext{
${ }^{22}$ Mitchell, $\mathrm{x}$.

${ }^{23}$ Stevens, 60.
} 
The pastoral imagination of Stevens's poem rests in the jar's presence, which makes the wilderness "no longer wild." But it is the pastoralist speaker, and not the jar, which does this work, entering the environment only to alter it with an acculturating perspective. Who is this speaker and is he indeed the pastoralist? What distances does this pastoral poem of modernism ascribe? No identity is named, no location other than Tennessee. Elsewhere would seem to be everywhere and, at the same time, stuck in the poem's identified location. (And where exactly in Tennessee? How far from Knoxville, Nashville, a highway?) The jar, an artifact, is, like a poem, made by human hands and imagination, and arrives in Tennessee like an outsider, intervening on the intrinsic wildness of the wilderness. Pastoral, in this sense, obstructs the natural by transforming it into a cultural space. Although Stevens set the poem in Tennessee, he could have just as easily chosen Ohio or Alabama. For, Tennesseeor Ohio or Alabama - is a metonym for the country, and the city that stands at an unknowable distance makes a stealth presence through the jar and, by association, the speaker. Their presence, however, does little to mitigate that they do not belong, that they bring with them the social and cultural distances that mark their status as urbane outsiders. Or, it is entirely possible that this Tennessee hill and the "slovenly wilderness" surrounding it are what do not belong, so transformative is the jar and its subsequent dominion, and certainly, the descriptor "slovenly" betrays the cultural prejudices of the speaker's otherwise subdued perspective.

Included in Wallace Stevens's 1923 first book, Harmonium, "Anecdote of the Jar" illuminates the conceptual tensions of writing pastoral in a modern time, when the encroachment of the city on the country was as much territorial as ideological, and it underscores the slipperiness of the pastoralist figure, whose modern consciousness is as elusive as it is destabilizing. Accordingly, Stevens's poem resonates with Simmel's 
observations that the "most significant aspect of the metropolis lies in this functional magnitude beyond its actual physical boundaries.... A person does not end with limits of his physical body or with the area to which his physical activity is immediately confined but embraces, rather, the totality of meaningful effects which emanates from him temporally and spatially." ${ }^{24}$ Where pastoral once replayed scenes from rural life from an urban perspective, by the twentieth century, the exigencies of modernity now complicated-indeed, blurredthe boundaries between people and places that had once seemed inviolable. Consequently, pastoral, as modernist poets rewrote it, must be read for "the totality of meaningful effects," wherein locations function beyond actual physical boundaries and the individual becomes diffused in time and space. While this no doubt makes pastoral harder to read, it also makes the work of reading a thrilling enunciation of the ontological questions of modernism and modernity: Where are we? Who are we?

\section{The Modernity of "Some"}

Although the political nature of modernism is no longer in doubt, it remains a subject of significant uncertainty with regards to the ecological turn in literary studies. As I noted earlier, modernists writing about the environment did so not for interventionist reasons but often as an aesthetic consequence of writing about images and locations. Consider, for example Ezra Pound's "In the Station of the Metro": an exemplar of Imagism, the poem's final line "petals on a wet black bough" is also a startling visual-material resolution to a description of a city crowd, performing an almost hallucinatory retreat after seeing the "apparition of these faces" while, at the same time, imitating Japanese poetics. Modernists' attention to the environment was largely unintentional or merely following the

\footnotetext{
${ }^{24}$ Simmel, 335.
} 
historical practice of troping on nature. (Consider, for example, Gertrude Stein's wetlands or Marianne Moore's imaginary toads.) More recently, though, Joshua Schuster and Sonya Posmentier have made astute work of discerning the environmental histories and ecological valences embedded in modernist poetics. ${ }^{25}$ Both have formed connections between concepts of space and place from scholars like Edward Said, Melvin Dixon, Paul Gilroy, Jahan Ramazani, Susan Stanford Friedman, among others, to ecocritical perspectives, observing that the environment is fundamental to aesthetics and culture. Pastoral Modernism contributes to this critical conversation by arguing that pastoral, as a social form contingent on the dynamics between identity formation and place-making, becomes a nexus of sociocultural and topographical transformations in the twentieth century.

Like Schuster, I read the environment as a kind of political unconscious in poems where nature is, in the case of Williams, evacuated by land development, or commodified, in the case of Claude McKay; and, like Posmentier, I consider how environmental phenomena reify histories of global migration and slavery. Even as pastoral lyrics concentrate on a solitary pastoralist, illuminating locational and historical sources of displacement, that individual character expresses synechochally, conveying through one example collective experiences of displacement that resulted from global and political modernity. As William Empson explains in his foundational, yet highly idiosyncratic study of pastoral, "literature is a social process, and also an attempt to reconcile the conflicts of an individual in whom those of society will be mirrored. ${ }^{26}$ To read pastoral as a mirror of modernity, reflecting back William Carlos Williams's question, further invites us to consider the efficacy of Empson's curious definition of pastoral as "putting the complex into the simple," which given the difficulties of reading modernist poetry would seem either inaccurate or

${ }^{25}$ See Schuster; Posmentier $(2012,2016)$.

${ }^{26}$ Empson, 19. 
impossible. And yet, as modernity makes pastoral more complex, pastoral modernism continues to crystallize the preoccupations of a culture within a specific historical moment. By reimagining the pastoralist figures, modernist writers identify marginalized populations and therefore mark the distances and social and political conditions that make them unseen. Poems in particular demand we pay attention, redirecting our perceptions from the prosaic rhythms of everyday life to the stop and start syncopation of lineation; only when we begin to see who is excluded from our culture can we truly understand it. To this extent, pastoral attempts to fulfill Adorno's conception of lyric as "containing the dream of the world in which things might be different." ${ }^{27}$

The very title of Empson's Some Versions of Pastoral gestures to the pluralities that pastoral modernism covertly cultivates. "Some" connotes the numerous, the considerable, an indeterminate many. Thus, when William Carlos Williams shifts to rhapsodic incantation in Spring and All, he sings of a peopled abundance: "The pure products of America / go crazy_-" are in fact an accounting of "mountain folk from Kentucky" to "deaf-mutes, thieves," "devil-may-care men... and young slatterns," rising out of "imaginations which have no / peasant tradition." This is an invocation of pastoral as well as a critique, a plurality of marginal characters written from the distant perspective of the "aristocratic" writer of pastoral who has "no peasant tradition." Williams's list leads us to an image of his own family through the lens of a domestic worker employed in his household, a leap of the imagination that emphasizes the pluralizing effect of "some":

Unless it be that marriage perhaps with a dash of Indian blood will throw up a girl so desolate so hemmed round

${ }^{27}$ Adorno, 40. 
with disease or murder

that she'll be rescued by an

agent-

reared by the state and

sent out at fifteen to work in

some hard-pressed

house in the suburbs-

some doctor's family, some Elsie-

voluptuous water

expressing with broken

brain the truth about us- ${ }^{28}$

James Clifford has written trenchantly on "some Elsie" as exemplary of how global

migration reconstitutes our localities, transforming through minute demographic changes the culture of small towns like Rutherford. ${ }^{29}$ Williams does not deny Elsie's personhood through the generalizing descriptor of "some," as some critics have indicated, but recognizes that she is one of many, a young woman integral to another community from which she is "sent out at fifteen to work in" his community. Elsie, to this extent, has crossed a distance while also representing that distance, from William's "house in the suburbs" to the elsewhere he can only imagine but that nevertheless reveals "the truth about us" as Americans. Pound's accidents of plurality bear similar small-town cosmopolitanism in The Pisan Cantos. When in Canto LXXV the flight of German composer Gerhart Münch out of fire-bombed Dresden ushers in a new space constructed "not of one bird but of many," Pound writes not against singularity but, instead, of an inherent plurality to poetry (birdsong) and culture (7) as he witnessed it in a military prison camp on the desolate outskirts of Pisa, Italy. ${ }^{30}$ His fleeting account of Münch's postwar survival launches the visual-material experiment of Canto

\footnotetext{
${ }^{28}$ Williams (2011), 64-66.

${ }^{29}$ Clifford, 1-18.

${ }^{30}$ Pound (2003), 28.
} 
LXXV, as well as the aesthetic production of abundance and variousness, reinforcing that

The Cantos arises not out of one art or culture but of many.

The importance of pluralism to equity and racial inclusion propels the pastoralism of Countee Cullen's "From the Dark Tower," a sonnet of the Harlem Renaissance that deploys conventions of pastoral to both reckon with the past and dream of a future: ${ }^{31}$

We shall not always plant while others reap The golden increment of bursting fruit, Not always countenance, abject and mute, That lesser men should hold their brothers cheap;

Not everlastingly while others sleep Shall we beguile their limbs with mellow flute, Not always bend to some more subtle brute;

We were not made to eternally weep.

The night whose sable breast relieves the stark, White stars is no less lovely being dark, And there are buds that cannot bloom at all In light, but crumple, piteous, and fall; So in the dark we hide the heart that bleeds, And wait, and tend our agonizing seeds. ${ }^{32}$

Cullen depicts the plight of field slaves, using the first person plural speaker to describe their enforced labor and express their powerful fortitude against it. "From the Dark Tower" is a poem of cultivation, a pastoral that, despite its adherence to formal tradition, also looks insistently toward the future. That future negates the present, protesting against the continuity of historical oppression: "We shall not always plant while others reap" arrives at the end of the octave with a decisive encapsulating rhyme, "We were not made to eternally weep." But the collective voice also absorbs the poem's contemporary moment in 1927 , when it was first published, at the height of the Harlem Renaissance. The "Dark Tower" refers to a gathering place on W. $136^{\text {th }}$ Street in Harlem, where black writers and artists held

${ }^{31}$ Claude McKay singled Countee Cullen out as "the most outstanding" of the writers and artists of the Harlem Renaissance. See McKay (2007), 144.

${ }^{32}$ Cullen, 139. 
their own modernist salon, and so the poem's "we" belongs equally to those working from the dark tower of art and the imagination. The poem therefore crosses centuries and locations, from the fields of slavery to a "black Mecca," joining together generations of black diasporic culture. Cullen's use of agricultural slave labor as a trope suggests that social justice, too, is back-breaking work and the poem illustrates how enduring oppression can ultimately cultivate insurrectionary energy. And so, the speakers, emboldened by their collective histories, wait: some voices looking toward some future. By connecting slaves to their Harlem Renaissance descendants, the poet highlights their shared sociocultural displacement, exploiting a literary tradition's tropes of labor and nature to "give a natural expression to a sense of social injustice." 33 Pastoral therefore serves as the poem's social form and its conceit.

Although Cullen's "From the Dark Tower" certainly makes a neat fit in demonstrating the potential for pastoral to engage and activate a plurality, not all pastoral lyrics employ a collective voice in order to evince an aesthetic and political modernity. What allows pastoral modernism to fulfill a "representative anecdote" is not solely the narrative construct of the life of herdsmen, but the re-imagining of herdsmen as the marginalized populations of the twentieth century. Every pastoralist figure, in this sense, is "some Elsie," a representative of global economic and cultural forces that transform "the country and the city" dialectic that pastoral refashions from one epoch to the next. To identify the pastoralist figure is to make specific and visible someone who was once undefined, unseen, and, in some cases, undocumented. This distinguishes the modernity of pastoral in the twentieth century as engaging a uniquely American practice. Moreover, while nativism in the United States encompassed a mounting anxiety over preserving a diminishing white European

\footnotetext{
${ }^{33}$ Empson 16.
} 
culture and population, pluralism articulated a need to redefine American cultural identity as new populations of immigrants from Southern and Eastern Europe and the growing migration of blacks from the country to the city were reconstituting it. As Walter Benn Michaels explains: "Since, in pluralism, what we do can be justified only by reference to who we are, we must, in pluralism, begin by affirming who we are; it is only once we know who we are that we will be able to tell what we should do; it so only when we know which race we are that we can tell which culture is ours. It is only, we might say, in pluralism, that the meaning of Americanism comes clear." ${ }^{34}$ Cullen's collective voice reflects the new populations resulting from the Great Migration and the Caribbean and Latin American diasporas, but pastoral absorbs other voices too that are little heard or seen and the work of identifying them becomes the work of understanding the meaning of Americanism in a new time.

\section{Pastoral Modernism: An American Poetics}

Pastoral Modernism: An American Poetics investigates the integrality of pastoral to developing the cultural and political inquiries at the root of American modernist poetics. Each chapter tracks the relocation of pastoral out of a conventional rural location, delineating how modernity changes conceptions of place and, further, erodes the boundaries between the country and the city. These changes were above all demographic and then topographic, the consequences of industrialization, urbanization, and mass movement. American modernist writers needed to relocate pastoral because the people that pastoralists would represent by the twentieth century now included blacks, immigrants, and other ethnic minorities, whose experiences of displacement, marginalization, and disenfranchisement

\footnotetext{
${ }^{34}$ Michaels, 15.
} 
made them peripheral figures regardless of whether they were in the city or far from it. Spanning the first half of the twentieth century, my chapters explore forms of displacement and the ways in which the people and places of modernity had a mutually altering effect on each other. From the provincialism of the years before World War I to the inescapable transnationalism of American culture in the years immediately following World War II, Pastoral Modernism reflects on how modernity enabled a classical mode of literature to join the innovative practices of modernist poetry to urgent questions about social space, racial exclusion, and American cultural identity.

My first chapter begins by investigating how William Carlos Williams's early experiments in pastoral poetry, which came to define his poetics, responded to demographic and topographical changes he observed in his locality of Rutherford, New Jersey, a oncerural town that stands the commuter's distance of five miles from New York City. I argue that Williams's reconceptualization of the page as spatial, visual, and social arise not only out of his engagement with visual artists like Charles Demuth, but also out of his everyday life in Rutherford, where his encounters while doctoring the working poor and local immigrant communities revealed to him the complexity of his cultural environment. Aesthetics, for Williams, ultimately facilitates questions about American space and belonging, and his own experience as the son of immigrants and modernist outlier, adamantly "homemade," informed a compositional process that expressed his desire for a more expansive sense of national cultural identity, one that included the new populations of immigrants, racial minorities, and the poor. ${ }^{35}$ Each of these "Others" informed Williams's conceptualization of who pastoralists are and what pastoral can accomplish as a modern American art form. Such questions of identity and place mark his early pastoral poetry as both democratic invitations

${ }^{35}$ Kenner (1989), 3-19. 
and modernist experiments and would then go on to shape his subsequent visionary work, the book-length poem Spring and All and the epic Paterson.

My second chapter focuses on Claude McKay's Harlem Shadows and the Jamaican writer's use of pastoral to claim black experience in America as a continuation of global diasporic history. In this way, McKay shares a collective place-sense with Countee Cullen, alternately expressing the limits and capaciousness of his dual American and global citizenship while, at the same time, recounting experiences of his acutely felt sociocultural alienation and racist oppression. As a foundational text of the Harlem Renaissance, Harlem Shadows, I argue, offers another approach to understanding the seminal artistic movement of African American culture as inseparable from transnational Modernism, challenging Harlem's centrality to the Renaissance and considering the nuances of exclusion in that movement as well as global social movements. Harlem was neither McKay's home nor his desired destination, but another reminder of his displacement and of the economic and emotional costs of modernity. The poet's depiction of places in the pastorals of Harlem Shadows delves deep into black global history and frequently connects environmental phenomena across cultures in order to make broader claims about cultural belonging and racial exclusions. Consequently, although McKay's poems appear on the surface to adhere to tradition, his poems manipulate English literary tradition with a deftness of rhetoric and detail, developing in his pastoral poetry in particular a politics and poetics of belonging. To this end, I read Harlem Shadows alongside and against McKay's prose, the memoir A Long Way from Home and an unpublished letter to The Nation, which together conjecture an "internationalist" elsewhere, neither American nor Jamaican, that the poet forever longed for and would never quite reach. ${ }^{36}$

${ }^{36}$ McKay (2007), 131. 
My final chapter reads Ezra Pound's The Pisan Cantos as an experiment in pastoralism and proposes that Pound's use of collage, literary-cultural allusion, and overheard dialogue emphasizes pastoral as a problem of language. The poem, I argue, builds toward pastoral through memory and repetition, by accident and inattention, and with an expansive sense of visual and material space that defied his traumatizing captivity in a U. S. military prison in Italy. My chapter makes no excuses for Pound's despicable politics and prejudices, but considers the poem as a kind of documentary capture of his first experience in decades of inhabiting American space, as his encampment was juridically deemed. Because of the population of soldiers imprisoned and posted, Pound's America in Pisa is racialized and profoundly pluralistic, and the poetic experiments on the page and in the language illuminate a cultural heterogeneity that Pound could not fully limit or control. Pastoral, in this sense, collects the details of the environment through the pastoralist's mere presence, and Pound's observations are often vibrantly indiscriminate. He reveals American space, and thus American cultural identity, as constructed of language, connecting historical pastoral language to American vernacular to the language of the world to produce a linguistic fabric reflective of the fully emerged multicultural, transnational, and heteroglossic character of the United States in the post-WWII period. As such, the place of pastoral in The Pisan Cantos represents a possibility for inclusivity, where whiteness is a vulnerable bystander to the inevitability of war, global migration, and rapidly emerging and insistently divergent localities.

The story I want to tell in Pastoral Modernism is about how American modernists made poems and how meaningfully material conditions interfered in that making. A poet 
wanders blocks from home into an unfamiliar neighborhood or peers into a Manhattan storefront window or feels the breeze coming through the bars of his steel cage, and what is observed in these moments can launch countless disparate memories, change the weather, and open up the space that confines him. Out of such vivid perceptual experiences, time escapes the clock, the world is traversed, and the poet begins to compose a poem. That composition process belongs not only to the poet, but also to a history and a world outside of the poet, animating the cultural imaginary that surrounds him. Another kind of distance that Pastoral Modernism explores, then, is between how a poem is made and how a poet is made, which is to say, the vast distance between intention and practice. Thus, each chapter of Pastoral Modernism treats distance as a variable of experience, one that destabilizes as much as it radically reshapes the dynamic between people and their places, poets and their poems. Distance, too, reveals a collective historical place-sense. What pastorals do for modernist poets and for the ongoing formation of modernisms is present us with the challenge of measuring this distance and recognizing it as a fact of topography, language, and culture. "Culture," Marc Redfield explains, "is acculturation—the forming of subjects, the reforming of the world." ${ }^{37}$ Pastoral stages culture, invites us to deliberate on what the culture is and what it might become, and so for modernism, in particular, pastoral becomes a means of forming new subjects and reforming the world. When Tagore received the Nobel Prize in Literature in 1913, he sent a telegram to the Nobel committee thanking them for having "brought the distant near, and made a stranger a brother." ${ }^{38}$ Tagore's observation alights on a fortunate accident of poetry, of reading and writing poems: the distant comes closer, the stranger suddenly more familiar. By identifying and studying the pastorals from an age of alienation and anxiety, this dissertation endeavors to cross the distances modernity creates

\footnotetext{
${ }^{37}$ Redfield, 2.

${ }^{38}$ Rabaté, 124.
} 
between people and between places. The work of Pastoral Modernism, then, is to locate the displaced, the marginalized, and the disenfranchised, and to finally see a landscape of modernism that had all along sought to accommodate a vision of the United States for the twentieth century and beyond. 


\title{
"No one will believe this of vast import to the nation": William Carlos Williams and the Democratic Invitation of Pastoral
}

\author{
Chapter One
}

\section{Strangeness and Distance}

In Politics of Modernism, Raymond Williams beseeches scholars to "explore [modernism] with something of its own strangeness and distance," and proposes a specific methodology. First, he suggests, recognize the city—namely, the metropolises of Paris, London, Berlin, and New York—as a "specific historical form." Second, he urges an unprecedented critical approach: to look "from time to time, from outside the metropolis: from the deprived hinterlands, where different forces are moving, and from the poor world which has always been peripheral to the metropolitan systems." While reading the city as a "specific historical form" has been standard practice in modernist studies, investigating modernism from outside of the city has thus far been narrowly interpreted. ${ }^{1}$ Scholars have followed through on Williams's directive by expanding modernism's geographies, as the editors of Bad Modernisms and Geomodernisms have recently demonstrated, and resetting the coordinates of modernist production to places as far-flung as São Paolo, Brazil and Filipino-America, which, in the figure of Carlos Bulosan, for example, maintained New York City as its cultural base. ${ }^{2}$ Which is to say, modernisms transnational, global, and aberrant have mostly succeeded in either unearthing cultural obscurities or contributing other metropolises to modernism's map. In challenging “the metropolitan interpretation of its own processes as universals," however, Williams is demanding that we take a detour away from the city and into the country, to the "hinterlands" and the "poor world"-locations that mark not only a geographical periphery but also a cultural one, where the

\footnotetext{
${ }^{1}$ Williams (1989), 47.

${ }^{2}$ Mao and Walkowitz, 238-268.
} 
"different forces" of different places—indeed, the difference forces of difference — also move us to see modernist aesthetics as less metropolitan than we've come to understand it.

In literature, the move from the city to the country has historically been a displacement framed by the pastoral. Intrinsic to modernist experience, displacement describes both the alienating effects of modernity, often—at least in Georg Simmel's metropolis—productively so, and the migratory habits of artists from Ezra Pound to Gertrude Stein. As Williams observes in another important text, The Country and the City, which focuses on the English pastoral tradition from the Renaissance to the nineteenth-century, displacement weds the country to the city while simultaneously sustaining their distance from each other. Because pastoral provides a formal space for this troublingly symbiotic, irrevocably co-dependent relationship between the country and the city, it also invites, often unintentionally, ideological critiques of the distances between social positions and between cultural values.

This chapter introduces the claim that pastoral contributes to the aesthetic and political programs of modernism through a mediation of social, cultural, and geographical distances and differences. I argue that William Carlos Williams, as an exemplary modernist innovator of pastoral, recognized the form's potential to reimagine American space and identity to reflect the demographic and topographical changes within his small New Jersey town of Rutherford. These changes resulted from the influx of new immigrants and from Rutherford's modernization, which included the macadamization of streets and the installation of street lamps. In pastoral, Williams discovered a formal space in which to explore national space and, as such, he was the first American modernist to explicitly approach poetics as a means of reconfiguring American space and identity to reflect the advent of modernity both locally and globally. He begins the project of national re-imagining that subsequent American poets would soon take up, including the poets I discuss in the next chapters. Williams's early pastoral poetry makes clear how the divide between the country and the city also 
needed to contend with the conditions of modernity, but they do not only record a town transitioning away from rurality. Leo Marx's handy axiom "No shepherd, no pastoral” underscores that pastoral is not locodescriptive, not merely nature writing; pastoral requires a human presence, marries person to place (and place to person), and is ultimately a social form. What binds the lineage from Theocritus's herdsmen to Wordsworth's nostalgic poet wanderer to Williams's New Jersey pastoralists is displacement - each is somehow isolated from society (by profession or vocation, emotion or experience) and therefore culturally inscribed as Other. Rather than unearthing the shepherds of modernism, I'll rely on the more fluidly transhistorical term "pastoralist" to refer to this strange and distant character whose presence throughout the American modernist canon arguably triggers questions about place and identity.

Focusing on pastoralists and the new locations of pastoral in modernism demands that we explore who is displaced and why, and that we take seriously how reading pastoral might re-orient modernism to foreground economic, social, and cultural differences embedded in our physical environments. Three poems titled "Pastoral" appear in Williams's third book of poetry Al Que Quiere!, and while they exemplify aesthetic innovations rooted in the sociocultural dynamics between people and places, pastoralisms abound in other poems, highlighting Rutherford's marginalized populations and neighborhoods. Williams's pastoralists were impoverished factory workers, outdoor laborers, and blacks and ethnic minorities in blue collar and domestic jobs. But the poet often casts himself in the role of pastoralist, reflecting an uncertainty as to what role his poems' speakers play in observing others far more marginalized than himself. The poet as pastoralist, after all, does not share the same material conditions as the "old man gathering dog lime" or "some Elsie," to cite two example from, respectively, Al Que Quiere! and Spring and All. In Williams's early pastorals, the uncertainty of who can justifiably assume the pastoralist role elucidates socioeconomic inequities at the same time as it invites us to consider the complexity of social space - of who belongs and to 
what extent. He thus reveals pastoral's capacity to represent and interrogate locality, providing a framework for understanding how places struggle to accommodate difference and how different people experience that accommodation, or more frequently lack thereof. Pastoral, as a "specific historical form," serves as formal space in which Williams can challenge, model, and experiment with both the integrative possibilities and limitations of national space and a burgeoning national heterogeneity. If pastoral exposes where and how individuals belong and, more persistently, don't belong, then how does pastoral serve Williams in conceptualizing national culture and identity in the early twentieth century?

Williams's experience of place informs his innovative pastoral work and, furthermore, connects his aesthetic practices to a critical inquiry of national identity and culture. Paul Giles observes that for American modernist writers, place is a "synecdochic embodiment of national impulse."3 Consequently, the poet uses pastoral to negotiate and reconfigure social space in order to negotiate and reconfigure national identity and culture. Moreover, pastoral's dexterous accommodation of distance, difference, and the pastoralist's socio-cultural desires suggests a pluralism that admits signifiers of otherness as, in fact, constituent of a democratic practice (and poetics) for the twentieth century. In each "Pastoral," the poet depicts his town of Rutherford, engaging the physical environment as a social experience. Reviving Robert Aubin's term “topographical verse," Stephen Burt makes a coherent case for a lineage of poems describing actual places from the Renaissance to contemporary periods. ${ }^{4}$ But while "topographical poetry" reflects Williams's perceptive observations of specific places, the three poems titled "Pastoral" do far more than offer descriptions of a town, connecting instead to the complex dynamics of belonging, disenfranchisement, and power that undergird the long history of pastoral. So one pastoral concludes, after a description of a poor neighborhood in Rutherford, "No one / will believe this /

\footnotetext{
${ }^{3}$ Giles, 45.

${ }^{4}$ Burt, 598.
} 
of vast import to the nation." ${ }^{5}$ In the pastorals of $A l$ Que Quiere!, Williams observes beyond his immediate topography to a critical understanding of the social distances absorbed into American places.

That writing pastoral seems counterintuitive to literary modernism was not lost on Williams, and he would revisit the significance of this mode to his early work. In a series of interviews with Edith Heal from 1963, he explained:

Without knowing Greek I had translations of The Odes of Theocritus and felt myself very much attracted by the pastoral mode. But my feeling for the country was not as sophisticated as the pastorals with their picturesque shepherdesses. I was always a country boy ${ }^{6}$

Williams acknowledges the historical lineage he writes out of and makes clear his own sense of difference. "I was always a country boy" declares an identity that implicitly contradicts literary modernism and cultural modernity. But he also contrasts himself to the sophistication entwined into the history of pastoral, which was written from the beginning from the perspectives of the city and/or aristocratic court. For Williams, geographical location was paramount because it transformed his home into not only poetic subject matter but also cultural locus, thereby forming an argument against the cosmopolitan metropolises designated as locations of modernism. While other American writers expatriated to Europe, seeking admission to a well-established cultural tradition and thriving contemporary scene, he stayed home and wrote about Rutherford. In this sense, he recognized Otherness early on as a potentially positive quality based on his own "homemade" experience as a son of immigrants, a doctor, and a modernist outlier.

\footnotetext{
${ }^{5}$ All poems by William Carlos Williams are quoted from The Collected Poems of William Carlos Williams unless otherwise stated. See Williams (1986), 65.

${ }^{6}$ Williams (1958), 21.
} 
Not belonging, then, might become a sort of identifying American trait. Describing the conditions that led him to poetry in I Wanted to Write a Poem, he remembers, "I was conscious of my mother's influence all through this time of writing, her ordeal as a woman and a foreigner in this country.... Remote, not only because of her Puerto Rican background, but also because of her bewilderment at life in a small town in New Jersey. ${ }^{7}$ With $A l$ Que Quiere!, his third book of poems and first aesthetically significant work, Williams selects for his audience this small town in northern New Jersey. Although the title translates as "To Him Who Wants It," the poet writes to and for the townspeople of Rutherford, addressing them from the book's first poem as "my fellow grotesques," and henceforth making explicit and implicit invitations to engage with and encounter the Other, specifically the town's population of blacks, immigrants, and the poor. For, in recognizing his mother's lifelong sense of estrangement "as a woman and a foreigner," Williams experienced firsthand the exclusionary practices of his hometown, whether these were municipally sanctioned or subtly inflicted in every day society, and AlQue Quiere! emerges as both a critical reaction to these exclusionary practices and an ambitious agenda for social correction through poetry.

One of the forms of social correction Williams uses in AlQue Quiere! is pastoral, and the three poems titled "Pastoral" relocate this mode to the streets and "houses of the very poor" and attempt to reconfigure Rutherford as socially equitable and culturally integrative. Through pastoral, he finally realizes, by contrast with the solipsistic apprentice work of his earlier two books, how "to connect the happenings in the world generally with what takes place in the poem." Although Rutherford seems a pale shadow of the world-let alone the United States, another New Jersey native shared Williams's small town perspective. Writing in the February 1913 issue of the Atlantic Monthly, the journalist and social critic Randolph Bourne identifies as the "real epitome of American life" towns that are "large enough to contain a fairly complete representation of the different classes

\footnotetext{
${ }^{7}$ Williams (1958), 16.
} 
and types of people... and yet not so large that individualities are submerged in the general mass." He then gestures towards a national cultural production: "If a modern writer wishes to win an imperishable name as a historian, he has only to write an exhaustive monograph on the life of such a town." " No evidence confirms that Bourne was writing of Williams, nor that the two ever met or read each other; still, in championing the integrality of difference to the nation's conception of itself, both men emphasize the importance of locality and invest in an anticipatory multiculturalismespecially Bourne in his 1916 essay "Trans-national America."

If pastoral grounds Williams and the poems of Al Que Quiere! in Rutherford, specifying a location did not limit the capaciousness of his democratic reach. Charles Bernstein explains: "while Williams insisted on the primacy of the local (often as access to the universal), even his most radical claims about American identity are accompanied by statements about the need to use the kind of singularity that artworks achieve to break down difference and weaken partiality." Investigating the singularity with which Williams uses pastoral "to break down difference and weaken partiality" as a means of forming an American cultural identity will direct the remainder of this chapter.

\section{Reading the Topography of "Pastoral"}

By writing pastoral, Williams could respond to municipal trends on the allocation of public space and to the ways in which social experience is spatially organized. In his lifetime, Rutherford would develop into a commuter town for Manhattan office workers and, at the same time, become part of a region of small flourishing factories, ${ }^{10}$ which the poet would observe in his pastoral poems

\footnotetext{
${ }^{8}$ Bourne (1913), 227. Like Williams, Bourne chose to live and write away from New York City in New Jersey and his town of Bloomfield was a mere six miles from Rutherford. ${ }^{9}$ Altieri, 109.

${ }^{10}$ In the first decades of the twentieth, Rutherford boasted several large-scale businesses in including the Rutherford Cement Construction Factory, the Braender Rubber and Tire Company, the Standard Bleachery, and George B. Holman's carpet cleaning company. The town also maintained
} 
as both a steady urbanization of a formerly untouched natural environment and a population suddenly diversified culturally and socioeconomically. To this extent, understanding Williams's innovations to pastoral requires an understanding of the social and spatial alterations happening in Rutherford during the first decades of the twentieth century. According to David Frail, Rutherford stands as the "pastoral middle ground between the untamed Jersey hills and the city." himself called it a "country town," underscoring that it was neither strictly urban nor rural, and not quite an exact classification of a suburb. By 1917, Rutherford had absorbed industrialization without quite forsaking its natural environment, for it had thus far managed to resist widespread urbanization due to the dominant conservatism of its leading citizens. Among other acts of provincial stubbornness, they successfully thwarted the construction of playgrounds in 1916, which were disdained by many as a "city idea."12 Although he counted among them, Williams was wary of the power of this socioeconomic elite, and believed that their tendency towards hypocrisy and social hierarchizing prevented them from accepting responsibilities to their community—such as allotting public spaces in which children, especially those of the space-deprived poor, could play. Yet, the political procedures of a small town - that the vehemence of collective voices could determine the fate of an undeveloped lot_-appealed to Williams's communitarian politics and to the sense that his place could potentially fulfill his democratic vision of America. Living at 9 Ridge Road on the corner of the town's main thoroughfare, Park Avenue, he could view from his window "the heart and pace and people of his town."13 A mile to his west lay the Passaic River, the banks of which he remembered in his youth as a stretch of rural landscape, traces of which still existed in the steadfast nature of marsh reeds and gulls. But he locates his pastoral lyrics to the east, on the other side of the its agricultural foundations through commercial farms, dairies, and greenhouses that took advantage of its rich land and proximity to New York City and important transportation networks. See Neumann and Newberry.

${ }^{11}$ Frail, 110.

${ }^{12}$ Ibid, 112.

${ }^{13}$ Neumann, 120-29. 
tracks, in the back streets and industrial alleys where poor laborers-many of whom were either black or recent immigrants—-made their home. In poetry and in life, then, Williams lived at the crossroads of a recent rural past and an encroaching urban modernity.

His frustration with Rutherford resulted from the exclusion of these other voices and the understanding that embedded in the argument against, for example, public playgrounds lies the fear of mixing populations. In the poem "Sub Terra," which opens Al Que Quiere!, Williams implores the town's leading citizens to join him in "poking in negro houses," demanding the very social integration that his "fellow grotesques" were avoiding. Exemplary of the new "trans-national America," a term coined by Bourne, Rutherford was experiencing the emergence of its own transnational, multicultural diversity. The 1910 U.S. Bureau indicates that ninety-five percent of the town's population was white; the other five percent is vaguely specified as "Other." The 1915 New Jersey Industrial Directory curiously notes that "the immigrant population [of Rutherford] consists of ten Italians." ${ }^{14}$ Accurate demography, however, depends on thorough investigation as well as anecdotal evidence, and informal histories of Rutherford and its environs contradict these demographic studies.

According again to Frail, the "not inconsiderable population" of blacks were "probably descended from the 2,000 free Negros and 600 slaves living in Bergen County in 1830 than [those that] had lately come North" in the years before the Great Migration. ${ }^{15}$ In other words, blacks had constituted an integral, if not integrated, population within Rutherford for nearly a century. By 1907 the number of immigrants arriving in the United States had reached a high of 1.3 million, complicating the identity of both a common people and a common place. ${ }^{16}$ These populations gravitated to the margins of city and country, occupying back streets and the lowest positions in

\footnotetext{
${ }^{14}$ Department of Labor, 542-43.

${ }^{15}$ William Eric Williams, 36; New Jersey Writers’ Program, 169-81.

${ }^{16}$ Daniels, 30-31, 39.
} 
industrial and domestic labor. The problem of spatial organization became the problem of where to locate these populations. New York City introduced zoning laws in 1916, which authorized municipal bureaucrats with the responsibility of a city's spatial organization or, as one historian has described it, the process of rationalizing land. ${ }^{17}$ The 1916 zoning laws claimed to regulate the balance between commercial and residential spaces, limiting the development of new businesses—from skyscraping corporations to industrial factories to small shops—-that might curtail a residential neighborhood's reasonable expectations for a peaceful existence. Thus, the laws were the culmination of a decades-long campaign from "mansion owners and merchants" who sought "to preserve the unique character" of their exclusive neighborhoods. But the laws also limited possibilities for accommodating increasingly heterogeneous populations into what Williams and later city planners might recognize as common places. ${ }^{18}$ Although zoning laws began as an urban municipal practice, it would quickly spread to rural and suburban towns, the "so-called hinterlands," and, curiously enough, the roots of these laws were believed to have arisen from neighborhood associations whose local activism could in fact reshape a smaller town. One of the most instrumental of these was the Fifth Avenue Association, which formed in New York City in 1907 as increasing immigration populations threatened to encroach upon clean and quiet streets. Arguing to keep businesses away from the residential blocks of Fifth Avenue, the Association sought to control who could live, work, play, and explore their neighborhood. In other words, spatial organization facilitated social organization that, in classifying neighborhoods, overtly and covertly, segregated the poor from the rich and ethnic and racial minorities from whites. Thus, the question of what constituted a common place inevitably decided who belonged where.

${ }^{17}$ Taylor, 1-41, 131-180.

${ }^{18}$ Although written nearly half a century later, Jane Jacobs's 1961 landmark study on the affect of zoning laws on misconceptions of city life, as well as on urban planning practices, provides indispensable history and social commentary on how neighborhoods have emerged and disappeared and how public spaces like parks and playgrounds become the contested terrain of political factions and the municipal government in New York City in particular. See Jacobs. 
Rutherford, too, found itself participating in a similar debate about how to organize the town's public spaces, specifically where to construct playgrounds. In 1914, two had been built in local schoolyards and Williams attended the opening ceremonies of both. He was a member of the playground commission's executive committee and included his signature on the fundraising notice “A Playground Appeal.” By 1916, however, Rutherford’s mayor, William C. Black, publicly denounced playgrounds as "a needless expense," arguing that "the population of Rutherford is not sufficiently dense to require these city ideas." 19 In fact, the population was growing denser, and the unstated argument was that a playground would allow populations old and new to mix in democratic play. Those who needed playgrounds most came from families that were often too poor to have a backyard or other adequate outdoor space to play in. A public playground would allow the children of factory workers and doctors, from back streets and Main Street, across classes and cultures, to interact and engage with each other, breaking down the invisible boundaries, or mere blocks, that separated them. Indeed, the "city idea" that the mayor and the townspeople who supported the end of playground construction was cosmopolitanism at its most unsophisticated level, literally child's play.

In the book's first pastoral, Williams walks to the "back streets admiring the houses of the very poor," where "yards cluttered with old chicken wire," "furniture gone wrong," and "outhouses built of barrel staves" betray a neighborhood crowded with fragmentariness— "parts of boxes, all”but no human presence. Save for the pastoralist, the poet wanderer who finds himself where he does not belong. "[P]oking in negro houses," then, represents one way to account for the unspecified five percent of Rutherford's population. "Pastoral" and the other townspeople poems begin to document the undocumented, and together propose a space in which other cultures and classes might merge. Writing to his brother in 1909, the twenty-five your old Williams insisted that "Art is

\footnotetext{
${ }^{19}$ Frail, 111.
} 
intrinsic[,] it is not a plaything, it is an everyday affair and does not need a museum for its exposition[,] it should breathe in the common places and inspire us at the moments of decision in our work and play." ${ }^{20}$ If pastoral represents and interrogates locality, then Williams's pastorals put forth that Rutherford's "common places" must also include, among others, the invisible inhabitants of the back streets, the black factory workers, and the Williams's Portuguese housekeeper who would figure prominently in Spring and All. Not only is art intrinsic, but their pastoral emplacement suggests that these Others - and their social, cultural, and economic differences — are also intrinsic to American experience by the early twentieth century. Moreover, that Williams asserts their presence throughout $A l$ Que Quiere!, facilitating an encounter between leading citizens and the unseen poor and minority population, reinforces a multiculturalism that was transforming small towns and big cities alike. To exclude them, Williams suspected, would not only further calcify art but also American life.

Although in writing $A l$ Que Quiere! Williams aimed to express "the language as spoken," 21 Marjorie Perloff points out that it is the "look" of his poems that organizes their form. She limits her reading of his "wholly distinctive visual prosody" to reading typography — and certainly, it is the type and typewriter that alights Williams's free verse. ${ }^{22}$ I'd like to expand Perloff's conception of visual prosody to include topography. The practice of describing a locality, topography alerts us to how social experience contributes to the particular places represented in Williams's pastorals. The absence of the Other in the back streets, for example, sharpens both the pastoralist's incongruous presence and the distance of that impoverished neighborhood from the town's center. (By center I mean not only the town's physical center, but also the social and cultural powers that the word

\footnotetext{
${ }^{20}$ Williams (1957), 15-16.

${ }^{21}$ Williams (1958), 75.

${ }^{22}$ Perloff (1996) 89, 92.
} 
"center" connotes.) Williams is simultaneously focused on organizing the space of poetic form and the space where social code and locality meet.

In writing the first "Pastoral" to appear in the book, Williams explained that he was "playing with the form of the line, and getting into the American idiom.."23 The poem begins:

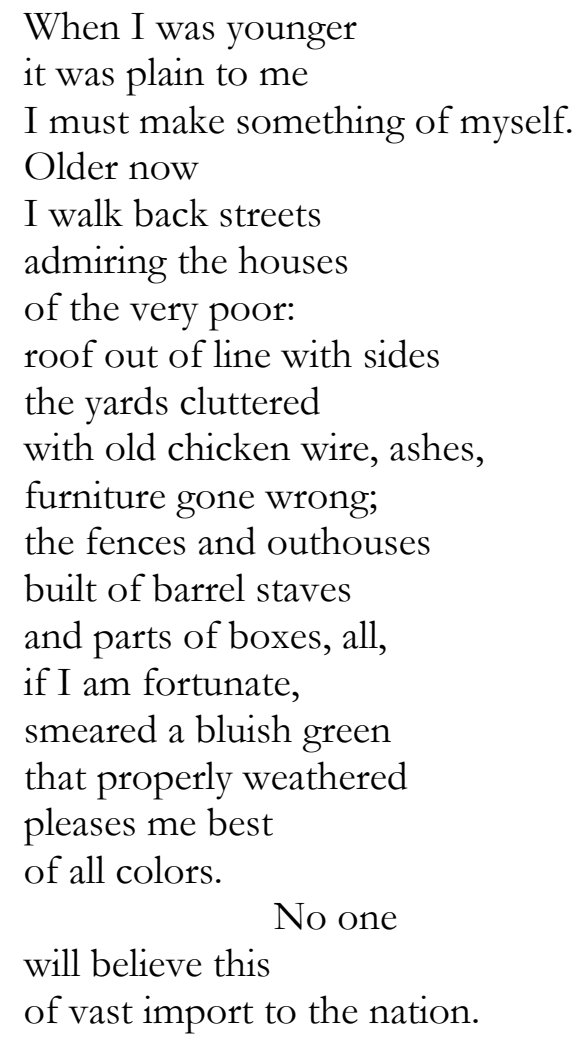

The first three lines break between each clause, a straightforward enjambment that matches the straightforward language: what's plain to the speaker (Williams the poet-pastoralist) is also plain to the reader. Although Williams's use of the vernacular persists, his enjambment becomes more abrupt as his one-sentence reflection gives way to environmental observation. Thus, the lines shift from what's spoken to what's seen, and this seeing is both selective and fragmentary. Enjambment in "Pastoral" illustrates how location comprises the visual. ${ }^{24}$ In the fifth and sixth lines, Williams enters a peripheral neighborhood in Rutherford_- "I walk the back streets / of the very poor"_-and

\footnotetext{
${ }^{23}$ Wagner-Martin, 74.

${ }^{24}$ See Cushman; Longenbach (2004).
} 
each subsequent line accumulates further detail to flesh out the scene. While these lines consist of fragments, the enjambment fragments what we see: the broken, cluttered, and wrong objects that construct the neighborhood of the very poor, "parts... all." And yet, despite this clutter, no one is home, and the sole human presence, the wandering poet and self-designated pastoralist, does not belong here. If these lines train the eye to read the depth of space depicted in "Pastoral," the idiom identifies a specific place, the back streets of Rutherford, and a specific perspective, the intruding pastoralist.

By scanning the visual prosody of "Pastoral," we see how typography and topography work together to show us what, or rather who, is missing: the invisible poor. If the enjambment highlights the fragmentary make-up of the back streets, the absence of its inhabitants makes it impossible for this scene, this neighborhood, and, most important, this nation to become whole. Visually, though the poem spans one columnar stanza, the indentation of line 20 splinters the poem, exposing a shard of white space soon after Williams has expressed admiration for a favored color, "bluish green." It is as if the work of describing the back streets, which becomes increasingly more poetic and expressive of the speaker than the environment, ruptures that space and makes it harder to see. Further, what's described in lines 15 to 19 arises from Williams's desire for aesthetic beauty, and this shift to the imagination and the ineffable complicates his authority by emphasizing his physical and perceptual intrusion. As the sole someone in "Pastoral, he is indeed making something of himself, but is it at the expense of the invisible dwellers of the back streets?

"No one / will believe this / of vast import to the nation" concludes the poem, and that spectral presence of "No one" stands in uncomfortable contrast to the very real absence of the very poor. Williams's pastoral relocation incites a political understanding of place. What population does "No one" represent, and why does no one believe this neighborhood will have "vast import to the nation?" How does such a spectral presence stand in a position of judgment? Further, the use of 
"import" encourages a range of connotations. "Import" could be read as ironizing the authorizing perspectives of the poet-pastoralist, who reduces the neighborhood into both poetic material and pleasing landscape. To read "import" as a commodity objectifies the population, much as "furniture gone wrong" and "parts of boxes" serve as synecdoche for who's missing and their intrinsic brokenness. "Import" also underscores the kind of mobility that Williams performs by wandering into the neighborhood and thereby introducing a figure of difference into a new environment. But "Pastoral" is broken, dubious, and Williams the poet and pastoralist, the insider-cum-outsider, cannot dismantle the many obstacles to social and cultural integration.

In 1917, the "very poor" living in the back streets were likely industrial blue-collar workers, a population that consisted largely of Germans, Italians, and Poles, recent immigrants and first generation Americans that, like the unseen inhabitants of his pastoral of the back streets, remained largely undocumented. This is reflected in the poem: the very poor ghost the scene, perhaps an antecedent to "this" or perhaps utterly excluded from the poem's language. Thus, the estranging pronoun "this" in the final lines, "No one will believe this of vast import to the nation," begs for an antecedent, but such definition has been obfuscated by the manifold machinations of the poem. Does "this" refer to the neighborhood, the absent poor, or the personal and poetic aspirations behind "Pastoral"? That Williams permits this uncertainty opens the possibility that each—the place, the people, and the poem—-might be of equal value and, further, equally undervalued.

If Williams offered his voice as a citizen to the need for more common places, he also found ways to engage in this conversation as a poet. For, in opening pastoral to new places, he opened it to new people. Pastoral space served as a blueprint for the common places he imagined to his brother, not only where art could breathe but also where individuals from all facets of society could encounter each other and potentially coexist harmoniously. Paul Giles reads the places represented in American literature as "geographical projections" that beyond mapping a location also inscribe 
the political and cultural instabilities that make places "contested terrains." 25 Although Williams places his pastorals in Rutherford, the poems do not merely map the town so much as disclose the tensions that make it, and other America places, such contested terrain. The pastorals intimate how keenly he had absorbed the debate over playground space and other contested terrains in Rutherford. He thus renders his location dynamically, suggesting that a "geographical projection," unlike a map, is not fixed on a page but nebulous as an image projected onto a screen and, consequently, vulnerable to external factors, from the varying light of critique to shifts in perspective - who's gazing and how. This becomes especially apparent when we observe Williams's revision process for one of the pastorals in AlQue Quiere!, which demonstrates how ungainly and malleable the "national impulse" could be. ${ }^{26}$ "Pastoral" reconstructs a particular curbside in Rutherford, a small space to be sure; however, from draft to draft, the poem's changing social coordinates graph the difficulty of accommodating social, economic, and cultural differences in local and national space.

The composition history of "Pastoral," the second in AlQue Quiere!, reflects his struggle to reinvent his poetics and his place-attending to the look of the poem, tuning the odd music of his enjambment, and articulating an aesthetic practice that somehow contributed to his increasing civic involvement as a local doctor, school medical inspector, and parent. This earliest known version of the poem accompanied a letter to his friend Viola Baxter Jordan in 1914 and was originally part of a sequence titled "Pastorals and Self-Portraits":

The old man who goes about

Gathering dog lime

Walks in the gutter

Without looking up

And his tread

Is more majestic than

That of the Episcopal minister

\footnotetext{
${ }^{25}$ Giles, 39 .

${ }^{26}$ Ibid, 45.
} 
Approaching the pulpit

Of a Sunday.

Meanwhile

The little sparrows

Hop ingenuously

About the pavement

Quarrelling

Over those things

That interest them

With sharp voices

But we who are wiser

Shut ourselves in

On either hand

And no one knows

Whether we think good

Or evil.

These things

Astonish me beyond words! $!^{27}$

Note that, though he's using free verse, Williams has yet to do away with the convention of capitalizing each line's initial letter. Meanwhile, in terms of space, "Pastoral" enacts a steady approach to the interior, away from the old man in the gutter to the sparrows' quarreling on the pavement to the enclosed collective voice. By the poem's end, this collective voice has diminished into one, and his wordless astonishment is as conclusive as it is isolating. Williams never positions this first person speaker as a singular subject, absorbed as " $\mathrm{I}$ " is into "we" and standing finally in the accusative, as the direct object to "these things" and perhaps a ghostly embodiment of that "no one" in the penultimate sentence. (It is as if, astonished, the speaker has turned into stone, has been silenced, and therefore cannot act as a subject.) But is this "me" the pastoralist? Or does the pastoralist figure in one of the poem's actual subjects — the old man, the little sparrows, or the enigmatic yet wise collective? It could be the old man because he is marginalized by location and engaged in manual labor, or the birds indulging in a Theocritan contest of song. The collective voice is the least likely to qualify as pastoralist and, given their illegible moral knowledge and seeming subjective authority, one could justly assume they are a stand-in for Rutherford's leading citizens.

${ }^{27}$ Williams (1986), 42-43. 
The indeterminacy of the pastoralist also marks the poem's spatial indeterminacy. From clause to clause, we encounter a new subject and a shift in location, and the two (subject and location) collaborate on the construction of a social space, rather than the delineation of a specific place: the gutter articulates the old man's poverty while the unidentified "we" dwells in an unidentified interior; between them the birds sing a quarreling song. Williams demarcates the distance between the old man and the collective authority with these birds— "little sparrows" as insistent as Rutherford's natural environment and, indeed, lyric history; however, it is a separation that reinforces the status quo, maintaining distance where community interaction might offer relief from the old man's degrading labor and release from the self-isolating collective. Which is to say, Williams's use of pastoral here accomplishes an accurate representation of how geography might serve social segregation, but he doesn't interrogate this experience or use of space. He hasn't yet figured it out.

The revision he prepares for Al Que Quiere! in 1917 alters none of the language. Rather, it rearranges the sentences, as if each were a discrete object or set piece, and in doing so, Williams repositions his characters. How does this repositioning, then, alter the space of the poem or, more pointedly, how does pastoral work to re-orient and reconstruct the topography? This is "Pastoral" as it appears in AlQue Quiere!:

The little sparrows hop ingenuously about the pavement quarreling with sharp voices over those things that interest them. But we who are wiser shut ourselves in on either hand and no one knows whether we think good or evil.

Meanwhile, 
the old man who goes about

gathering dog-lime

walks in the gutter

without looking up

and his tread

is more majestic than

that of the Episcopal minister

approaching the pulpit

of a Sunday.

These things

astonish me beyond words. ${ }^{28}$

By 1917, the initial capitalization is gone, the concluding exclamation point has been replaced with the more sober period, and the concluding sentence remains in the same place. The dominant changes are social and topographical. Williams revises the poem—or, re-arranges it—to advance song before labor, for now we begin with the little sparrows laying claim to the pavement and the music of this redesigned space. Further, Williams delays the figure of the old man, so that his emergence later in the poem reads like a quiet revelation. No longer lost to the mysteries of the wiser "we," his comparison to the Episcopal minister is the last of "these things" which astonish the solitary speaker beyond words. The old man is the final astonishment. To arrive at the individual, and concurrently the specific, after encountering the collectives of the sparrows and the wiser implies a more hopeful experience of community life. An individual can emerge, and with greater majesty than a preacher (another pastoralist of sorts), despite the indifference and emotional distances of the rest of the town. The old man moves freely, continues with his work, and persists. More important, his convergence with the solitary speaker, both in silence, puts them in the poem's closest example of confrontation, and this approximate encounter intimates not only recognition, but also respect for the old man.

And yet, the revision resists the ease of movement Williams's “ingenuous" language and syntax otherwise permit. Instead of forming a direct line to the interior and the solitary, "Pastoral"

\footnotetext{
${ }^{28}$ Williams (1986), 70-71.
} 
circulates from outside to inside, requiring that we make room for the birds and the old man and move around the "we" of the leading citizens. Such destabilizing spatial orientation emphasizes how freely subjectivity can become dispersed. From every social and geographical perspective, we must experience the space anew. Although who the pastoralist is comes into sharper focus in this revision, who dominates the space has become far more difficult to discern. Indeed, merely repositioning the old man towards the end of the poem makes it less likely to forget about him and leave him behind. Distributing subjectivity therefore distributes a certain kind of social power among "Pastoral"'s characters. But reading "Pastoral" strictly for space is not enough, and one of the crucial revisions Williams makes is temporal. He re-assigns the word "meanwhile" to the old man, enforcing the continuity of his poverty and labor and suggesting that his presence remains incontrovertible despite nature (in the form of birdsong) and society (in the form of that unidentifiable, constrictive "we").

Both versions of "Pastoral" aspire to a condition "beyond words," quietly entangling readers in a complexity of orientation and interpretation from which one can't easily be freed: this poem astonishes us beyond words, too. Its 1914 pairing with self-portraits further implies that Williams associated the form with reflexivity; while self-portraits reflect individual identity, pastorals reflect spatial identity. Moreover, that he originally conceived of the pastorals within the framing device of a lyric sequence anticipates the expansive pastoralism of Spring and All, a work that both brandishes its endless potential for re-arrangement (social, formal, and topographical) and assembles figures from a multitude of cultural and economic differences (from J. P. Morgan to the "dark woman" that concludes the poem). Like these earlier pastorals, Spring and AlPs formal innovations continue to be indebted to Williams's experiments with social and topographical space. Consequently, his ambitions for pastoral as a literary mode, from 1917 to 1925—and arguably later-enact a far more difficult reflexivity than one would expect, a difficulty that arises when we begin to recognize that, in citing self-portraiture, his pastorals ultimately mirror a self that is not individual, but collectivized and 
national. To this extent, the ideological critique embedded in pastoral guides, in Williams's pastorals, a democratic cultural production; as he writes in another pastoral: "If I talk to things / Do not flatter yourself / That I am mad / Rather realize yourself / To be deaf and that / Of two evils, the plants / Being deaf likewise, / I choose that. ${ }^{, 29}$ Such hostility targets Rutherford's elite and the reader of poetry, neither of whom are, in a sense, paying enough attention to their surrounding environment. Williams tempers such hostility by the time he prepares his pastorals for publication, but the posture of his critique persists. One of the difficulties in reading "Pastoral" ["The little sparrows'] is measuring this critique, and the poet's revision by re-arrangement, however intentional, hints at the poet's own desire to relinquish authorial control - as if the poem could be endlessly re-organized, as if any order would result in wordlessness.

While its lack of an "overall external structure" offered him a broader capacity for formal experimentation, ${ }^{30}$ Williams recognized pastoral as a form through which he could study his own locality, where "the countryside was a real world but nonetheless a poetic world." Pastoral, in his understanding of it, therefore spotlights the world rather than the self: "I have always," he stated, "believed in keeping myself out of the picture."31 Instead of Williams, the picture we see in "Pastoral" — from draft to revision, drawn without a fixed subjectivity—is Rutherford's own image: inconstant and in need of revision. A reification of community, "Pastoral" also proposes improvements that cannot be executed by law but must be practiced in everyday life. In other words, the responsibility for social change is passed onto the reader. Indeed, that the pastoralist is hard to identify, and delayed from view, puts us readers, too, in a pastoralist position; and we must negotiate the space sentence by sentence, managing and making sense of our own displacement as a

${ }^{29}$ Williams (1986), 45. Litz and MacGowan identify "Pastorals and Self-Portraits" as a sequence in the notes: see Williams (1986), 478. Although the revision of "Pastoral" appears in Al Que Quiere!, the sequence as it was sent to Viola Baxter Jordan was not published until Red Townley's edition of The Early Poetry of William Carlos Williams in 1975. See Williams (1975), 177-85.

${ }^{30}$ Fowler, 107.

${ }^{31}$ Williams (1958), 44. 
network of cultural, social, and spatial distances. Pastoral, as such, becomes participatory and tangible, activating a politicized poetics that engages the reader by sharing its responsibilities of perspective and place-making. Otherness as an intrinsic condition, then, exists within the poem and without, reflecting the poem's own destabilizing movements.

Soon after the publication of $A l$ Que Quiere!, Williams wrote an article for the November 1917 issue of Poetry Journal, in which he intimates his social ambitions for the book and its distinctive pastoralisms:

back of these aristocratic forms [of poetry] lies the democratic groundwork of all forms, basic elements that can be comprehended and used with new force. Being far back in the psychic history of all races no flavor of any certain civilization clings to them, they remain and will remain forever universal, to be built with freely by him who can into whatever perfections he is conscious of. ${ }^{32}$

The freedom Williams espouses in his defense of American poetry_ “to be built with freely by him who can into whatever perfections he is conscious of"- echoes in the very title of Al Que Quiere!, which translates as “To Him Who Wants It!” As a literary mode unencumbered by a prescribed formal structure, pastoral allowed the poet free range to mediate between the real and poetic worlds and to thereby experiment with the spaces of the page and the town he lived in. In fact, the book was not to whomever wants it but the leading citizens of Rutherford, his intended audience. Further, the mediation is the structure, and in reaching between seemingly disparate worlds, Williams measures the distance between the pastoralist and this audience, revealing how his structure aims to fulfill formal and social objectives. As Bourne was quick to note, the cultural plurality brought on by a thriving immigrant population did not imply "the failure of Americanization" but the need for "an

\footnotetext{
${ }^{32}$ Williams (1917), 29.
} 
investigation of what Americanism may rightly mean." ${ }^{33}$ If "America shall be what the immigrant will have a hand in making it," 34 then pastoral was exactly "the democratic groundwork" where Williams could begin investigating how different people and different places were remaking America and, in turn, "Americanism."

\section{The All of Spring and All}

Critics typically refer to Spring and All as Williams's most avant-garde work because of its chronological disruptions and collaging of prose and poetry, and perhaps more than any of his early poems, it engages with the material reality of the page as a painter would a blank canvas. Dedicated to Charles Demuth, the poem owes much to visual art, as both critics and Williams attest, and further aligns with Dadaist principles of fracture, juxtaposing images of the country and city as a Dada artist might splice together disparate scraps of media. But these formal experiments and aesthetic debts, I would argue, first began taking root in earlier work by Williams on the social life and aesthetic efficacy of American modernism and therefore follow his already substantial considerations of the relationships between people, place, and sociocultural experience. That his revision of "Pastoral" ("The little sparrows") enacts a zoning of the page reflects his perception of literary space as hybrid, interdisciplinary, and topographical, engaging practices that reach beyond mere prosody. Essays he wrote in the same period reveal the extent to which space preoccupied his aesthetic practice. Space was not simply a problem of visual prosody but also a cultural discourse in which Williams ultimately sought resolution through the pastoralisms of Spring and All.

In Al Que Quiere!, Williams reconfigured Rutherford as exemplary of a "trans-national America," experimenting with the poetic space of pastoral to remake national space. These experiments get tested in Spring and All, where the poetic space has expanded exponentially and

\footnotetext{
${ }^{33}$ Bourne (1964), 108.

${ }^{34}$ Ibid.
} 
conceptions of national cultural identity have become increasingly complicated within the possibilities of pastoral writing. This expansion is formal, dialectical, and willfully chaotic, and the book-length poem is an exuberant testament of Williams's modernist ambition. Beyond its significant aesthetic achievement, though, Spring and All is an avant-garde experiment born of the poet's pastoral impulses. Reading the poem through the lens of pastoral, as a culmination of his pastoral inquiry into national space and identity, we begin to see the dazzling promises and potential fault lines of a multicultural, transnational America expanded beyond the lyrical scale of Rutherford. In Spring and All, Williams not only stakes his considerable claim in modernist art, but also continues to interrogate American cultural space and identity through an innovative pastoral poetics.

Spring and $A l l$ is not the first text in which Williams collaged genres and mixed tonal registers. As noted earlier in this chapter, in "America, Whitman, and the Art of Poetry," he surveys the current state of American poetry by first rejecting the influence of Whitman, then addressing Pound and his attachment to European masters like Dante, and finally listing numerous literary publications and their diverse contributors, from Marianne Moore to J. P. Morgan. (Notably, various names in this list re-appear in Spring and All.) Published in the November 1917 issue of Poetry Journal, Williams's article showcases a curious mélange of essay, epistolary, manifesto, and roll call. If he makes a mess on the page, he does so as a tribute to and, indeed, a representation of the pluralities of American modernism. Further, this is vibrantly reflected in the eclectic and very social nature of Williams's literary enterprise. The prologue to Kora in Hell does similar work: dropping names of modern writers, artists, and citizens, Williams mingles a defense of American poetry with excerpts from letters of Pound and H. D. that express doubts about their stateside friend's poetics and, in Pound's case, cultural authenticity. Deeply critical of the state of American arts and letters, Pound mocks Williams: "And America? What the $\mathrm{h}-\mathrm{l}$ do you a blooming foreigner know about place.... Would H. [D.], with the swirl of the prairie in her underwear, or the Virile Sandburg recognize you, 
an effete easterner as a REAL American? INCONCEIVABLE!!!!!” ${ }^{35}$ Pound's letter is dated 10 November 1917 and is concurrent with the period in which Williams was completing the manuscript of Al Que Quiere! Only a few short months before, Congress approved U. S. entry in the Great War. The letter suggests an ongoing, and quite anxious, conversation between the two poets about the formation of cultural identity within an increasingly fraught transnational context. Unsurprisingly, Pound in the end deems Williams's ethnic hybridity as what saves him from the American provincialism he himself had escaped by expatriating to Europe: "You thank your bloomin gawd you've got enough Spanish blood to muddy up your mind, and prevent the current American ideation from going through it like a blighted colander."36

Because Williams's letters to Pound from this period have been lost, the prologue offers a response that the archive cannot. Alongside H. D., Pound's voice provides a salient counterpoint against which to defend his writing, American cultural life, and the problematic discourse of identity. Williams's defense of his own writing in the prologue consequently underscores a broader perspective on a new American cultural identity. He declares his intentions as such:

There is nothing sacred about literature, it is damned from one end to the other. There is nothing in literature but change and change is mockery. I'll write whatever I damn please, whenever I damn please and as I damn please and it'll be good if the authentic spirit of change is on it. ${ }^{37}$

Contradictory in tone, Williams's words nevertheless continue a conversation between writers, transatlantically and discursively. Williams meets Pound's nitpicking and H. D.'s sermonizing - "I consider this business of writing a very sacred thing!" - with brazen irreverence. He refuses to allow the conversation of art to descend into the jockeying of cultural principles: "If the inventive

\footnotetext{
${ }^{35}$ Williams (1969), 8, 3-27. See also Witemeyer.

${ }^{36}$ Witemeyer, 31.

${ }^{37}$ Williams (1969), 10.
} 
imagination must look, as I think, to the field of art for its richest discoveries today it will best make its way by compass and follow no path."38

But Williams is also responding to other American poets. As he began writing the prologue, after completing the manuscript of prose poems, "The Love Song of J. Alfred Prufrock" appeared in Poetry's XXX 1919 issue, and the violence of his reaction to Eliot's poem in part fueled the vigor of the prologue's claims that art was a means for imagination and discovery, not an acquiescence to tradition:

I had a violent feeling that Eliot had betrayed what I believed in. He was looking backward; I was looking forward. He was a conformist, with wit, learning which I did not possess. He knew French, Latin, Arabic, god knows what. I was interested in that. But I felt he had rejected America and I refused to be rejected and so my rejection was violent. I knew he would influence all subsequent American poets and take them out of my sphere. ${ }^{39}$

I felt he had rejected America and I refused to be rejected... Williams's conflation of self and nation here explains his defensiveness against not only the expatriate community's perception of America as a cultural backwater, but also the Old World erudition that Eliot represented. As he declared in the earlier article on Whitman, America provided new groundwork that made Pound's and others' reverence for European masters seem beside the point. Moreover, his attack of Eliot's poem reveals how personally he took accusations of American provinciality, and he counters the expatriate poet by charging him with being traditional. William's “sphere” was the New World - pathless, ahistorical, and thus truly modern. The struggle to realize a modern American poetry was ultimately a struggle over both people ("subsequent American poets") and territory ("my sphere"), both of which Eliot's poem, in Williams's view, leave out.

\footnotetext{
${ }^{38}$ Ibid.

${ }^{39}$ Williams (1958), 30.
} 
The crowds he enumerates in these various texts- the Whitman article, the prologue of Kora in Hell, Spring and All, as well as later reminiscences of this time in the Autobiography and interviewsform a bulwark against the robust doubt espoused by Eliot, Pound, and H. D. that the United State could produce a potent cultural force. Indeed, Williams's crowd serves as a public arena for art. The individuals he lists in these texts are both audience to new work (as in his recounting of the Armory Show in Autobiography) and the creators who fill the pages of countless American journals (as he attests in the Whitman article). Williams's name-dropping abounds in both texts and warrant quoting, in part, to demonstrate the inclusive work of his prose. About The Soil, he notes, "It is all very democratic, all very decorative, this apotheosis of trust magnets and trip hammers and Jack Johnsons. I like it. I think it makes a fine lively magazine.” He praises the Others, the magazine he occasionally edited and frequently published in, as attempting "to present a blank page to Tom, Dick, and Harry with the invitation to write a masterpiece." He goes into greater detail about the contributors of The Poetry Review:

Fletcher and Eliot and Stevens are going over the forms of yesterday and making fine stuff to read and enjoy. So is Pound.

Kreymbourg is concerned with "finger exercises." That is, he is studying musical form.

Bodenheim is indifferent to everything but the delicate adjustments of his adjectives. And so forth. ${ }^{40}$

Most of these names — with the exception of Tom, Dick, and Harry—recur in the prologue, which also includes poets Mina Loy, Marianne Moore, and Wallace Stevens (in the form of an excerpted letter) as well as visual artists Walter Arensberg, Marcel Duchamp, Man Ray, and others. As these names suggest, both works of prose reflect an American cultural space as transnational, without

\footnotetext{
${ }^{40}$ Williams (1913), 36.
} 
borders between geographies or identities. Williams simply portrays the interactions between American artists and between artists in America and consequently expands the kind of common place he envisioned in 1909 and when writing the pastorals of Al Que Quiere! In this sense, his perception of national cultural identity evokes Leopold Bloom's claim that a nation "is the same people living in the same place.... Or also living in different places.”41 Although Williams often waxes cantankerous about these interactions and even specific cultural productions from Eliot's "La Figlia Que Piange" to the Century, he acknowledges the abundance and plurality of artistic forms and practices in American life: "In America to speak of the art of poetry is pure imbecility unless there be an art in America. And if I cannot speak of that which exists here where I can know it, it stands to reason that I cannot speak of the art anywhere." In his constellations of artists, Williams enforces American art as integral to transnational modernist culture.

John Plotz has described the crowd as "a public discursive space," arguing that "the crowd actually seems to offer a new way to structure social space." ${ }^{42}$ While Plotz's remarkable literary historical investigation into the way the action of crowds affected the social work of literary texts focuses on $19^{\text {th }}$ century Britain, his attention to the porousness between social experience and cultural production (en masse) offers valuable insight into how we might read the sociocultural work of Williams's particular textual crowd-sourcing. For the twentieth century American poet, social space is also textual space, understood by Plotz as "the space, one might say, in which it was decided what would come to count as public conversation at all." ${ }^{, 43}$ Listing the names of artists, journals, and other cultural venues, Williams provides incontrovertible proof of American cosmopolitanism by patch-working conversations and epistolary exchanges, by countering what he perceived as misconceptions about American provincialism with the messy facts and language of artists at work,

\footnotetext{
${ }^{41}$ Joyce, 331.

${ }^{42}$ Plotz, 3.

${ }^{43}$ Plotz, 10.
} 
in dialogue, and on the go. If these texts supply the missing half of his correspondence with Pound, they more importantly challenge and alter the critical conversation dominated by American expatriates during Williams's time, as well as now, during our time, as modernist studies continues to be directed towards cultural life abroad. To this extent, textual space makes its material mark for Williams, whose most persuasive defenses of American cultural vibrancy happened in prose, cultivating a field of action that becomes on the page literally crowded with names, a field of language that reflects culture in action. Critics then and now persist in dismissing Williams as one of modernism's weaker rhetoricians, not fully capable of articulating a coherent poetics; however, in his use of textual space we find a convincing argument for formations of an innovative "homemade" modernism that simultaneously implies how Perloff's visual prosody might also serve our reading of the poet's prose. The crowd on the page and the crowd in action portray American art as socially constructed, a product of a dynamically inclusive discourse, and together attain one of the more significant artistic statements that Williams makes in Spring and All: "My whole life has been spent (so far) in seeking to place a value upon experience and the objects of experience that would satisfy my sense of inclusiveness without redundancy." 44

To recognize the crowds of Spring and All as consolidating a plurality of Americans within a new cultural space would seem to be at odds with my argument that the poem elucidates the nationbuilding claims of Williams's pastoral imagination. For Williams, though, the crowd not only disputes claims that the United States housed an enervated culture but also contextualizes and contributes to the discursive practices the poet first introduced into pastoral in Al Que Quiere! The crowds of Spring and All arise out of the agon of the poem's first pages, responding to one crowd in order to construct another, much as the Whitman article and the prologue to Kora in Hell do. Typographically, the crowds manifest as a work that relentlessly returns to prose to both rebuke

${ }^{44}$ All quotations from Spring and All are from the 2011 facsimile edition, which reproduces the original 1923 edition published by Contact Press. 
critics and enumerate a new poetics. The page models the cultural and physical topographies of a new nation, as perceived and rebuilt by the poet, and so the crowd becomes material for an elsewhere, a collective experiment in determining what might constitute an American individual and, indeed, an American cultural space.

Further, what Spring and $A l l$ shares with its precursor texts is a distinctive subjectivity that might well explain the book-length poem's connection to pastoral. The observations of the speaker, forthright though the may be, often emerge from a distance of place and perspective. Similar to the pastorals in AlQue Quiere!, the speaker subordinates himself to the activities of his environment, and though he is rarely alone, he distances himself from these activities, speaking from a recognizably pastoralist position. As is the case in the Whitman article and Kora in Hell prologue, he-the narrator/the pastoralist/the poet—is never quite in the scene, but it is his purview that collects individuals, experiences, and texts into a complete, yet variegated cultural landscape. In poem X of Spring and All, for example, the speaker's distance allows him a similar range of movement and expression, beginning with

The universality of things
draws me toward the candy
with melon flowers that open
about the edge of refuse
proclaiming without accent
the quality of the farmer's
shoulders and his daughter's
accidental skin, so sweet
with clover and the small
yellow cinquefoil in the
parched places. It is
this that engages the favorable

${ }^{45}$ Williams (2011), 45-6. 
Drawn to the material world of pastoral, the speaker gathers melon flowers, the farmer's shoulders, his daughter's accidental skin, clover, and yellow cinquefoil, but rather than engage with this specific environment, he reflects on their universality. Rather than narrow experience, Williams's particularity reveals the inclusivity of experience, inviting the reader into an open engagement with this pastoral environment through her encounter with language. The melon flowers do the work of "proclaiming without accent," connecting us to the figure that cultivates these flowers, the farmer, whose body and whose daughter's body suggest the work of that cultivation.

While Williams absorbs the conventions of pastoral's highlighting of labor and land, his attention to the particularities of these conventions expresses a language-based, image-driven poetics. His lines isolate one noun from another ("candy" from "melon flowers," "accent" from "farmer," "cinquefoil from "place"), allowing each word to become a localizing event for the eye. His enjambment, too, focuses on a series of end words that not only propels the reader onto the next line but also suggests how Williams observes the world and what he privileges within such a poetics of material experience: things, candy, open, refuse, accent, farmer, daughter, sweet, small, the, is, favorable. Open to the thingness of all he sees, he ably shifts to the comparable thingness of art and cultural formations:

A letter from the man who wants to start a new magazine made of linen and he owns a typewriter July 22, 1922

All this is for eyeglasses

to discover. But they lie there with the gold earpieces folded down tranquilly Titicaca $-{ }^{46}$

\footnotetext{
${ }^{46}$ Williams (2011), 46.
} 
Here the end words betray the poet's distinct visual-linguistic preoccupation: who, magazine, linen, typewriter, 1922, eyeglasses, gold, down, and Titicaca enumerate the particulars that can cohere into the modernist crowd, yet diminished to a most concentrated form. Words alternately coalesce into literary culture and reduce into the colloquial instruments of that culture. Poem X thus employs pastoral as the occasion by which Williams connects low to high, from the American farmer to the bespectacled literary impresario to the pastoralist's dream of a more tranquil elsewhere, accomplishing a cross-cultural movement (and production) in one lyric section of an expansive book-length poem.

Or, pastoral is the blank canvas on which he redraws American cultural experience. Poem X models a pluralism of seemingly mismatched objects and forms, assembling a dynamic hybrid of, among things, pastoral and epistle. Ironically, it is the individual subjectivity of the speaker which, rather than individuating the poem's perspective, eases the incongruities of farmer and magazine editor, the United States and Titicaca, to make a new kind of whole. Not only does this resemble the work of a pastoralist whose perspective binds the country to the city — and all the economic, cultural, and social distinctions that each evokes — the speaker's ability to see so vastly also resembles the position of the beholder in landscape, whose visual perception expresses a "cultural (rather than cognitive) primacy of vision" and thereby determines for the reader/spectator what counts as an American landscape. ${ }^{47}$ To read pastoral in Spring and All requires us to consider how Williams alights on pastoral as a constructive process, extending the mode's perceptive possibilities in order to test the social and cultural work of poetry. He does not simply see a social space or a natural and/or cultural environment. He creates it a through a systematic selection of images and words, perceiving a more complicated American landscape so that the reader may see it anew. To write pastoral, then,

47 Mitchell, 206 
Williams balances the portrayal of a crowded field (of people and things) and the solitary, singular eye of his individual subjectivity.

Williams's versification also contributes to this pastoral expansion, as he explains in the Whitman article that “Free verse merely means verse whose proper structure escapes a man's efforts to control it. And without comprehension there will be little unfolding-Demuth." ${ }^{48}$ Demuth, too, appears in Spring and $A l l$, as the person to whom the book is dedicated, further emphasizing its debts to visual art. But that the poet favored free verse for how it allowed him to relinquish control reflects the pastoralizing work of the speaker as an observer of the social, cultural, and natural world around him rather than as that world's author. (Similar to the speaker in "Pastoral," this speaker is astonished by what he sees.) The constructive process of pastoral may grow out of Williams's perceptual selectivity, but his selections revel in coexisting differences and narrow distances between, for example, the farmer and the magazine editor as he would observe it in his own locality. After all, as I noted earlier, transport between the rural margins of Rutherford and the avenues of Manhattan had become increasingly accessible by the 1920 s.

This ease of transport also occurs in his use of free verse, particularly the enjambment. As Stephen Cushman points out, Williams's enjambments force readers to pay attention to, for example, "her netherlip," "passionate cotton," "elysian slobber," "the folded handkerchief," and "the old / jaundiced woman" in Poem XVI, connecting a young woman to an old woman, human bodies to cosmic ones. As Cushman explains, "The straddling of lines by sentences dramatizes 'the larger process of the imagination' as the poem disguises and reveals connections between words and objects. ${ }^{, 49}$ In the early prose sections of Spring and $A l l$, the poet-speaker proclaims the imagination as his interlocutor - "To whom then am I addressed? To the imagination" 50 - but it is the reader's

\footnotetext{
${ }^{48}$ Williams (1913), 28.

${ }^{49}$ Cushman, 17.

${ }^{50}$ Williams (2011) 3.
} 
imagination that completes the process that enjambment first puts into motion. Described by Josh Wallaert as "an ecology of form," the poem engenders an "economy of language" that manifests as a collaboration between writer and reader, as “words in interaction” but also bodies (the poem's and the reader's) in interaction. ${ }^{51}$ Line by line, the reader focuses on one person or object within William's crowded plurality before the poem finally coheres into a different kind of unity, and in this way, a certain cultural authority rests with the reader as she begins to recognize the nation, as the poet beholds it, anew.

Such interactive prosody derives as much from the careful crafting of lines as from a poem's visual performance on the page. Prose and verse crosshatch like a shadow of our very selvesapparently formless, and yet also formally heterogeneous—and further, in a nod to Demuth, Williams organizes his pages so that they can be read visually, like a painting. For, like Demuth's artwork which traffics in geometric fragments that encourage viewers to reorient their perceptions towards other patterns of meaning, the text of Spring and All invites readers to see the poems not as a system of language guiding the eye left to right, but as a system of images that might require a more dynamic engagement. Consider the visual symmetry of the following poems:

\footnotetext{
${ }^{51}$ Wallaert, 82.
} 
one day in Paradise

a Gipsy

smiled

to see the blandness

of the leaves -

so many

so lascivious

and still

\section{XXII}

so much depends

upon

a red wheel

barrow

glazed with rain

water

beside the white

chickens $^{52}$

In the 2011 facsimile edition, the poems stand one atop the other, the form of each poem mirroring the other. Composed of four sparse couplets, Poem XXI would seem to begin a pattern that Poem XXII picks up, as the first line of each couplet reaches toward the right margin and the second line retreats. But there are notable asymmetries. The second couplet of Poem XXI reverses the pattern of a longer first line and diminutive second line, while the third couplet uses the sole punctuation in either poem, an em-dash. The most notable asymmetry is subject matter: Poem XXI depicts a paradise in which a Gypsy dwells and Poem XXII philosophizes on a crucial piece of farm equipment. And yet, both poems invoke pastoral conventions. Paradise and agricultural life recur in pastoral literature as idyllic environments far from the chaos and discontentment of the city. In

\footnotetext{
${ }^{52}$ Williams (2011), 74.
} 
Poem XXI, though, instead of Adam or Eve or even a pastoralist, Williams gives us a Gipsy, immediately evoking a dark-skinned itinerant Other. Meanwhile, in Poem XXII, as he did in an earlier pastoral, he has evacuated the scene of any human beings, their presence existing only in the objects left behind. How do the symmetries and asymmetries contribute to the visual reading of these two poems and how do they build toward an understanding of modernist pastoral?

As a pair, the poems illustrate the range of pastoral Williams traverses: as an idyllic space; as a space of sociocultural difference; as a space where man interacts with his environment. Further, the poems exemplify the social nature of nature and each indicates how intertwined the human, even absent, is with the natural. In mirroring the poems, Williams equates the Gipsy with the absent farmer and the space of paradise with the space of the farm, allowing the reader to, in a sense, see the poems as the Gipsy sees "the blandness / of the leaves - / so many / so lascivious / and still." It is that final "still" on which meaning pivots for both poems, expressing the tranquility of their pastoral spaces while hinging one to the other, as if Poem XXI were hesitant to conclude or let Paradise rest. Moreover, if the poems, twinned as visual objects, perform a sameness, then their slight differences challenge our ability to accept "the blandness / of the leaves," encouraging again a another way of seeing or reading. Like the asymmetries in the second and third couplets of Poem XXI, the Gipsy and the red wheelbarrow stand out in their respective poems, solitary against what collects around them - the leaves in the first poem and the chickens in the second. Williams may equate the poem visually, but upon further inspection it's hard not to miss these anomalies, which break form and resist uniformity. It is the Gipsy's gaze, seeing the bland multitude and then hesitating, that provokes Poem XXII's quiet revelation. So much depends on that object of difference, the unfamiliar social element that directs us to a new perspective.

Although Wallaert approaches Spring and All through an ecocritical perspective, his reading of the poem's language as existing beyond semantics intimates how we might read Poems XXI and 
XXII as material objects, which also manifests as an experience of visuality. Through the alternately profligate and strategic placement of objects Williams images a tangible text, and thus a multifarious world. Wallaert asserts that for the poet "the word is no longer (only) a sign, or a point of reference to the natural world. It is a thing in itself, a thing to be picked up, looked at, taken apart, laughed at, and embraced in its materiality." ${ }^{53}$ While the prose tallies names of modernist artists alongside the recurring words “spring," “nature," and “imagination," each verse section introduces a new set of objects that would seem to coalesce similar incongruities. For example, "the contagious hospital" coexists with "twiggy stuff of bushes and small trees" in Poem I, while Poem VIII roams from “anemones in Persephone's cow pasture" to the "extraordinary privileges" of J. P. Morgan" to "the finest [motor cars] on the market today" to "sunlight and grass" to "earthquakes in Manchuria." These juxtapositions or miscellanies within single sections articulate the title's "and all," and they elide transcultural and transnational distances simply by enclosing broad disparities into a few anxiously enjambed lines. The poem depicts spring and all that thrives in spring.

But Williams's materiality would also seem to be a demographic accounting. Objects of difference recur throughout Spring and All most often as female figures, from "some Elsie" to the Gipsy to "the savage beast" to "dark kisses" and then the most specifically exoticized of these, the “Arab Indian dark woman” who concludes the poem. Although the presence of these ethnic and racial Others stands out as individuals within the crowded text, none ever truly achieves subject status, posing a puzzling fissure in the poem. They invite a sharpening of attention: we can't help but notice this remarkable difference within the already remarkably heterogeneous crowd of people and objects. Their persistence in the poem destabilizes what's most culturally productive about the crowds because the estranging presence of these figures gets reproduced in the reader, jarring her into sudden alienation. If these women can't get absorbed into the crowd, can they fully belong in

\footnotetext{
${ }^{53}$ Wallaert, 82.
} 
our national space? What Williams notices, and forces us to notice, in the poem is also what he cannot see, that within the heterogeneous crowd is a resistance to cohere and become a truly inclusive national space. His attention to the dark Others, then, also obscures a disquietude in his privileged perspective as cultural producer and self-designated pastoralist. He cannot not see the difference posed by "some Elsie" and the "Arab Indian dark woman," and he cannot identify them as American without noting their Otherness. Perhaps it was for this reason that Williams was so bothered by Pound's accusations of provincialism that he felt the need to defend himself and American culture in the prologue of Kora in Hell. And perhaps here is where pastoral meets a limit posed by its history, wherein the poet's privileged ("aristocratic") perspective cannot help but reveal his distance from the true pastoralist's plight, despite the depth and sincerity of his sympathetic engagement.

All of the poems I've examined in this chapter effect a seemingly conclusive isolation; however, in Spring and All, this isolation is racially constructed, inflected by Williams's sometimes simplistic use of difference as novelty. The Gipsy alerts us to discern the individual within the crowd, while Elsie represents for Williams an overlooked impure "product of America," whom James Clifford has characterized as reflective of "a truly global space of cultural connections and dissolutions" because of her "inarticulate muddle of lost origins." Elsie, Clifford explains, is "somehow different: a troubling outsider turns up inside bourgeois domestic space. She cannot be held at a distance." ${ }^{54}$ Elsie's silence, and her generalization as "some Elsie," resonates because of the context Williams provides in Poem XVIII, suggested narratives of mixed marriages and desolate women that provokes the speaker's moral outrage that there is "no one / to witness / and adjust, / no one to drive the car." But how are we to read the poem's final exotic image, which Williams poses as a contrast in color and temperament to the white crowds and compares to a black-eyed

\footnotetext{
${ }^{54}$ Clifford, 4-6.
} 
Susan? How does this dark woman affect the American cultural space he has been constructing in Spring and All all along?

Here is the poem in its entirety:

\section{XXVII}

Black eyed susan
rich orange
round the purple core
the white daisy
is not
enough
Crowds are white
as farmers
who live poorly
But you
are rich
in savagery -
Arab
Indian
dark woman

These lines name the crowd that Williams has been constructing and make plain the critique he has with American cultural space, an outdated faith in nativist values of ethnic and racial homogeneity. He uses pastoral here as a vehicle for metaphor: the crowds do not consist of white farmers but are "white / as farmers / who live poorly," implying that what's retrograde about crowds is comparable to conventions of pastoral that are no longer viable in the twentieth century. Pastoralists are not just agriculturalists working far from centers of civilization, without knowledge of the city, technology, or culture. Further, Williams's turn to the discourse of race, prefigured by the recurrent dark woman, highlights the misconception of a racially homogeneous United States, and so the poet, in a sense, complicates the crowd's demographics and, thus, whiteness. "But you / are rich / in savagery"

\footnotetext{
${ }^{55}$ Williams (2011), 93.
} 
emphatically opposes the poor living of the farmers, an impoverishment that extends beyond economics to society and culture.

And yet the dark woman's emergence, "rich / in savagery," participates in a familiar modernist primitivism, exposing contemporary readers to what would be most unsettling about human nature and, moreover, the demographic changes that make it harder for some people to blend into the crowd. If the "you" to whom the final section is addressed is from the white crowd, then the dark woman is diminished into a mere literary device - an object for gazing, an oddity. But the syntax also allows the "you" to be the dark woman herself, a move that would come close to identifying one of "nameless particulars making up the poet’s local world." 56 Williams's form reinforces what's unsettling about the dark woman and the you and how we are to read either. The tercets begin to approximate a visual symmetry: in the first three tercets, the first line of each tercet contains two words and then the second line contains two words. By the third line, though, the pattern collapses, as does the intelligibility of the images. The visual asymmetry of Poem XXVII reflects the formal incoherence of Spring and $A l l$, the difficulty of insinuating certain individuals into the American crowd. However, without these individuals, "Crowds are white / as farmers / who live poorly." The poem's central tercet presents clearly the problem Williams perceives in American cultural space: the disturbing insistence on the "Arab / Indian / dark woman" and her rich savagery reflect his inability to adequately resolve this problem. Consequently, there is a troubling sense that the "rottenness" that Pound discerned at the root of American provincialism, which I'll elaborate on in the next section, might be impossible to fully eradicate. Simply placing her in the poem, a new pastoralist in that final tercet, does not bridge the distances between the proverbial city and country, nor does it consolidate a heterogeneous population into a coherent cultural community.

\footnotetext{
${ }^{56}$ Miki, 13.
} 
The prose sections of Spring and All repeatedly announce Williams's ambitions to create a poetry that could overtake the material world, and this corrective impulse continues the ambitions he set out in AlQue Quiere! Often visionary in scope, though, he does concede that what happens on the page will not necessarily happen in life. In this way, the poem's pastoralism replays a familiar distance between the real world and the imagined one:

First must come the transposition of the faculties to the only world of reality that men know: the world of the imagination, wholly our own. From this world alone does the work gain power, its soil the only one whose chemistry is perfect to the purpose.

The exultation men feel before a work of art is the feeling of reality they draw from it. It sets them up, places a value upon experience ${ }^{57}$

One might think that the very presence of a pastoralist would preempt the kind of harmonious world Williams envisions. After all, what is a pastoralist without a social and cultural hierarchy? And yet, this excerpt from one of the Spring and All s prose sections posits reading as a valid experience, suggesting that the pressures pastoral can place on people and their social and geographical locations might be felt as powerfully real. If Spring and All expresses the limitations of what the poet and his poetry could do to affect change in his locality, his nation, and the transnational community, it nevertheless creates "everywhere around him, the presence of forces pushing to break apart the insular world." 58 Pastoral may have allowed Williams to create a world of the imagination wholly his own, but the reality of this world was one that many other American modernists were equally committed to imagining.

\section{"A Pastoral": Williams Writing Pound}

Although William Carlos Williams never shared the undated, unpublished poem "A Pastoral" (either in print or in his correspondence), the poem is not exactly unknown, as it is

\footnotetext{
${ }^{57}$ Williams (2011), 61.

${ }^{58}$ Miki, 31.
} 
catalogued at the Poetry Collection at the University of Buffalo and anyone who has spent an obsessive amount of time in this archive is likely to have come across it. The folio containing "A Pastoral" consists of ten pages: half penciled draft, half typewritten revision. The typescript is littered with cross-outs, further revising, and marginalia, suggesting that the poet was not quite done with the poem. Perhaps Williams forgot about it, abandoning the poem mid-composition, or perhaps these pages must simply take their place with all the other materials documenting Williams's writing process. Certainly, it would be easy to dismiss "A Pastoral" for these reasons. After all, what poet doesn't have a stash of drafts—-what is a poet without this secret stash? But every draft exposes a poet's thinking — however fleeting, however modest—illuminating a perspective into the making of poems and, moreover, the context that ignites that making. While we know a lot about how Williams made poems, I'm interested in how the context of "A Pastoral" gets absorbed into the poem to become its source of inquiry, even its wound. My sense is that the poem is a lost artifact that annotates a loss, a loss that Williams attempts to forget or bypass or, in the very least, rewrite.

Upon first reading "A Pastoral," it becomes immediately clear that the poem was written later in Williams's career - in fact, the opening lines begin to date the poem:

The 3 rocks south of Welfare - that is

Blackwell's Island - across from

Durtle - that is Turtle Bay and the eminence

(East $51^{\text {st }}$ Street)

where the British housed themselves

in the Beekman Mansion, '76 to '83, seven

long years, are as they were then -

I suppose they have a name of some sort $-{ }^{59}$

The poet describes a view of the East Bay from mid-town Manhattan, a landscape that for an older man had become a palimpsest of topographical history. What he identifies as "Welfare" in the first line gets corrected in the second as Blackwell's Island. The name change travels back in time: the city renamed the island "Welfare" 1921, when it served as a site for "a prison, an insane asylum, and

\footnotetext{
${ }^{59}$ Williams (undated).
} 
hospitals," while "Blackwell's Island" was its first English name, purchased from the Dutch during the Colonial era. ${ }^{60}$ (The island would be renamed yet again in 1971 as Roosevelt Island.) Beekman Mansion is a ghost in these lines, used by the British during the revolutionary war - to which the years '76 to ' 83 refers - and was torn down in 1874. Indeed, all these lines, making up the first stanza of "A Pastoral," betray ghosts - the ghosts of other people and nations, the ghosts of other environments. Where the contemporary perspective stands is fuzzy until we get to the first line of the next stanza: "A helicopter driving the gulls up in a cloud." An interruption of technology, war, and modernity. World War II was the first time helicopter technology had improved enough for sustained and effective use - primarily for observation and emergency medical transport, and even in 1945 helicopters were a rare sight in the New York skyline. What we see in "A Pastoral," then, is a picture of postwar America and the interruption of the helicopter signals to Williams and the reader that this pastoral space - a specific place layered in history - has irrevocably changed and the helicopter weaves in and out of the five-page poem.

Unlike Spring and All, "A Pastoral” does not represent a culmination of the sociocultural poetics motivating Williams's early pastorals in AlQue Quiere! However, it is keenly attuned to distance, particularly the distance between the poet's New Jersey and the New York he occasionally visited, and the poem opens at the moment the speaker emerges from the country and into the city. One way to read "A Pastoral" within the context of Williams's sociocultural project of pastoral is as a final accounting of space, and more than an urban space or a cultural space, the space of the city has become a space where the locality is itself a kind of history. It is not even a national space as the historical remnants the speaker observes testify to the colonial American roots and the British empire. What Williams sees in those opening lines, and later as he shifts away toward the end to directly addressing an unnamed "you," is the past - the past of nature, the past of colonization, and

\footnotetext{
${ }^{60}$ http:/ / www.nyhistory.org
} 
the past of pastoral. This is not to say that "A Pastoral" reflects a failure or even a disavowal of pastoral as a politically efficacious form. Instead, I want to consider how "A Pastoral," like Spring and All reaches a meaningful, yet troubling, limit: Williams returns to pastoral and conducts a final inquiry into space and identity only to find an expansive place-sense, a palimpsest of histories that is not exactly or not sufficiently culturally marked. But this palimpsest is nevertheless all-consuming, indiscriminate, and strangely diffused; it is neither exclusionary nor contained. What does pastoral accomplish for Williams? In the end, what we encounter "A Pastoral" is a process of compositiondrafts that will become material for other poems, each poem rooted in the poet's particular pastoral desires - suggesting that poetry, too, is a palimpsest of histories.

In the years after World War II, Williams had become, borrowing from Yeats, "a sixty year old smiling public man." He was beginning the hard work of writing his most ambitious poem, Paterson, while regularly receiving lecture invitations and other honors. At the same time, he was reacquainting himself with his oldest poet friend, Ezra Pound, who had been forcibly returned to the United States on charges of treason in November 1945 and taken to St. Elizabeths, the mental hospital in Washington, D.C. where he would be held in for the next 12 years. The other retrospective Williams seems to conduct in "A Pastoral" is on his lifelong friendship with Pound. The poem concludes with a valedictory "Song" that begins, "No one man / No one man shall be / the master of this world - // or city" and then ends:

and this is where the rot grows here.

And where can you go to get away from it? there is no country freer:

Nowhere but to the mental hospital where you are protected as Cervantes and Bunyan [were protected before you.] 
These lines track the transformation of "no one" into "you," an embodiment that happens within a page. While the mental hospital points to Pound, so, too, does the marginalia Williams has scrawled in pencil into the left margin: "Many years so many years of reading have not made you wise." ${ }^{61}$ Williams was throughout his life in awe of Pound's vast and prolific reading; in his 1951 Autobiography, Williams griped, ““Ezra, even then, used to assault me (as he still does) for my lack of education and reading." ${ }^{62}$ An unpublished letter from Pound to Williams, dated 6 November 1946 and sent from St. Elizabeths, provides additional echoes, "Dear Bull," Pound writes, "Can you never understand the rottenness," ${ }^{33}$ suggesting that Williams's line "and this is where the rot grows" might be a response to his imprisoned friend. My speculation is hardly far-fetched, though, as "A Pastoral" evokes exhaustion, regret, and valediction, and if the "you" is Pound, we discover a pastoralist figure displaced from his countries of origin and exile and displaced from the revolutionary aspirations that incited modernism earlier in the century and that Williams shared. During Pound's incarceration years, Williams would repeatedly attribute his friend's grievous predicament to his initial departure, lamenting "I wish to Christ you'd been here all these years.... There is so much I should have liked to talk over with you through the years - but not in the mood you were habitually in and not there, where you were, but here - on the ground." ${ }^{64}$ In the typescript, Williams crosses out "there is no country freer," perhaps believing that Pound could - after the war, after Modernism - go nowhere, that Pound was finally lost.

The last poems that Williams titled "Pastoral" were three short lyrics in Al Que Quiere!, his third book of poems and the first to evince his distinctive colloquial poetics. Published in 1917, these early pastorals innovated the ancient literary mode by relocating the locus amoenus to decidedly un-rural Rutherford, New Jersey and by foregrounding pastoral's history for sociocultural

\footnotetext{
${ }^{61}$ Williams (undated).

${ }^{62}$ Williams (1951), 53.

${ }^{63}$ Pound (1946).

${ }^{64}$ Witemeyer, 218-9.
} 
critique; all three pastorals focus on the metaphorical distances between Main Street and the other side of the tracks, between the "knowing" townspeople and the "very poor" of Rutherford. In "A Pastoral," the distances Williams portrays are mapped by memory; unlike the early pastorals, the later poem is historically expansive, ruminative, and richly textured with allusions. The sociocultural critique in "A Pastoral" and what makes the poem modally a pastoral are harder to pinpoint.

Like the time-travel in the poem's first lines, Williams's turn to pastoral is retrospective. “A Pastoral" returns to the form that first helped him find his poetics and suggests that he may have remained the "country boy" who sought to make the real world of the countryside "a poetic world." It was through those early pastorals that he could translate the geography of his American idiom the town of Rutherford - into a poetic language - "a real world, but nonetheless a poetic world." The place of "A Pastoral" is complicated in environment and history, but it is indisputably New York, a place whose present seems indivisible from its past. But pastoral is also a social form, and the animating tension of the poem is its social silence, the absence of any human interaction. Is Williams the pastoralist? Is the helicopter? For, human figures stand far in the background, distantly observed by the poem's detached poet-observer, who drifts along Manhattan's eastern coast, dips between buildings, spans the city panoramically like a helicopter, and settles on no human scene. The poet constructs a human absence so palpable it feels spectral, as if the pastoralist were himself a ghost wandering the city.

"A Pastoral," however, does not ultimately go nowhere. Of its roughly 126 lines, roughly 45 re-emerge in Book Four, Part One of Paterson, widely scattered throughout a section titled "An Idyl," as Williams spells it, an act of renaming that underscores the difference in tone and perspective where "A Pastoral" proceeds with vatic dread, "An Idyl" traffics in ironic play. ${ }^{65}$ And the marginalia, too, gets repurposed, serving as the final line of a short poem "Mists Over the River," published in

\footnotetext{
${ }^{65}$ Williams (1992), 151-52.
} 
the 1948 collection The Clouds. The presence of Pound is nowhere in "An Idyl" or "Mists Over the River," at least not in any discernible form. "I suppose they have a name of some sort," Williams intones ironically in "A Pastoral," well-aware that names convey more history than semantics. But there is no Williams without Pound (no Pound without Williams): if "A Pastoral" grants Williams the space to understand his complicity in Pound's "tragic outcome," as he would call it, and Pound's complicity in his writing life, the poem also grants a space for reckoning, for new possibility in our pastoral imagination, where "the rot" might grow. 


\title{
Pastoral and the Problem of Place in Claude McKay's Harlem Shadows
}

\author{
Chapter Two
}

\section{McKay's Displacements}

Published in 1922, Harlem Shadows was Jamaican writer Claude McKay’s first American publication, a book of poems that has long been recognized as one of the texts that launched the Harlem Renaissance. ${ }^{1}$ Although many of the book's poems depict the rhythms and crowds of black life in New York City, particularly in Harlem, McKay also includes other locations and cultures, environments that are tropical, rural, and neither urban nor American. He sets numerous individual poems in New York City only to imagine his speaker elsewhere: an idealized memory of Jamaica or an imagined place of belonging. In making such seamless, yet fraught associations between the city and the country, he rehearses the conventions of a literary mode that would seem antithetical to the Renaissance and Modernism, the pastoral. Pastoral lyrics abound in Harlem Shadows and, while set in New York, scrutinize the geographical and socioeconomic distances that marginalize their poetic subjects, pastoralist figures reimagined as oft-impoverished, black émigrés like the poet himself. What are we to make of the significance of pastoral in this seminal work of the Harlem Renaissance? What are we to make of a poet who consistently wanders away from the urban topography by which Harlem Shadows and the cultural movement it sparked have been defined? McKay's pastoral lyrics emerge out of the distances that displace his autobiographical speakers, henceforth identified as pastoralists, but, diverging from convention, they often wander far from their initial settings. Although scholars have noted

\footnotetext{
${ }^{1}$ David Levering Lewis notes that Harlem Shadows was "the first book of poetry [by a black writer] since Paul Laurence Dunbar" [(1994), xvii] and that McKay became the "most famous poet in Afro-America" [(1979), 54].
} 
the pastoralism of Jean Toomer's Cane (1923), and Robert Bone has argued that the pastoral imagination is fundamental to the history of African American fiction, these claims have been overshadowed by Toomer's idiosyncratic career and insufficiently elaborated upon with regards to lyric poetry or to the innovations McKay introduced to the mode. ${ }^{2}$ For McKay, pastoral becomes a productive means for reimagining the social and cultural structures that shape any location. In Harlem Shadows, he innovates the pastoral mode, in part, by highlighting how conventions of pastoral—specifically, figurations of displacement, distance, and belongingness — align with Modernist poetics. Moreover, pastoral, in this poet's hands, becomes an incisive critique of American culture and society because his pastorals insist on American place as transcultural and transhistorical, complicated and enriched by other races, classes, cultures, geographies, and histories.

The geographical capaciousness of McKay's pastorals not only reflects his own diasporic rootlessness but also underscores the problem of placing the Harlem Renaissance in Harlem alone. Its writers, artists, and thinkers arrived from the South, the Midwest, and Africa and the Caribbean, among other far-flung locations, and many lived not in New York but in Washington, D.C., Chicago, or cities abroad. ${ }^{3}$ In fact, McKay himself would leave New York City for Moscow in the fall of 1922 and spend the ensuing twelve years traveling through Europe and Africa. About his absence from the United States during the rise of the Renaissance, he would explain in his autobiography, A Long Way from Home (1937), "Much as

\footnotetext{
${ }^{2}$ Marx (1999/2000), 483-496. Marx singles out Toomer as an "insufficiently valued practitioner of the pastoral mode" and notes the absence of discourse on the role of pastoral in "the history and the expressive life... of women, ethnic and racial minorities, gays and the working class" [493, 492]. See Dixon, 31-55.

${ }^{3}$ A mere sampling suggests Harlem was a cultural headquarters in name only. Langston Hughes hailed from Missouri, and his family had roots in Kentucky. Born in Alabama and educated in New York, Zora Neale Hurston always considered Florida home. Sterling Brown was born in Washington, D. C. and spent his professional life there, where James Weldon Johnson also lived while working for the NAACP. Johnson also spent years in South and Central Americas. Like McKay, Marcus Garvey was born in Jamaica.
} 
all my sympathy was with the Negro group and the idea of a Negro renaissance, I doubted if going back to Harlem would be an advantage. I had done my best Harlem stuff when I was abroad, seeing it from a long perspective." ${ }^{4}$ But McKay's "long perspective" begins even as he's writing in and about Harlem and the United States, seeing through the lens of a global citizen intimately familiar with the historically tangled networks of black cultural identity.

How the Harlem Renaissance could happen abroad would be puzzling without understanding how writing pastoral allowed McKay to mediate complex emotional and geographical distances unique to modernity. Indeed, it was in Moscow in 1922 where the thirty-three-year-old McKay would make note of pastoral's power to cross cultures, languages, and eras. While attending a literary gathering, he found himself so moved by one man's recitation he would write about it years later:

I was particularly pleased with the poem of a slim young man in a coarse peasant smock buttoned up to his chin, and with a worried, unhappy expression in his sensitive features. I knew at once that he was a peasant become proletarian like myself. He gave a charming poem. Even before translation I knew from its communicative color and the soft threne running through it like a silver chord that it expressed an individual longing for the life of the country, perhaps the ways that nevermore would be.

As soon as the poet had done I clapped my hands heartily. His poem and personality had unusually excited me, because I rarely applaud. I liked that the poet with the intellectual anxiety of his face showing clearly that he was a little bewildered by that world-moving social shake-up.... [his fellow poets] criticized his subject matter.... I said that I thought it was natural for

\footnotetext{
${ }^{4}$ McKay (2007), 247.
} 
man who had lived in the country to express his longing for it, whether he was bourgeois or a proletarian. ${ }^{5}$

Outside McKay's poetry, this passage comes closest to articulating his perspective on pastoral and on how he found something like home in the worlds poems construct.

Although he does not know Russian, he recognizes the poem as pastoral by its "soft threne," a quality of lament he associates with "an individual longing for the life of the country." $\mathrm{He}$ recognizes the young Russian poet as a fellow "peasant," invoking pastoral's principal characteristic as “an interpretation... of the central fiction that shepherds' lives represent human lives." This longing delineates the pastoralist's distance from home, a geographical displacement, and his inability to belong in the dominant culture of his current location, a sociocultural displacement. For the young Russian poet, these displacements are experienced within the poem and without. While others in the audience decry his poem as old-fashioned, sentimental, and irrelevant, McKay is "excited" by a profound sense of understanding and sees himself in this young Russian poet. Like McKay, he doesn't quite fit into his newfound society and his “intellectual anxiety" reflects McKay's own doubts about the potential for socialism to accomplish global racial, economic, and social equality. After all, those doubts were born of an actual experience of marginalization rather than theoretical knowledge. ${ }^{7}$ McKay's laudatory attention towards pastoral, especially within the unequivocally "Modern" setting of a socialist gathering in Moscow, encourages us to rethink the relevance of pastoral to his contemporary moment.

\footnotetext{
${ }^{5}$ Ibid, 145.

${ }^{6}$ Alpers, 27.

${ }^{7}$ These doubts probably first arose when McKay was in England, engaging with various socialist and Marxist organizations, and became more troubling while working with Max Eastman on the staff of the Liberator in New York, which in part motivated his travels to Russia. See Cooper (1987), 103-70.
} 
The young Jamaican poet and the young Russian poet unite through a poetic form that marks them as poor, rural, and emotional and announces their shared displacement in the modern world. And yet, theirs is a cross-cultural exchange that, nourished by McKay's keen insight, develops an argument against the institutional structures that marginalize them. In twice attributing the Russian poet's "individual longing" to a longing for the country and thus for home, McKay dismisses the socialists' disdain and distinguishes himself and the young Russian, marking, like pastoral, a distance between the metaphorical country and city within the audience. Subtly, he contends that pastoral continues to work even after peasants, like himself, become politically inscribed as "proletarian," when their ways "nevermore may be."

But McKay's moment of pastoral recognition also crosses racial lines and directs us to larger claims about the social experiences and political perspectives pastoral as a lyric form can encompass. Traveling to Russia as a special delegate to the Fourth Congress of the Third Communist International, he persuasively argued that the problem of race and labor were not only intertwined but international. As he would write to Max Eastman, his friend and former editor at the Liberator, "I maintain that a revolutionary magazine in advocating the issues of the class struggle in America should handle the Negro problem in the class struggle in proportion to the Negro population and its position in the world." ${ }^{8}$ While the pastorals in Harlem Shadows evoked the social and economic injustices of black lives in America, his experiences in Moscow helped McKay articulate how these injustices were not limited to one nation or one historical period. What he saw in the Russian poet was a shared class struggle, and thus a possibility of social revolution through cultural connection. Although he introduces himself as a poet, his experiences in Russia made him increasingly aware of

\footnotetext{
${ }^{8}$ McKay (1973), 85.
} 
himself as a critic. He would explain this in his first serious literary effort after Harlem Shadows, which he wrote "in the spirit of a critic imbued with class consciousness, exactly as one would write in America in order to be heard by both whites and blacks." "That class consciousness roots his work in the brute economic fact of pastoral, so that it is impossible to detach the race of McKay's pastoralist figures from their poverty. Pastoral is therefore not irrelevant, but crosses cultures, transcends class ("whether he was a bourgeois or a proletarian"), and serves as a potential palliative to "that world-moving social shake-up," which refers specifically to the Russian Revolution and more generally to modernity. What is "natural" about pastoral, then, is not simply the environment to which "individual longing" directs us but how the emotions of displacement animated social and cultural experience in the early twentieth century. Wherever McKay went, he longed for an elsewhere. A pastoral convention, this longing could alternately mean a home, an irretrievable past, or a space of belonging, and it informs the geographical imaginary of Harlem Shadows. But the longing was also very real for McKay, unfixing him and the locational setting of his poems, and even writing about Harlem would conjure memories of other places. Thus, his speakers travel, imaginatively, farther afield, and what does and does not constitute home consistently troubles his speakers' relationships to wherever they happened to be.

While not exactly pastoral, the poem "Enslaved" provides a context for reading the pastoral lyrics because it makes explicit how McKay understands place as instrumental to the formation of identity:

\footnotetext{
${ }^{9}$ McKay (1979), 4. The State Publishing Department asked McKay to write the book shortly after he gave his speech on the Negro worker in America at the November 20, 1922 Comintern congress, which was quickly developed into a book that was then published in Russian in the spring of 1923. It was translated into French in 1963 and into English in 1979.
} 
Oh when I think of my long-suffering race, For weary centuries despised, oppressed

Enslaved and lynched, denied a human place

In the great line of the Christian West;

And in the Black Land disinherited

Robbed in the ancient country of its birth

My heart grows sick with hate, becomes as lead,

For this my race that has no home on earth. ${ }^{10}$

The single sentence of this sonnet's octave bursts forth from the exclamatory lament "Oh," gathers a stream of past participles that together describe a painful history: "despised, oppressed / Enslaved and lynched / denied," and then "disinherited / robbed." Much like Whitman’s lyric “I,” McKay’s speaker contains multitudes, expressing an individual identity that is historically indivisible from a collective identity. Further, this collective identity is indivisible from the placelessness the poet describes. As part of a "long-suffering race," the speaker has been "denied a human place" and thus has "no home on earth. McKay moves from thought ("I think of my long-suffering race) to feeling ("My heart grows sick with hate"), and the poem climaxes with a displacement that is both individual and collective ("this my race that has no home on earth"). The historical displacement of a man's race becomes the lens through which he understands his place in the world. The poet's own experiences of displacement join a history of displacement, from the African Diaspora to the Great Migration. Not only had he emigrated from Jamaica to the United States, but he also moved from Tuskegee, Alabama to Harlem, New York, with numerous stops in between. The word "Enslaved" maps these migrations, while clarifying how every experience of place reinforces the poet's displacement, which is at once psychological and socio-historical.

Experiencing one place through the lens of past experiences exemplifies what Lawrence Buell has called "place-sense," a feeling and cognition that arises out of "a kind of

${ }^{10}$ McKay (2008), 167 
palimpsest of a series of place-experiences." The place-sense expressed in "Enslaved" is a palimpsest of numerous personal and historical displacements that have been collectively experienced. Although the self-described "vagabond" poet geographically displaced himself, "Enslaved" describes his place-sense in a world where he has been denied a place, where he feels strange and unwelcome everywhere. The poem therefore demonstrates how, beyond psychological experience, double-consciousness is spatially felt. ${ }^{12}$ But "Enslaved" is also a private response to painful public history and concludes with a cry for vengeance:

To the avenging angel to consume The white man's world of wonders utterly: Let it be swallowed up in earth's vast womb, Or upward roll as sacrificial smoke To liberate my people from its yoke!

In "Enslaved," the pastoralist's longing for a home that is always inescapably elsewhere, or terrifyingly nowhere, reveals what is perhaps most radical about McKay's pastorals: the pastoralist longs for a home that does not exist. Longing becomes like a Freudian wound, melancholic and inconsolable. And yet, McKay's individual longing opens his pastoral lyrics to a collective place-sense that, through the mediation of art, stands in for a kind of belonging. His pastoralist figures are informed by an awareness of belonging to a race that cannot or has yet to achieve a home, in the fullest sense, in political modernity. If reconciling a home seems an impossible task for the pastoralist, then pastoral keeps the project of home alive for the wandering McKay. For, it is in pastoral that distance and difference can be held together and become the potential terms for a wider belonging.

The formal expression of McKay's pastoral, as well as the fact of his supposed "truancy" during the Renaissance, poses a direct challenge to Harlem as a home for the New

\footnotetext{
${ }^{11}$ Buell, 73.

${ }^{12}$ McKay (2007), 9-10.
} 
Negro and to the notion that the Negro Question was a strictly American question.

"Enslaved," in this sense, identifies the problem of place that the poet tasks pastoral with resolving. The poem was written in 1921, while McKay was on the staff of the Liberator, where the poem first appeared. In that earlier version, he locates "Africa" as the place of first disinheritance, before later revising it to the general and emphatically nationless "Black Land." McKay's editorial change reflects his experiences as a black man in America, where his first encounters with segregation and the excoriating racial discrimination of the Deep South were hardly different from the prejudices he encountered further north. ${ }^{13}$ In his experience, the "Black Land" of and within America repeatedly disinherited him, and by the time of his departure to Russia, even Harlem held limited opportunities for him as a writer, despite his increasing importance in the black literary community.

\section{McKay Reading America: Pastoral and Imperialism}

That McKay turns to geography as the prime source of self-determination signals how imperialism shapes his pastoral imagination. In this sense, "Black Land" names a country for the wandering citizens of the Diaspora, a home that, while imaginary, at last unifies a historically disenfranchised population. Consequently, McKay’s pastoral writing identifies the distance between the pastoralist and his desired home as a calamitous loss that spans centuries and continents. Historians and cultural geographers have observed that the African Diaspora has resulted in five centuries of displacement for African people and their descendants. Because these first migrations were forced, they "never did give up their rights to citizenship on the continent of Africa, even though the nation-states that now make up

\footnotetext{
${ }^{13}$ McKay's most famous poem, "If We Must Die," was written as a response to the race riots breaking out in American cities during the summer of 1919.
} 
this geopolitical entity did not exist during the time of transatlantic slavery." ${ }^{14}$ What this means for cultural modernity and, in particular, to McKay's pastoral writing in the twentieth century, when migrations were "induced," most often from the lack of economic opportunities, is that the imagined spaces of home, as well as the recurring trope of return, were foremost aimed at political self-determination. ${ }^{15}$ Literary production—in McKay's case, writing pastoral—therefore contributes to the "redefinition process based on their historicosocial experiences." ${ }^{16}$ McKay's unique status as a black immigrant to the United States and a British colonial subject emphasizes that this complex process is global, however rooted in specific American experience Harlem Shadows is. Again, his time in Russia was deeply illuminating to how global his American experience had been, stating in his speech to the Fourth Congress, "Every American official abroad, every smug tourist, is a protagonist of dollar culture and a propagandist against the Negro." ${ }^{17}$

Reading “America” suggests how McKay reads America as space of racial discord that is also invariably shaped by imperialist history. While the poem mediates the distance between pastoral's idealistic imaginary and bleak American reality, it more troublingly recognizes Harlem as yet another colony wherein blacks and other descendants of the Diaspora are merely colonized subjects. It is a space that cannot wholly belong to them, and therefore they cannot wholly belong in that space, reflecting Edward Said's claim that "Life in one subordinate realm of experience is imprinted by the fictions and follies of the dominant realm." ${ }^{\prime 18}$ That dominant realm is as much the United States as it is Great Britain, revealing a more complicated place-sense out of which McKay's pastoral grows. No doubt,

\footnotetext{
${ }^{14}$ Davies and M'Bow, 17.

${ }^{15}$ Ibid.

${ }^{16}$ Ibid.

${ }^{17}$ McKay (1973),98.

${ }^{18}$ Said, xix.
} 
McKay views the United States through his Jamaican immigrant perspective; however, the critical insight of "America" is how poetic language and form absorb imperialist tensions, even as the poem makes claims towards creating a new social space:

Although she feeds me bread of bitterness, And sinks into my throat her tiger's tooth, Stealing my breath of life, I will confess I love this cultured hell that tests my youth! Her vigor flows like tides into my blood, Giving me strength erect against her hate. Her bigness sweeps my being like a flood. Yet as a rebel fronts a king in state, I stand within her walls with not a shred Of terror, malice, not a word of jeer. Darkly I gaze into the days ahead, And see her might and granite wonders there, Beneath the touch of Time's unerring hand, Like priceless treasures sinking in the sand. ${ }^{19}$

What kind of rebellion does McKay stage in this Shakespearean sonnet? Subject as the poet is to the British Empire, he employs metaphors that embellish America's dominion over the speaker, a pointed illustration of American cultural imperialism that is ironically animal and natural in its cruelty. America ravages the speaker with "her tiger's tooth" and her "bigness sweeps... like a flood." This "cultured hell” seems to be a catastrophic environment. The speaker stands within "her walls," the political and social constrictions within the United States, but McKay's enraged language stand within the walls of a sonnet, suggesting that the "cultured hell" is also western literary tradition.

McKay contributed much to a Modernist reinvention of the sonnet, shifting it away from the courtly and erotic examples provided by Petrarch, Sidney, Shakespeare, and D. G. Rossetti, but the sense of unrequitedness between lover and beloved—or, indeed, between immigrant and host nation-remains. In this, he continues an alternate tradition of the sonnet that elucidates the power dynamics that such frustrating relationships can foster, and

${ }^{19}$ McKay (2008), 153. 
the concluding lines of "America" echo those of Shelley's "Ozymandias," another sonnet that observes the ruinous outcomes of power. Reinventing the love poem as protest poem, McKay invests his sonnets, many of which appear in Harlem Shadows, with an urgent sense of futurity: the desired outcome is never romantic union, but political self-determination, or a harmonious union between self and state.

"America" is not unique in Harlem Shadows or McKay's oeuvre, though, and several poems appropriate traditional forms for his political means, and yet, the poem spotlights how his formal resourcefulness arises out of something like a "contrapuntal reading" of English literature, as Said demands of global readers, and the uniquely "spatial imagination" that Homi Bhabha has observed from "a progressive, postcolonial cast of mind.",20 Moreover, the preoccupation with geography and social space in "America" distinguishes the poem's pastoralism, even as it avoids other conventions of that mode: the poem exists in the elsewhere that refuses the speaker's full occupation, and the distances rendered are far more abstract and psychodramatic than the pastorals discussed in subsequent sections of this chapter. Rather, "America" demonstrates a uniquely sensitive reading of living in the United States as a colonized subject of British Jamaica, historicizing the poet's feelings of oppression and liberation while embodying those feelings in a provisional space. Fed and then mauled in the first two lines, the speaker is figured as a victim of violence and America the actor of that violence. McKay portrays his newly adopted country as antagonistic, overpowering, and ruthless, but she is also a cruel mother, nurturing the poet speaker with "her hate" and it is with unsentimental elation that he announces, "I love this cultured hell that tests my youth!” If America is an antagonist, then McKay is a worthy contender, a "rebel" who stands without a "shred of terror." The power of the United States is

\footnotetext{
${ }^{20}$ Bhabha, xiv.
} 
formidable, yet the crucial observation he makes in the poem is that that power can be overcome.

In the poem's final four lines, McKay turns toward the future- "Darkly I gaze"and while he recognizes the "might and granite wonders" of his newly adopted country, he also foresees its inevitable demise: "Like precisely treasures sinking in the sand." This is a vision of the immigrant's victory, in which the imperial power is merely material grown immaterial. What the poem offers to the discussion of power lies in these fraught exchanges between oppressed and oppressor, past and future, vehicle and tenor, country and city. “America” documents McKay's understanding of his host country as a force of cultural imperialism and illustrates how a colonized subject has absorbed the colonizer's canon as an expression of domination. As a poem, "America" stages this engagement as a contest of violent rhetoric that is indebted to the geographies of power undergirding western literary tradition. If the poem provides an imperative to unearthing the invisible hands of history and culture in shaping and subordinating the subaltern, it also reveals pastoral as a mechanism for finding what can't be easily seen. By deciding to read for the pastoral in "America," we decide to seek out what distances comprise the poem and how. We find the distances between the painful past and future liberation, the weak speaker and the almighty nation, the rebel's rhetoric and the sonnet's oppressive form. In this sense, McKay's pastoral writing reflects Raymond Williams's uncanny observation that "one of the last models of 'city and country' is the system we now know as imperialism." ${ }^{21}$ Significantly, McKay's space for selfdetermination, a political space that must also occupy a physical location, remains unmapped in the poem; it is a future projection. Where the poet belongs — and how he might belongin the United States becomes the central project of his pastoral lyrics in Harlem Shadows.

${ }^{21}$ Williams (1973), 279. 


\section{Wandering, or a Poetics of Place-Sense}

Were we to read books for their first and last words alone, then Harlem Shadows tells the story of the inconclusive journey glimpsed in "Enslaved": beginning at "far" and ending on "quest," one wonders, What distances will the poet travel, and what exactly is he looking for? This question grows in significance when we consider the book's publication history. Published in New York by Harcourt, Brace, and Company in 1922, Harlem Shadows grew out of an earlier, sparser collection, Spring in New Hampshire, which had been published two years earlier in England. ${ }^{22}$ As with "far" and "quest," the two titles wander, a move from country to city that parallels not only McKay's lifelong peripatetic habits but also the dramatic changes he made to the manuscript, notably the addition of forty-six poems written between 1920 and 1922. Although he wrote the majority of these poems in New York, McKay did not leave New Hampshire or the countryside entirely behind in Harlem Shadows. Among the new poems set in bucolic environments were "Summer Morn in New Hampshire," "Homing Swallows," "Wild May," “The Wild Goat," and "On a Primitive Canoe.” Even McKay's native rural Jamaica is a recurrent topography of Harlem Shadows. In "When Dawn Comes to the City," the speaker's depiction of life in New York (“Out of tenements, cold as stone, / Dark figures start for work; / I watch them sadly shuffle on / 'Tis dawn, dawn in New York") turns by the next stanza to a longing for home: "But I would be on the island of the sea, / In the heart of the island of the sea." 23 Harlem Shadows frequently wanders across and within poems far beyond the borders of that Manhattan neighborhood. As "far"

\footnotetext{
${ }^{22}$ The English critic and editor for Cambridge Magazine C. K. Ogden facilitated the publication of Spring in New Hampshire, while Max Eastman was instrumental to the publication Harlem Shadows and wrote its introduction. See Cooper (1987) on the publications history and the role of literary patronage in McKay's career.

${ }^{23}$ McKay (2208), 181.
} 
and "quest" suggest, the problem of place for McKay does not merely reflect a biographical context; it directly informs how he shapes the poetics of Harlem Shadows.

The distance between country and city evinces distances between cultures and the distances formed through time and feeling. While McKay might locate a poem in one place, other locations arise as his speakers invoke them by memory or association. Such an imagination of distance and geography reinforces how pastoral provokes investigations of social experience by rendering spaces real and imagined (and typically non-urban). It is its central figure, the pastoralist, who enables pastoral's mediation of social, cultural, and geographical distances and differences. Despite their relocation to the metropolis, McKay's pastoral lyrics reflect the conventions of the mode, wherein the environmental situation of the pastoralist identifies his displacement from, at least in Harlem Shadows, white America. For McKay, pastoral was a formal embodiment of his placelessness. Whereas Jean Toomer employed pastoral in Cane to survey modernity's evacuation of the Negro "folk-spirit," regarding his book as "a song of an end" to rural life and culture, McKay highlights the generative power of pastoral to reimagine place and American cultural identity. ${ }^{24}$ To read McKay's pastorals in Harlem Shadows as a challenge to Modernism's complacencies about the relationship between identity and location directs us to more clearly see how he and other Harlem Renaissance writers make pastoral new. Indeed, investigating how poets like Langston Hughes and Countee Cullen, to name only two, have used pastoral to write about race and American culture would enrich the connections between Harlem Renaissance and Modernist studies, while compelling a more robust consideration of pastoral as a politically efficacious literary mode.

\footnotetext{
${ }^{24}$ Toomer, 123.
} 
"In the very process of being transplanted, the Negro was being transformed," Alain Locke would write in $1925 .{ }^{25}$ He might have added that the place to which the Negro had been transplanted was being transformed as well. Harlem's emergence as a cultural center not only altered New York City, but also the nation, building on Randolph Bourne's 1916 claim that the United States was a "federation of cultures" and races. ${ }^{26}$ McKay's use of pastoral illustrates how the cosmopolitanism of the Harlem Renaissance grew out of the rural past and included the non-urban environments found along transnational and diasporic routes.

In writing pastoral, McKay does more than mark the distances between disparate locations: he approaches the pastoral lyric as a form in which to interrogate cultural and social identity and, further, to imagine a space composed of distances and differences, a space where he might belong. "Place-sense" thus distinguishes McKay's pastoral from conventional descriptions of displacement. The pastoral lyric "When Dawn Comes to the City," for example, alternates between New York City and Jamaica, and the stanzas alternate depictions of the contrasting environments of these two islands. From stanza to stanza, the speaker travels quietly between frenetic city streets, populated by anonymous "dark figures" and a "lonely newsboy," and the bright jubilance of Jamaica, where even the animals claim specific identities like "dear old Ned" and "the shaggy Nanny goat." McKay expresses his longing for pastoral's elsewhere_-his home_-formally: the New York stanzas are eight lines, the Jamaica stanzas are fourteen lines, and this leap from an octave to a balladic sonnet, from a fragment to a whole song, parallels the poet speaker's emotional attention. He is not in Jamaica, but the natural phenomenon of dawn in the city returns him there. Accordingly,

\footnotetext{
${ }^{25}$ Locke, 6.

${ }^{26}$ Bourne (1964), 86-97.
} 
the refrain "I would be on the island of the sea" has a transporting effect, and the space of the poem reveals how one experience of dawn unifies the two places.

In "When Dawn Comes to the City," the New York octaves portray an alienating city, so lacking in natural beauty that the poet describes the stars as "dull" and "dying. This observation of the natural in an urban environment ("Red streaks strike through the gray of

the sky, / The dawn comes to the city") launches the next stanza's sonnet and, consequently, poetic production. That is, the speaker's displacement produces poems (two sonnets, in fact) within the larger poem. "But I would be on the island of the sea, / In the heart of the island of the sea," the speaker declaims, and so the arrival of the sun precipitates his departure. Although his displacement remains, for the departure happens in mind only, McKay manages the poem's form to suggest a sort of replacement: the incomplete octave, missing the resolution of a sestet, finds completion in the ensuing sonnet and in a different location, a second attempt at what New York's formal space could not fulfill. Two sonnets and two geographical locations collaborate to construct one uniquely American topography. In this way, "When Dawn Comes to the City" marks the divergent experiences of place that can converge in one poem, and McKay's fusing of New York and Jamaica begins to suggest the meaningful complexity of reading Harlem as a location of multiple cultures and geographies.

\section{"The Tropics in New York"}

While McKay could find "no home on earth," he found in pastoral an answer to the problem of placelessness: the poem could stand in for home. In "The Tropics in New York," he draws on the pastoral mode to reach beyond the boundaries of nation and literary form, constructing a poetic space of transnational cultural belonging. 
Bananas ripe and green, and ginger-root,

Cocoa in pods and alligator pears,

And tangerines and mangoes and grape fruit

Fit for the highest prize at parish fairs,

Set in the window, bringing memories

Of fruit-trees laden by low-singing rills,

And dewy dawns, and mystical blue skies

In benediction over nun-like hills.

My eyes grew dim, and I could no more gaze;

A wave of longing through my body swept,

And hungry for the old, familiar ways,

I turned aside and bowed my head and wept. ${ }^{27}$

“The Tropics in New York” traces McKay’s place-sense: standing on a New York sidewalk, gazing into a storefront, he flashes back to his native Jamaica. The poem dwells on memory and on what triggers memory, invoking a global imaginary that, at the same time, intimates the brute economics of what might otherwise be recognized as Modernist primitivism. For, while these "exotic" fruits_-bananas, alligator pears, mangoes—signify elsewhere, they have become in America "detached commodities no longer part of the land," now signifiers of extravagance. ${ }^{28}$ They are on display, delicacies meant to lure the customer into the store. And yet, their presence in the poem is synecdochic of Jamaica and intensifies the poet speaker's acute sense of lack. His homesickness manifests as economic privation and hunger.

But McKay shares more than a country of origin with these fruits. Marked by his difference, he is also himself a synecdoche for elsewhere. The mere fact that he cannot enter the store announces that he does not belong, and one wonders how passersby respond to this sad figure, the weeping poet speaker, standing on the sidewalk. Hence, the second stanza's shift into memory doesn't merely perform a Romantic displacement. For, unlike Wordsworth in his longing for a field of daffodils in the pastoral lyric "I Wandered Lonely as

\footnotetext{
${ }^{27}$ McKay (2008), 154.

${ }^{28}$ Pedersen, 259.
} 
a Cloud," McKay cannot fully escape his location or his incongruous presence in that location, and the memory of home only compounds the pain he feels as a poor black emigrant in New York. Where Wordsworth's memory brings him the pleasure of escape, McKay's memory reminds him that he cannot escape his race, poverty, or displacement. My reading of the poem therefore contradicts Michael North's claim that "the language [of 'The Tropics in New York'] is the language of memory, softened by distance," as distance in fact makes the memory more raw. ${ }^{29}$ McKay's positioning of the "fruit-laden trees," "dewy dawns, and mystical blue skies" in the second stanza, as if "set in a window" of the poem, reinforces how these memories are physically separated from the poet speaker by the glass pane and the prohibitive price of these native fruits. As pastoral, "The Tropics in New York" administers a definitive distance between the city and the country, and makes clear that New York is a center of civilization, or at least commerce, while Jamaica exudes the tranquility of nature, where hills are "nun-like" and the rills "low-singing." McKay's portrayal of himself as the pastoralist emphasizes that this distance is more than geographical and the third stanza's turn away from memory also enacts a physical turn away from the very objects that announce this poem as pastoral. "I could no more gaze," the poet writes. Looking at the fruits reminds the pastoralist that he now finds himself a long way from home and in an unwelcoming place.

In "The Tropics in New York" McKay creates a space of multiple geographies and multiple exclusions. The longing for "old familiar ways" looks forward to what he would later observe of the young Russian poet, "the ways that nevermore would be." One reason that the speaker of "The Tropics of New York" cannot return home is because home exists in the past. McKay's use of pastoral is distinctly modern, for the distance between the

${ }^{29}$ North (1994), 111. 
country and the city also manifests as a distance between past and present. He tucks his memory of Jamaica into the poem's second stanza, concealed within the first and third stanzas' harsh modernity. For McKay, the role time plays in pastoral enhances the historical imagination of "Enslaved": that "wave of longing" gestures toward the diasporic metaphor of the sea, reaching from one colony to another.

Time also plays more slyly into the poet's sense of literary history. Writing pastoral, as well as sonnets and ballads, McKay inscribes himself into the English literary tradition. Thus, his formal decisions reflect his substantial ambitions as a writer and allow him to critique and alter the tradition to which he aspires. As a young man in Jamaica, his mentor Walter Jekyll, a Scottish expatriate, availed to McKay an extensive library, where the young poet first read "Childe Harold, The Dunciad, Essay on Man, Paradise Lost, the Elizabethan lyrics, Leaves of Grass, the lyrics of Shelley and Keats." 30 Of the poems McKay wrote prior to his expatriation, Wayne Cooper notes that "[d] espite his facility with dialect, at a most basic level he had also assimilated as his own the language of the dominant culture. He had not yet, however, learned to use its literary traditions to explore thoroughly the nature of his fundamental estrangement." ${ }^{31}$ What emerges in reading Harlem Shadows is how pastoral engages this "fundamental estrangement," while flaunting McKay's agility in adopting and reinventing tradition. Pastoral, in particular, excavates a space for his perspective. McKay accomplish this not simply by assigning the pastoralist role to a poor black émigré, but by deftly observing how the essential characteristics of the pastoral mode might translate into the twentieth century.

As "The Tropics in New York" demonstrates, McKay uncovers in pastoral how modernity's displacements and alienations can alter the very experience of place, which is to

\footnotetext{
${ }^{30}$ McKay (2007), 16.

${ }^{31}$ Cooper, 46.
} 
say, the place-sense that individuals introduce to a location can even alter the topography of that place. A storefront therefore becomes a site of loss, and this pastoral lyric, by delineating their distance from each other, forms a direct route between Jamaica and Harlem. Within the history of pastoral, this is a new kind of distance. But it is also a new kind of space. Harlem as global terminus becomes a neighborhood of émigrés and immigrants, one destination on the map of the African Diaspora and the Great Migration. To understand any location as entire, discrete from the reach of other cultures and societies, is to misunderstand the constellation of geographies every identity can absorb in a lifetime.

Moreover, McKay's pastoral reflects a map of the Harlem Renaissance that restores the significance of nature and the land to black experience in America. As a "means of attaining psychic equilibrium, establishing continuity with the past," and "discharging the artist's obligation to the black community" pastoral emerges from the complex history African Americans have had towards their natural environments. ${ }^{32}$ From slavery of the Colonial era to the Great Migration of the early twentieth century, America was inhospitable as a social space and a cultural environment. This "Black Land" is the site of racialized labor and concomitant oppressive systems, from which many generations sought escape. How then do we reconcile the historical pastoralism of Harlem and Harlem as the cultural capital and diasporic center of the black world? ${ }^{33}$ Or, to borrow a phrase from Brent Hayes Edwards, how does pastoral, as an African American literary form, respond to the "epistemology of fracture" that the Diaspora poses within American cultural space? The past, however much it might invoke an idyll of nature, is not the elsewhere to which Harlem Renaissance pastoralists long to return, and herein lies the quandary expressed so forcefully in "Enslaved": that "denied a human place" every place reinforces its global displacement.

\footnotetext{
32 Bone, 123.

${ }^{33}$ Edwards (2001), 292.
} 
For McKay, pastoral rooted aesthetic invention to questions about time and space that were critical to understanding the integrality of racial difference to American cultural identity in the twentieth century.

\section{"Subway Wind"}

While "The Tropics in New York" suggests the limitations of New York as a place of belonging or the neighborhood of Harlem as a home, a poem like "Subway Wind" explores how writing pastoral can serve to remake the very space where the pastoralist feels his exclusion. Despite a recent article that reads "Subway Wind" as exemplary of McKay's "agricultural imagination," the poem has been largely overlooked in the poet's oeuvre and in the canons of Modernism and the Harlem Renaissance. ${ }^{34}$ Like Ezra Pound's "In a Station at the Metro," McKay's poem rises out of modern experience - mass transit and the masses. And, like "The Tropics in New York," the poem homes in on manifestations of nature in the city: in this case, a current of wind passes through an underground subway platform, where the pastoralist stands at a distance from the crowd of city dwellers:

Far down, down through the city's great, gaunt gut

The gray train rushing bears the weary wind;

In the packed cars the fans the crowd's breath cut,

Leaving the sick and heavy air behind.

And pale-cheeked children seek the upper door

To give their summer jackets to the breeze;

Their laugh is swallowed in the deafening roar

Of captive wind that moans for fields and seas; ${ }^{35}$

McKay portrays the subway wind as "weary" and "captive," trapped in the manufactured world of "the city's great, gaunt gut," from which the wind "moans for fields and seas." While the pathetic fallacy here is evident and the pastoralist identification with the wind

\footnotetext{
${ }^{34}$ Posmentier (2012), 279-80.

${ }^{35}$ McKay (2008), 178.
} 
expresses the diffuse pain of his dislocation — uncontainable, inexhaustible, unbearable-by

isolating the one natural element in an unnatural environment, like the wind and like a vagabond, he wanders away from the white commuters and their "pale-cheeked children." McKay's wandering pastoralist bears a resemblance to Modernism's flâneur; however, where anonymity liberates the flâneur, freeing him into the crowd, this pastoralist's racial and cultural identity glare.

Captive to his environment, the pastoralist's only recourse is to imagine himself elsewhere. The lines that immediately follow resituate the poem in a Jamaica of the mind:

Seas cooling warm where native schooners drift

Through sleepy waters, while gulls wheel and sweep, Waiting for windy waves the keels to lift Lightly among the islands of the deep;

Islands of lofty palm trees blooming white

That lend their perfume to the tropic sea, Where fields lie idle in the dew drenched night, And the Trades float above them fresh and free.

The wind connects city and country figuratively and meteorologically, so that not only does McKay—as wind, as pastoralist, as vagabond—travel back and forth between New York and Jamaica, but he also inhabits both places at once. That this happens within the sixteen lines of the poem, and that the movement between places happens within a single sentence, demonstrates once more how double-consciousness can be spatially organized. I use DuBois's term to signal the psychological underpinnings of the African American experience of "two-ness"; for, McKay describes the feeling of racial alienation, brought on by "looking at one's self through the eyes of others," that divides his speaker into "two souls, two thoughts... two warring ideals in one dark body." ${ }^{\prime 36}$ But McKay’s imaginative departure from the subway platform to Jamaica reflects what I read as the spatialization of doubleconsciousness, which builds on its originally intended meaning: even as the pastoralist stands

${ }^{36}$ DuBois, 11. 
on the crowded platform, he is displaced by his racial alienation, as if he were somehow made invisible. Physically, he is in the crowd; psychologically, he is elsewhere. The fragmentation of double-consciousness is not merely interior but manifests as a place-sense. A part of this place and, at the same time, apart from it, he observes his environment and his dislocation with a "second sight" and a second feeling. ${ }^{37}$ McKay experiences his specific place as an ethnic minority, a citizen of the diaspora, and a country person. He shows through pastoral how New York evokes and embodies other cultures and environments, places that perceived together inscribe his painful social distance, so that both place and person are hybridized.

In addition, McKay historicizes the pastoralism of "Subway Wind" by converting the subway wind into a trade wind, transforming a trope into a specific tropospheric effect. The "Trades," also known as "trade winds," were patterns of wind that directed European imperial trade routes across the Atlantic Ocean to the Americas, dispersing populations of dust and people from Africa to the Caribbean Seas; the trade winds reflect the poet's peregrinations and literally navigated the diaspora of which he was a part. If citing the Trades connects "Subway Wind" to the history of the slave trade, then by rendering them in the final line as afloat, "fresh[,] and free" attempts to redress their problematic associations. As with the word "vagabond," McKay co-opts an old term and endeavors to make it new, and in doing so, he begins a sociocultural recovery, escaping from under the long shadow of traumatic history. He liberates (poetically) the Trades and himself.

Pastoral may mark social and geographical distances, but more significantly, it enables the writer to interrogate these distances. Although McKay allocates the first eight lines of the poem to New York and the last eight lines to Jamaica, reconstituting their

\footnotetext{
${ }^{37}$ Ibid, 10.
} 
geographical discreteness, the tight knit of the interlocking rhyme weaves the two places into a revisionary space, a space in which city and country can become one. Form therefore accomplishes what language and the imagination cannot: it proffers the interrelatedness of train, crowds, fields, seas, memory, grief, "pale-cheeked children," and McKay. Form, like the wind, insinuates the imperceptible but powerful connections between the islands of Manhattan and Jamaica, and allows the displaced poet to imagine a place that fuses old and new environments and corrects the distressing fragmentation of his distinctive place-sense. In "Subway Wind," McKay critiques the hegemonic structures within American experience by employing new conceptions of pastoral and its pastoralists. Ultimately, the poem moves toward a cross-cultural ecological community: a space in which every organism plays an integral part, a place where everybody might belong.

Paul Gilroy observes that one of the objectives of the Harlem Renaissance lay in "the politics of fulfillment," which he explains as "the notion that a future society will be able to realise the social and political promise that present society has left unaccomplished...[and] this is a discursive mode of communication." ${ }^{38}$ Pastoral, too, is a discursive mode. The poet's Modernist revision of pastoral communicates to readers the urgency of recognizing who the pastoralist is and how we might better understand the conditions and circumstances of his displacement, especially as they are shaped by modernity. While psychic and historical griefs abound in Harlem Shadows, they serve above all to document the racial, social, and economic injustices McKay experienced and observed firsthand. The poems of Harlem Shadows are never merely lamentations or elegies, though elements of both appear, and rarely do the poems seek sources of consolation beyond their immediate lines. Rather, pastoral lyrics like "The Tropics in New York" and "Subway Wind," which alternately depict

${ }^{38}$ Gilroy (1993), 37. 
pastoralist displacement and catalyze reader disorientation, invite readers into the poem, where they can encounter other lives and share in re-imagining more inclusive places.

\section{Forms of Belonging}

McKay posits a space beyond nation and culture, a potential home for his displaced people, and yet his pastorals also project a vision of America that radiates throughout Harlem Shadows. After Moscow, McKay traveled to Hamburg, Berlin, and Paris, and then hopped around the south of France during the latter half of the 1920s writing his first novel Home to Harlem (1927), before making his way to Africa in 1930 via Barcelona. In Morocco, he found his nationality the subject of much conjecture. Was he American or British? What was he and where exactly did he come from? To a Moroccan doorman and messenger, a chaoush, he gave this reply:

I said I was born in the West Indies and lived in the United States and that I was an American, even though I was a British subject, but I preferred to think of myself as an internationalist. The chaoush [a Moroccan doorman and messenger] said he didn't understand what was an internationalist. I laughed and said that an internationalist was a bad nationalist. ${ }^{39}$

McKay's coyness here is provocative and, interestingly enough, formally inscribed. Like his pastoral lyrics, his first sentence occupies multiple nations and assumes multiple identities, none of which he differentiates from the other. One might think an "internationalist," pluralist in identity, would be at home anywhere, but at the root of this odd self-definition, a vagabond sentence, he asserts himself as American and internationalist, as if the two were synonymous. In this sense, the pastoral lyrics in Harlem Shadows uncover how the problem of place —indeed, of placelessness — could very well be the misconception that places are distinct and inviolable. Decades earlier, he used the term "internationalist" to emphasize

${ }^{39}$ McKay (2007), 131. 
that transformative class struggle could not be confined to nation-specific revolutions, indicating that a capacious sense of identity was invaluable to global economic equality. ${ }^{40}$ To fix a location, even in a pastoral, would be to fix identity, which McKay observes to be more capacious than the chaoush can comprehend.

McKay's "internationalist" participates in this discourse of place by reminding us that the desire for a global citizenry predates contemporary critical terminology like "transnational" and "planetary," and the poet's vision of America anticipates a latter-day multiculturalism. However, his borderless perspective, vagabond in spirit and "long" in history, complicates the conventional understanding of culture as nationalist and therefore emblematic. Remarking on this same passage, Brent Hayes Edwards argues that McKay's idiosyncratic terminology "insists on locating internationalism against the grain of nationalism without grounding it in any alternate universalism. ${ }^{, 41}$ Likewise, the culture of the Harlem Renaissance cannot be so easily defined, nor so easily absorbed by the dominant culture of the United States. As Michelle Stephens explains, McKay knew that "African Americans were themselves black colonial subjects in search of a national home, in ways similar to the plight of other black colonials in Africa and the Caribbean." 42 In other words, the displacement his pastorals elucidate connects African Americans to a global enterprise of identity formation. His pastoralists are black colonial subjects, and with neither home nor nation, theirs is inevitably a radical global displacement. McKay's pastorals therefore reveal Harlem to be not simply the site of an African American urban modernity, but a location of culture animated by tensions between the promise of a geographic home for blacks and the

\footnotetext{
${ }^{40}$ McKay (1979), 4.

${ }^{41}$ Edwards (2003), 239. Edwards elaborates on McKay's internationalism as cognizant of non-institutional identities resistant to the framework of nation or bureaucratic categorization, which would truly entertain the global vagabond McKay: "This is an internationalism of the defective: the unregistered, the undocumented, the untracked" (239). ${ }^{42}$ Stephens, 133.
} 
various trajectories of diasporic subjects; between a seemingly American-cultural project and the pressures of a truly transnational culture; between modernization and a longing for the past/home that is also a site of dispossession; between the black avant-garde and traditional forms and forms of longing. These tensions might be individually expressed, but they are collectively felt. McKay's pastorals illustrate his acute sense of never quite belonging, and yet pastoral more broadly shines a light on the unseen, the lost, and the disenfranchised.

Indeed, the poet uses pastoral to envision a different community and culture, one where he and others like him might belong. If estrangement can, counterintuitively, empower McKay' pastoralist speakers, the poems thus stage a reconciliation between person and place, between the poet and his eventual home. ${ }^{43}$ Perhaps this is why in transmuting an elsewhere into a here so critical to the pastoral mode, the poems never fully erase either the modal references on which that transmutation depends or the local context they refigure. For McKay, the problem of place can only be understood within "the global context of empire and colonization, war and revolution," and the pastorals in Harlem Shadows explore "forms of cultural belonging" as emphatically American in culture and lyric in form. ${ }^{44}$ However fraught, these poems often culminate in a "localized dream" of McKay's environment, wherein the experience of exclusion triggers a turn to pastoral. The speaker's mind wanders, but the location remains fixed, so that the "localized dream," by its very difference, comes to critique American space. In "The Tropics in New York," for example, McKay scrutinizes the pastoralist's position "in and towards [his location]," an accounting of cultural and geographical relationality that begins to carve out a space for his dislocated pastoralist. ${ }^{45}$ In noting the distances invoked by his surroundings, McKay's pastoralists, like

\footnotetext{
${ }^{43}$ McKay became an American citizen in 1940 and died in Chicago in 1948.

${ }^{44}$ Stephens, 138.

${ }^{45}$ Williams (1973), 26, 164.
} 
Williams's, announce who and what is overlooked, not only blacks but also poor and immigrant populations.

McKay's autobiography concludes with a chapter titled "On Belonging to a Minority" and, as in his poems, he reads his experience beyond the personal and into the political, beyond subject and into culture:

It is hell to belong to a suppressed minority and outcast group. For to most members of the powerful majority, you are not a person; you are a problem. I think I am a rebel mainly from psychological reasons, which have always been more important to me than economic. As a member of a weak minority, you are not supposed to criticize your friends of the strong majority. You will be damned mean and ungrateful. ${ }^{46}$

Here, revisiting a trope he used in Harlem Shadows, the poet is a rebel facing down the "powerful majority"; his sense of himself never strays far from his sense of community. If his pastorals construct a place out of placelessness, McKay suggests that not belonging can become a form of belonging. But it must be contentious. The weak must criticize the strong; the "outcast group" must be a group of outcasts, rebels all. McKay's pastoralist is a rebel in lyric form, challenging the conventions of pastoral in order to challenge an outdated mode of national and cultural identity. Looking back on the publication of Harlem Shadows, McKay would remember the intense excitement of having, for the first time, a presence and audience in the United States: "to me America was the great, difficult, hard world." his vagabond life, McKay’s geographical imagination fixated on America, deciding that it could be a model for the world. It was through pastoral, then, that he conceived of an

\footnotetext{
${ }^{46}$ McKay (2007), 263.

${ }^{47}$ Ibid, 117.
} 
American imaginary as global, racially inclusive, and socially fluid. That McKay could see the "great, difficult, hard world" in America suggests that he saw it, too, in Harlem.

\section{Notes on Jamaica}

In his introduction to Constab Ballads, McKay explains, "I am, by temperament, unadaptive." ${ }^{48}$ These are canny words from a very young man, warning readers, immediate and future, of his inherent resistance to belonging. Significantly, the pastorals of Harlem Shadows respond to this resistance by mediating the obstacles to adaptability, both the speaker's sense of alienation and the environment's inhospitableness. And yet, McKay's unadaptive temperament emphasizes how inflexible he was to particular physical and social settings, even as he chose to wander farther from home. He could also be uncompromising, argumentative, and resistant, too, to the sway of consensus_ - or conciliatory—-thinking, as he would demonstrate throughout his life, severing ties with mentors (Walter Jekyll), journals (Liberator), and his most supportive friends (James Weldon Johnson and Louise Bryant). In this final section, I grapple with McKay's unadaptive temperament and how it compromises the ambitions imbued into his pastoral writing and, at the same time, nourishes a far richer complexity to what national identity can and must encompass. Harlem Shadows would be McKay's last published book of poems, and while that fact in itself suggests an end point to the politically generative poetics of his pastorals, the problems of place that his pastorals elucidate and attempt to resolve continue, troublingly, without resolution for the remainder of his writing life. We can read this as a symptom of McKay's temperament, but more productively acknowledging what his pastorals cannot accomplish advances the difficult project of cultural recovery and remapping that the Harlem Renaissance introduced to

\footnotetext{
${ }^{48}$ McKay (1912), 7.
} 
Modernism. In a sense, I'm now directing this chapter's investigation into another distance pastoral reveals, the distance between the beautiful impossibility of elsewhere and the cold reality of here. If this distance ultimately measures differences in perception, McKay no doubt recognized that such differences inform how we read, imagine, and try to revise the spaces we inhabit and share with others. Or, as the young McKay would insist, "the rebellion was in my heart, and it was fomented by the inevitable rubs of daily life-trifles to most of my comrades, but to me calamities and tragedies." ${ }^{, 49}$

One of these trifles would appear in the last year of his life. By 1947, McKay was suffering from dropsy, the debilitating condition that led to his mother's early death, and made a concerted effort to improve his health by traveling from Chicago, where he had settled, to the warmer climate of San Diego. The move was temporary and brought little relief from his persistent ailments or his frustration with his American literary career. It was in San Diego that he stumbled upon "Notes on Jamaica," a two-part article appearing in the April 12 and April 26 issues of The Nation in 1947. Written by then literary editor Margaret Marshall, the article is a breezy travelogue that poses as ethnographic record, sharing specious observations on race, class, gender, and cultural production of a country that the author seems only to have visited for a brief time. Marshall reports, "To one coming in from the great world Jamaica seems an archaic, period piece, something left over from a simpler time. It has its charm." Listing anecdotes, she identifies her sources as members of the island's white, primarily American and British expatriates who disclose the following: [a]ll 'nice people' agree that the natives have no morals. One woman told me that the native population was 75 per cent illegitimate. The old grannies say that you are not a woman until you've had a child, and girls are anxious to

\footnotetext{
${ }^{49}$ Ibid, 7.
} 
prove their womanhood. Besides, marriage is a costly affair, since it is a great event and must be celebrated properly. By the time they get around to it there may already be seven or eight children on the scene. The connection between sex and sin has simply not been established. ${ }^{50}$

Such frivolity is uncommon in The Nation, so why was this article written? As literary editor, Marshall assigned book reviews, contributed occasional cultural criticism, and had no previous experience with travel journalism or reporting from the field. The article reflects an American postwar moralism that was itself a casual form of cultural imperialism.

"Notes on Jamaica" incensed the convalescing McKay. A longtime contributor, he had most recently published an essay on the Moslem population of North Africa four years earlier and was proud of his affiliation with the progressive publication. But Marshall's article would warrant no discussion had McKay not written an angry letter to the editor in response. Although he mailed the letter, The Nation chose not to publish it, nor has it appeared elsewhere in print, and there is no record of a response from the editor. The letter is currently housed in The Schomburg Center for Research in Black Culture, archived in a roll of microfilm marked “Correspondence Sent.” In it, McKay imbues his political historical acumen with racial rage and the rawness of a reopened wound, his lifelong nostalgia for home. Indeed, the fresh nostalgia that prompted him to write the pastoral lyrics of Harlem Shadows has, in the letter, morphed into a far bleaker expression of cultural self-knowing, and McKay writes from the exile's profoundly conflicted perspective on his adopted country and his native home. To read his letter alongside Marshall's "Notes on Jamaica" is to witness a conversation where neither interlocutor hears the other. It is a conversation about Jamaica, but it is more importantly a conversation about cultural authority and the ethics of cultural

${ }^{50}$ Marshall, 476-77. 
perception. Marshall is a visitor and McKay is an erstwhile native, exiled for more than half his life-between the two, who sees Jamaica?

Dated 23 May 1947, his letter eviscerates Marshall's (and, consequently, The Nation's) perspective and provides a compelling account of his Jamaica, one that is no doubt filtered through his expatriate years. He derides the article as "the sophomoric diary of a school girl" and then asserts that "[although] Jamaica is materially poor, it has spiritual values (not church or religious) which the great United States hasn't.” He continues:

Here are some of the facts about Jamaica. The trains of the railroad (owned by the Jamaican government) may be wooden and battered, like some in Jersey in New England, but the engineers, the brakesmen, the conductors, the station agents and clerks are all Negro. There is no 'race problem' in Jamaica. If there is a 'color problem' it is not between whites and non-whites, but between the blacks and the near-whites and it exists only in the city of Kingston... ${ }^{51}$

For his readers, McKay's choice of the railroad as a first fact of Jamaica is poignant. During World War I, he worked as dining-car waiter on the Pennsylvania Railroad, crisscrossing the country while writing the poems of Harlem Shadows, but the experience was marked by intractable bosses, in-fighting amongst workers, and his own economic hardships, which he would later recount with gripping realism in his semi-autobiographical first novel, Home to Harlem. In contrast, the government-owned railroad of Jamaica reflects the equal opportunities available to Jamaican blacks, who occupy the most menial to the most powerful positions. The proclamation that there is no race problem in Jamaica emphasizes his defining experience and chief criticism of American life. And yet, one senses that he

${ }^{51}$ McKay (1947). 
might be idealizing when he claims that conflict within black populations "exists only in the city of Kingston.”

If McKay previously obscured his identity by self-identifying as a "vagabond," he did so in part to detach himself from the emotional repercussions of displacement and in part to suggest that his wanderings aim at no destination. That his pastorals tend to abstract place through the lenses of memory and imagination follows a Romantic convention; however, a lyric gauze overlays his representation of places that gestures ultimately toward placelessness. His pastoralists, in a sense, have no destination and are, like McKay, vagabonds. Writing about Caribbean Modernism, Simon Gikandi explains that "[Caribbean writers] used exile (in intense cases of ironic reversal and dispersal) as an instrument for transcending the prison house of colonialism. In both a psychological and an ideological sense, exile would be adopted as an imaginary zone distanced from the values and structures of colonialism."52 Gikandi spatializes exile, as if placelessness can affect a provisional location. The exile lives nowhere, but that nowhere can by itself become a kind of home. Such an "imaginary zone" conveniently maps the exile's distances from not only his homeland but also the political and cultural pain of being a colonized subject. The exile is not merely displaced so much as defined by both the place from which he's departed and the place at which he's since arrived. At the same time, paradoxically, the exile stands at a remove from both places. Existing in the language of memory, McKay's home almost isn't there, and "vagabond" comes to stand in for an exilic identity.

The dual citizenship granted by Gikandi’s “imaginary zone” bears a striking resemblance to double-consciousness with a spatial inflection. As I discussed earlier, such double-consciousness effects a twoness that is both interiorized and exteriorized. Dickson

${ }^{52}$ Gikandi, 34. 
Bruce speculates that Du Bois repurposed the term "double-consciousness" from psychology, which describes a self that splits into two distinct identities, and from Emerson, who saw an irreconcilable division within oneself between the world and the spirit. ${ }^{53}$ Even before exile, the colonized subject loses his home when his people lose their sovereignty. The exile's inhabitation of an imaginary zone enforces two identities, each located in a distinct space - a nowhere that sheds his identity as exile and colonized subject and the empire that enforces that identity. The home of the colonized subject thus gets consigned to memory, and yet he inhabits a space that physically, if not politically, becomes his home. Colonialism engenders something like double-consciousness in the colonized subject by dividing the individual into a confusion of history that Glissant and Brathwaite have likened to an erasure. McKay's comparison of American and British societies reveals that the burden of colonialism on the colonized subject might manifest as an unshakeable conflict of allegiances. Representing both his culture and his oppressor, his home becomes impossible to love, but also impossible to disavow. The Jamaica he describes in his letter arises out of an emotional and intellectual compromise, existing in memory, imagination, and, quite possibly, nowhere. It is a Jamaica that resonates with the pastoral lyrics of Harlem Shadows, as if the letter were also written in "a wave of longing," and yet the distance of time, the memory aged out of accuracy, poses a problem to the pastoral work McKay was so passionately committed to in the 1920s. Are the flaws of his memory a consequence of an unfulfilled pastoral vision? Through the eyes of exile, McKay once recognized the "American Negro group is the most advanced in the world... But it sadly lacks a group soul." ${ }^{\text {"5 }}$ If McKay's pastoral writing exposed the need for a group soul in the United States, his inability to ultimately cultivate an inclusive community meant he had to once again look elsewhere. The

\footnotetext{
${ }^{53}$ Bruce, 299-309.

${ }^{54}$ McKay (2007), 267.
} 
letters suggest he looked to the past, where he could project his desire for a group soul onto Jamaica, as he had imagined it through the project of pastoral.

Years removed from home, years of enduring flagrant racial discrimination and painful poverty, McKay could hardly help but have an inconsistent perspective. And yet, his excoriation of Marshall and subsequent description of Jamaica's harmonious society give way to a surprising justification of British imperial rule:

Like the peasants of France, every Jamaican peasant worth his salt, [stet] owns his piece of land. And this much may be said in favor of the British Imperial government: When a few years ago the American United Fruit company tried to buy up the best banana lands of the peasants, the British government blocked the attempt and organized agricultural societies and subsidiary banks to help the peasants. And what is so sacrosanct about the present British Labor government? It consists of Britons, Englishmen, Scotchmen and Welshmen, who think first of the interests of Britain, and why shouldn't they?

It's hard to reconcile these words from the poems he wrote as a former constabulary, when he had been torn between his fellow Jamaicans and the British Empire. Or, from the pointedly anti-imperialist passage in Home to Harlem, in which Jake first learns about the Haitian Revolution. Having served the "interests of Britain," McKay knew quite well what was so egregiously sacrosanct about the British government. However, despite his active involvement in Socialist publications like The Liberator and his work as a delegate at the Fourth Communist Congress in Moscow, McKay often resisted articulating a coherent politics, attending instead to his passionate sense of injustice. "I could never be a radical agitator," he admits in $A$ Long $W$ ay from Home, "For that I was a temperamentally unfit. And 
I could never be a disciplined member of any Community party, for I was born to be poet." ${ }^{55}$ Perhaps transplanting himself from one empire to another, McKay could see his colonized homeland in a more positive light, or perhaps time and distance mitigated past aches. Without more evidence, one can only conjecture whether the letter conveys his true politics or radiates from the heat of argument.

In Constab Ballads (1912), the pain McKay depicts of living as a colonized subject is acute and is heightened upon his serving as a vessel of imperial authority. He laments in "The Heart of a Constab":

'Tis grievous to think dat, while toilin' on here, My people won't love me again, My people, my people, me owna lack skin,De wretched t'ought gives me such pain.

But I'll leave it, my people, an' come back to you, I'll flee from de grief an' turmoil; I'll leave it, though flow'rs here should line my path yet, An' come back to you an' de soil. ${ }^{56}$

"The Heart of a Constab" gives voice to the divisions of self that colonialism imposes on the colonized individual. The "toilin" of the speaker highlights his identity as a worker, even as that work is the enforcement of British imperial authority. In the repetition of "my people," the constabulary speaker voices a solidarity that he's nevertheless excluded from because of his work. The echoing rhyme from "toilin" to the chiming ends words "turmoil" and "soil" is powerful for its emotional description and aspirational energy, and the triumvirate of work, pain, and land invokes the conditions of exile, particularly as Jan Carew has described the Caribbean writer as "a creature balanced between limbo and nothingness, exile abroad and homelessness at home, between the people on the one hand and the colonizer on the

\footnotetext{
${ }^{55}$ McKay (2007), 136.

${ }^{56}$ McKay (2008), 117.
} 
other. ${ }^{, 57}$ At the same time, the poem anticipates McKay's subsequent work in pastoral, in which the longing for home underscores the urgency of self-determination for the nation of Jamaica as well as the exigent transnationalism of modern culture.

In "Notes on Jamaica," Marshall uses two textual examples to demonstrate the country's backwardness: a poem in dialect, which opens the second article, and the newspaper in which that poem was published, The Daily Gleaner. ${ }^{58}$ She describes the poem as written in "a pidgin English that is almost unintelligible" and allows that "it has some rather good lines." George B. Wallace's "Plain Talk" is a dramatic monologue in which a mother beseeches her daughter's lover to love without pretense, to "play noe mo tree-card" and "meck ye plain to you." The irony of Marshall's citing this poem is twofold. For one, the poem's deft appraisal of love's language and romantic performance contradicts the subsequent critique of the natives' mindless, amoral coupling. Secondly, Marshall misreads the dialect as "uneducated," committing a crime of cultural arrogance. Brathwaite would later coin the term "nation language" as an antidote to western European conceptions of “dialect” as "bad English" or "inferior English.” Instead, nation language, according to Brathwaite, is "an English which is not the standard, imported, educated English, but that of the submerged, surrealist experience and sensibility.... it is in an English which is like a howl, or a shout or a machine-gun or the wind or a wave."59 In replacing "dialect" with "nation language," Brathwaite rejects the largely pejorative critical perspective on dialect poetry that was, at its best, patronizing. McKay's departure from Jamaica may have been influenced, in part, by the pressure to continue writing in dialect and he would never again write in dialect

\footnotetext{
${ }^{57}$ Carew, 91.

${ }^{58}$ McKay published his first poems (in dialect) in the 1910s in The Daily Gleaner, and the Kingston-based newspaper was instrumental for his early fame as a poet in Jamaica and England. See Tillery, 23.

${ }^{59}$ Brathwaite, 13.
} 
upon arriving in the United States. Indeed, even in 1947, Marshall cannot see past the "lingo" of Jamaica to give "Plain Talk" a fair reading, an oversight that McKay would have no doubt noticed.

Marshall was not the first or only reader to underestimate the aesthetic values of dialect poetry and her dismissal of "Plain Talk" and The Daily Gleaner reflects a far broader error of what might be considered under-interpretation. Paul Peppis explains that "the dialect poems in Constab Ballads as a verse of repossession that rehabilitates dialect as a medium for poetic expression and colonial critique. ${ }^{, 00}$ McKay, in particular, has received critical revaluations that recognize how his "creolization of dialect speech and traditional prosodic forms and poetic genres serves to defamiliarize English verse, making it less transparent, more resistant to interpretation, more alienating and alien - in a word, modernist." ${ }^{61}$ In reading dialect poetry and the literature of non-Western cultures, Marshall, and critics before and after her, deem the text at hand as "alienating and alien" and then foreclose further interpretive evaluation without questioning the nature, context, and assignation of what seems merely strange, simple, and/or Other. This is not to say that "Plain Talk" must be elevated into the Modernist canon. Rather, that Marshall cannot see Jamaica or, indeed, the modernism and modernity expressed through alterity reposes the questions of where cultural authority resides and who may write that culture. Is there ever any accuracy in writing culture? Given McKay's temporal and geographical distance from post-World War II Jamaica, his depiction of Jamaican social harmony is most likely filtered through nostalgia and bitter experience. But he writes as an insider, while Marshall writes as an outsider. While McKay's home and Marshall's elsewhere might share more qualities of fictiveness than either writer would be comfortable admitting, their perspectives require careful differentiation, a

\footnotetext{
${ }^{60}$ Peppis, 59.

${ }^{61}$ Ibid, 61.
} 
call to nuance that might be more accurately conveyed through poetry. As a dialogue between texts, "Notes on Jamaica" and McKay's letter meet at an impasse, stalling finally in an incommensurable silence.

How McKay writes about home_-as an emotional longing, as a political yardstick, and as the lens through which he experiences his American life-exudes a powerful and operative ambivalence in the pastoral poems of Harlem Shadows. That longing for home resonates palpably in the 1947 letter, whatever McKay's politics have become. In not condemning British Rule, he allows the implication that he condones it, which is especially disturbing to scholars who have focused on his deep engagement in leftist politics during his life and his far-reaching influence on the Black Arts movement and protest literature after his death. However, McKay's attack of Marshall outweighs his political equivocations, and his portrayal of Jamaica ultimately dominates the letter. In this sense, the letter is a defense of home and nation. If the letter expresses a politics at all, it is the politics of cultural authority and, in particular, of spokesmanship. Who gets to speak for and write Jamaica, and whose knowledge reigns supreme? It is no coincidence that this, too, is an argument over territory. "Notes on Jamaica” offends McKay not only for Marshall's erroneous reportage, but also because there are those in the United States—indeed, former contributors to The Nation — who can write a better, truer article. McKay had been writing about Jamaica for his entire career, and the uncomfortable emotional conflicts his home produced in himwhether as a colonized subject, a constabulary, or an exile-was an essential way of understanding a nation steeped in the cross-cultural, transnational history of the Diaspora. While none of this justifies the pro-British thrust of the letter, it would be a mistake to read McKay's letter as mere nostalgia or to attribute his change of heart to feeble health. Above all, the writer is making an argument against Margaret Marshall and, more 
importantly, against the United States. His surprising praise of British rule in Jamaica consequently supports his passionate anti-Americanism. We can certainly puzzle the contradictions of McKay's latter-day perspective on Empire and culture, but it his loss of faith in the United States, his adopted home, that is most pertinent to the discussion of pastoral. If the poems in Harlem Shadows indicate the nuances of his political thought as rooted in personal experience, the imaginative work of place-making that he performs in the pastoral lyrics expresses a faith in the enterprise of becoming American. Consequently, we can read McKay's turn away from poetry as a turn away from pastoral. In the end, this turn suggests how completely McKay believed that the United States had failed racial and ethnic minorities, the poor, and the socially outcast and, moreover, how the revisionary objectives of his particular pastoral would remain impossible.

The 1947 letter further serves as a way McKay writes himself home at the end of his life. Coincidentally, the letter was written almost exactly a year before the writer's death on May 22, 1948. Is the letter a final reckoning with his peripatetic life, his frustrated writing career, and his profoundly complicated global citizenship? My interest here lies, in part, in the coincidence of timing and, in part, in what the letter implies about the work of pastoral for the poet in exile. To look at the letter as a final resting place, a final Jamaica, is to assess what the place-making poetics of McKay's pastoral writing accomplishes as both a modernist effort and a sociopolitical act. As Carew claims, "[the Caribbean writer] by going abroad is in fact, searching for an end to exile." ${ }^{62}$ At the end of his life Jamaica becomes for McKay what America finally could not be, a place where the power of the "group soul" could accomplish racial equality. The letter performs a return to an idealized home and, oddly enough, stands as a culmination of his writing life. Beginning and ending in the

\footnotetext{
${ }^{62}$ Carew, 91.
} 
imaginative figuration of home, the poet's lifelong inquiry into belongingness was the core of his pastoral project. It is bittersweet, then, that the letter demonstrates once again, and once and for all, that only through writing could McKay find way home. 


\section{The Pisan Cantos and the Modernity of Pastoral: \\ Discourse, Race, Locality}

Chapter Three

\section{Pastoral Discourse}

Among theorists of pastoral, Terry Gifford has been most convincing in reading pastoral as a problem of language, explaining, on the one hand, that pastoral "is a way of using language that constructs a different kind of world from that of realism" and, on the other, "pastoral discourse is a linguistic borderland that constructs the artifice of Arcadia." Both these statements apply to Ezra Pound's The Pisan Cantos (1945), which unlike previous and subsequent cantos, is rooted in both a specific place and a specific autobiography and ruminates expansively on the social and cultural distances that distinguish pastorals by American modernist writers in particular. To the extent that pastoral is a problem of language, Pound demonstrates in The Pisan Cantos that that problem arises out of the contingencies of place.

Within the annals of literary history, Pound's place in The Pisan Cantos is extraordinary. In May 1945, the American émigré poet was charged with treason for incendiary broadcasts he made for Radio Rome in support of Mussolini, among other offenses, and then taken from his home in Rapallo to a military prison camp outside of Pisa. The U. S. Detention Training Center was a rehabilitation center housing roughly 3,600 military prisoners, soldiers who had committed minor crimes like disobedience or desertion to crimes of horrific violence like rape and murder. The majority of the "trainees," as the

\footnotetext{
${ }^{1}$ Gifford, 45, 46.
} 
prisoners were known, were African-American; Pound was the sole civilian inmate. ${ }^{2}$ Despite being on Italian soil, the DTC was technically American space, under the jurisdiction of the U. S. Army, and the social phenomena Pound recounts in The Pisan Cantos intimate significant changes to American life, even abroad and even in the peculiar world of a military prison camp. Although he was exempt from the grueling "reprogramming" regimen of the trainees, the poet shared with his fellow inmates a displacement from their native country and, at the same time, a virtual space for national cultural belonging. Indeed, Pound's imprisonment at the DTC from May to November 1945 represents his longest "stay" in the United States in decades, actualized not by his geographical emplacement but by language. He was embedded in an American vernacular language whose "melopoeia" aroused the poet's philological attention and launched a uniquely discursive pastoral in The Pisan Cantos. ${ }^{3}$ In particular, the slang of African American soldiers transformed the Italian landscape into a provisional America. Further, the mix of discourses throughout the poem-from the soldiers' vernacular to various literary and historical discourses-elaborates the social and cultural distances that Pound's distinctive pastoral negotiates, often with meaningful unease. The DTC represents a "linguistic borderland" not for its provisional nature brought on by wartime but for how language as Pound captures it in the poem stands on the verge of cultural formation. As a form that attends to and historically foregrounds the margins of society, culture, and nation, pastoral makes possible a discourse of becoming, and Pound and his fellow inmates, represented in the poem as a collective of pastoralist figures, express an anticipatory American cultural identity.

\footnotetext{
${ }^{2}$ Pound (2003), ix-xliii. For more on Pound's life at the DTC and its concomitant traumas, see Torrey, Allen, and King.

${ }^{3}$ Pound (1954), 25.
} 
Why Pound deploys pastoral in The Pisan Cantos is as pressing a question as how. One line, a refrain that interrupts the poem's rhythm of thought and memory, exemplifies the poet's anxiety about his geographical and cultural emplacement. "Le Paradis n'est pas artificiel," he writes in Cantos 74, 76, and 83, citing Baudelaire, who was commending the hallucinatory states that accompany drug use. ${ }^{4}$ Within Pound's poem, the sentence occurs as a non sequitur but can be read as random reflection, pretentious citation, or an ironic lament of his decidedly unparadisical environs. The repetition of Baudelaire's line makes emphatic that Paradise is not artifice, not a man-made construct, and not an abstraction, and thus highlights a definitive sense of material reality and, especially, space. For, implicit in Pound's repurposing of the line is the question of location. If, for Pound, Paradise is not here but elsewhere, where do we locate that elsewhere? And what exactly is the DTC? As a geographical fact and a provisional nation, it is an American space that is also not an American space, a prison camp that stands in the middle of an open field. While the refrain of "Le Paradise n'est pas artificial" enunciates the realness of Paradise, it has the indirect effect of implying that the DTC may instead be the artificial space. Vividly embodied and experienced as it is, the DTC is a temporary and provisional location, enacting the juridical and social laws of the United States due to the consequences of war. Pound plays with the slipperiness of which location is real and which is not real, exploiting a pastoral tendency to abstract places. But the denial of Paradise's artifice poignantly conveys the poet's overpowering desire to be elsewhere and, further, to erase where he currently, and unquestionably stands. Pound's pastoral dramatizes the psychological urgency attached to place and the distances we long to traverse, as much as it illustrates the sheer strangeness of where the poet suddenly finds himself. (In this sense, the allusion to Baudelaire is apt: being

${ }^{4}$ All quotations from Cantos 74-84 are from Pound (2003). The quoted line is from 74.457 , 76.242, and 83.22. 
at the DTC is hallucinatory.) Discerning what is real and not real, then, is the critical challenge of reading the pastoral of The Pisan Cantos, and more than replaying a tendency, it illustrates the struggle of making a place for oneself in a world that has been so radically upended - by war, by Pound's crime, and, above all, by displacement.

The poem, too, represents a conflict between the work of representing place and of affecting experience, so that it seems at once a document of realism and an occasionally pained reverie. Accordingly, the second iteration of the "Le Paradis n'est pas artificiel," a declaration of the real, leads immediately to a statement of opacity: "States of mind are inexplicable to us" (76.243). Here, Pound seems to comment on the random replay, an interjection, of Baudelaire, while also suggesting that the poem arises out of an extemporaneous composition process. For years, after the book was published to controversy and acclaim in 1948, Pound insisted that The Pisan Cantos emerged entire, drafted in captivity, "not more than three lines" changed afterward, and never revised amidst the throes of his traumatizing imprisonment. ${ }^{5}$ The archive disproves his claims that Cantos 7484 are spontaneous and without artifice, corroborating a complicated textual history that remains in contention by editors and scholars to this day. In expressing the inexplicability of his mind and his poem, Pound performs candor while evading intelligibility. Line by line, he "violates the boundaries between his poem and the outside world," between intention and impulse, to document and affect the social and environmental dynamics of his experience. ${ }^{6}$ Memories drag us in and out of present time; fragmentary observations evoke the extemporaneity of diaristic writing; and bits of dialogue remembered and witnessed engage in a broader conversation about place-making, belonging, and freedom. If Pound

\footnotetext{
${ }^{5}$ Pound was first held in a cage where, exposed to the elements of nature and the constantly shining lights of the DTC, led to a psychological and physical breakdown two weeks in. On the composition history of see Bush.

${ }^{6}$ North (1991), 184.
} 
administers these poetic strategies using collage techniques, he does so in part to dramatize the act of composition. ${ }^{7}$ The reader therefore encounters a poem that seems always to be in process, always in between, always mediating a range of distances and differences. This process is in itself a "linguistic borderland" and illuminates how pastoral as a discourse, as Pound wrote it, is actively engaged in its own making, negotiating between centers and margins that are alternately geographical, cultural, and social. It is the discourse of pastoral that makes this sequence seem so spontaneous and unconstructed.

Reading The Pisan Cantos as a pastoral discourse effectively gathers the array of speakers and utterances into one place and suggests how the DTC as a social space and a marker of nationality informs the identities of its inhabitants. As Ronald Bush has cogently argued, The Pisan Cantos participates in the American pastoral tradition. Like Emerson and Thoreau, Pound, from his early Imagism to his later goals of "Confucian clarity," relationship between sign and signified in nature: to "make it new," the poet must rewrite (and rewrite again) the "primal warblings" of nature with the aim of uncovering the "primitive senses" of a word. ${ }^{9}$ Bush justly highlights the ideological bases of this lineage, a Jeffersonian vision of America as agrarian that would be contaminated by commerce, industrialization, and other expressions of cultural modernity. ${ }^{10}$ In The Pisan Cantos, Pound turns repeatedly to nature as a trope of prophecy and redemption, adhering to the Transcendentalists' theory of language, but he also shares in their "cultural animus against the political and economic conditions of modern America." ${ }^{\prime 11}$ But this animus is often at odds with the sociopolitical forces at work in The Pisan Cantos, which imply the modernities

\footnotetext{
${ }^{7}$ See Perloff (1981), 155-99.

${ }^{8}$ Bush, 278.

${ }^{9}$ See Canto 53; Emerson, 322; and Thoreau, 650.

${ }^{10}$ See Marx (1964), 133-44.

${ }^{11}$ Bush (2005), 282.
} 
Jefferson found potentially contaminating. While Bush's attention to Pound's use of nature to allude to classical pastoral and, in particular, to Emerson and Thoreau clearly engages the history of pastoral, he makes no accounting for Pound's attention to the voices, interactions, and power dynamics that animate his daily life at the DTC and that form the poem's distinctive environment. To claim, as Bush does, that "when Nature speaks, America speaks" in The Pisan Cantos overlooks who actually speaks in the poem and how these speakers voice an America counter to Pound's politics and the agrarian vision upheld by American pastoral tradition. Although The Pisan Cantos certainly participates in this tradition, Pound's capacious attention to his environment leads to a radical reinvention of pastoral as a form and America as a culture.

In addition to the language of nature forming the "germinal consciousness" of the poem, ${ }^{12}$ other voices_ — "a multiplicity of social voices and a wide variety of their links and interrelationships (always more less dialogized)" — stimulate the poet's imagination of place, rendering an environment in which nature and the social are inextricably entwined. ${ }^{13}$ After all, the American-ness of the DTC lies in the voices of the soldiers, not in the nature that Pound observes and collects. That the poet can be at once in the United States and in Italy is only possible because of this duality in the environment: intrinsic yet socially—indeed, dialogically_constructed. Although Bakhtin excludes poetry from his conceptualization of heteroglossia, The Pisan Cantos exemplifies the "diversity of social speech types (sometimes even diversity of languages) and a diversity of individual voices, artistically organized" that he observes in the modern novel. ${ }^{14}$ Pound resists the unity Bakhtin deems characteristic of poetic genres, fracturing his authorial position with a steady injection of competing, chaotic

\footnotetext{
${ }^{12}$ Pound (1968), 92-93.

${ }^{13}$ Bakhtin, 263.

${ }^{14}$ Ibid, 262.
} 
dialogue: a multitude of western and eastern languages and the speech of soldiers, which ranges from black vernacular slang to Army officialese to heavily accented English. Heteroglossia thus enters and creates "spectral dispersion in an atmosphere filled with... alien words, value judgments and accents." ${ }^{\prime 15}$ Voices waft in and out of the window of his attention like weather; on the page, this is paralleled in the various languages that interrupt a rhythm of thought or simply get collaged into the poem. In fusing discourses across registers of speech, cultures, and traditions, Pound develops a pastoral discourse that is surprisingly transnational, inclusive to the point of indiscriminate, and that reflects "the work of imagination as a constitutive feature of modern subjectivity." 16

That Pound "constitutes bonds of nature, culture, and language" through pastoral accords with Gifford's conception of the mode as "a discourse," but the question of what this discourse becomes as a poetics and a document of American culture remains unresolved. Or, to put the question another way, can we read this discourse to better see the cultural work of pastoral as both a modernist experiment and an expression of modernity? How Pound uses discourse to construct pastoral is innovative and exemplary of the modernist poetics that pastoral engenders. Further, I want to argue that the accidents of discourse in pastoral, which spring out of cultural contingencies and flukes in composition, rehearse an emergent American cultural identity and space that reflects demographic and social realities that Pound's political vision could neither have anticipated nor authorized. Pastoral discourse activates social spaces and American localities, and thus Pound unintentionally positions pastoral in The Pisan Cantos as a generative tool for re-imagining American identity as both multicultural and global.

\footnotetext{
${ }^{15}$ Ibid, 277.

${ }^{16}$ Appadurai, 3.
} 


\section{Racing Pound's Pastoral}

About place, William Wordsworth observes: "How exquisitely the individual Mind / ... / to the external World / Is fitted: —and how exquisitely, too- / .. / The external World is fitted to the Mind." Pound's depiction of the external world in The Pisan Cantos is both an expression of mind and the shape his mind comes to assume. Because pastoral indicates the spatial dimensions of a sociocultural dynamic, Pound's demonstration of mind and world in The Pisan Cantos reveals a fraught historical moment in the United States, when demographic changes brought on by new patterns of migration and mobility required a reassessment of American culture, language, and identity. Pound was attentive to these changes, even as they were often subsumed into background or environmental detail. Throughout the poem, he exhibits a curiosity about black soldiers, with whom he interacted daily, listening intently to their use of African American vernacular slang. The experience of these black soldiers—imprisoned, disenfranchised, and yet still identified as American—was hardly different from the African American experience at home, entrenched as it was in Jim Crow laws, and their persistent dialogic presence in The Pisan Cantos replays pastoral conventions like the grievance and the singing contest that seem to resonate with the animating questions of the civil rights movement. Who can be free if all are not free? In giving voice to the black soldiers, Pound humanizes them, makes their presence integral to the environment of the DTC, and permits them to be the poem's other authors, making with Pound another America. Neither Pound nor his fellow inmates are free, and yet, together they are Americans abroad, stand-ins for a nation and its culture. How their racial and social differences manifest, collide, and align with each other in The Pisan Cantos might indicate the promises entailed in a provisional American space. 
I want to propose that the mind to which the external world is fitted in The Pisan Cantos_-and its inverse, the mind fitted to the external world-belongs not only to Pound but also to the social culture of the DTC and, concurrently, the United States at mid-century. Fusing a citational imagination and poetics of assemblage, Pound depicts the external world around him, enriching what he observes with a vast array of literary, historical, and economic allusions and a lifetime of memories. However, if the mind is also to be fitted by the external world, Pound's movement of mind, which Ramazani has identified as a "geopoetic oscillation" for the "rapid-fire transnational displacements" in the Pisan Cantos, suggests both a global vastness and topographical instability to the external world of the DTC. ${ }^{17}$ It is a provisional territory of the United States in transition and in chaos, not unlike the political purgatory Pound presciently describes in Canto $72 .^{18}$ The Pisan Cantos' depiction of American space is problematic not only because of the DTC's wartime functionality nor even the transnationalism of Pound's traveling imagination, though each certainly supports the poem's “[r]apid, multidirectional, unexplained" discursive gestures at place-making. ${ }^{19}$ That depiction is problematic because Pound's effort at pastoral ultimately reveals the contentiousness of American space.

In writing pastoral, Pound sublimates the question of freedom, his own and his fellow inmates', by turning repeatedly to problems of space, in particular how discourse launches the social environment and the natural topography of the DTC. And yet, freedom comes to represent an elsewhere, a location made figurative by its powerful impossibility,

17 Ramazani, 58.

${ }^{18}$ One of the two Italian Cantos, Canto 72 stages a conversation with a resurrected F. T. Marinetti, during which the poet decries the armistice Italy signed with the Allies as treason and that precipitated a period of political purgatory for Mussolini's regime. Numerous descriptions throughout these controversial cantos seem to anticipate Pound's own purgatorial experience in Pisa, though they are explicitly imaginary. See Baciagalupo. ${ }^{19}$ Ramazani, 51. 
which I will explore in greater depth in the next section. Pound's four months at the DTC represent the first time he was embedded in American culture in over a decade and, thus, mark, in a sense, his re-entry into the States. But while his captivity in the DTC rehearses a homecoming, it is further complicated by the freedom of his observations and his poetics and it is informed in no small way by the soldiers' dialogues. The soldiers offer Pound a compelling and uncomfortable reflection of himself while challenging his complex placesense.

"I like a certain number of shades in my landscape," Pound explains (79.31), a declaration of aesthetic taste that echoes William Carlos Williams's "Pastoral," in which the pastoralist speaker wanders into the slums "admiring the houses / of the very poor." Pound's line reflects how discourse shapes his pastoral writing, and his attention to the landscape, a pastoral convention wherein the external world inaugurates private reflection, avails him to literary allusion, not only Williams but also Homer. In the scene that follows Pound's line, though, another allusion for "shades" becomes clear:

I like a certain number of shades in my landscape as per / "doan' tell no one I made you that table" or Whitside:

"ah certainly dew lak dawgs, ah goin' tu wash ou"

(no, not to the author, to the canine unwilling in question) with 8 birds on a wire

or rather on 3 wires, Mr Allingham

The new Bechstein is electric and the lark squawk has passed out of season (79.31-40).

Pound follows his pronouncement of visual preference with fragments of dialogue, a gesture of synesthesia that emphasizes how "shades" is laden with discourse and then makes troublingly clear that "shades" is also being employed in the form of derogatory American slang for black people. What follows then are the voices of trainees, black soldiers whose American vernacular racializes the environment and suggest pastoral as both soundscape and 
a dialogue Pound is perpetually overhearing. But the visual does come into play in these lines: counting birds, Pound must distinguish how many birds sit on how many wires, which a trick of light can make difficult. Sight and sound embellish the landscape, and the poet rehearses the painterly eye alongside his musical ear. He blurs the natural and the mechanical: the Bechtstein piano ("new," "electric"), silently noted, gives way to the "lark squawk."

These lines begin with the poet's subjectivity, and then end with two lines of commentary of unclear provenance. After that lark, he writes, "The sight of a good nigger is cheering / the bad'uns wont look you straight," shifting from sound to sight, seamlessly illustrating the environment as a mixed media text. While the first line seems to be observed, possibly by the poet, the second line could be either overheard or parroted. The diction of the two lines stand in contrast: the genteel word choice of "cheering" gives the first line a formal feel, whereas the second line turns on an American vernacular, eliding syllables to percuss a rougher consonance. The textures of these lines, and those immediately preceding, alternate between the visual and the auditory, and each moves further away from the subjectivity of the poet's "I" on line 31. The discourse becomes increasingly material, practicing a collage technique that diminishes ordinary birds and ordinary voices into items to be arranged, each line's utterance or perception merely an object. Turning sight and sound into material form, Pound affects a topography, sensory perception made into place, cultivating a pastoral through the language of nature that is also the soldiers' speech.

"How does literary utterance arrange itself when it tries to imagine an Africanist other?" 20 Toni Morrison's provocative inquiry is almost impossible to answer with regards to The Pisan Cantos, in part, because Morrison is writing about literary fiction and, in part,

${ }^{20}$ Morrison, 16. 
because Pound's documentation of languages in these particular lines refuses imagining. Discourse here is "decorative—displays... the agile writer's technical expertise" and serves not to reveal the consciousness of the poet but the environment he inhabits. ${ }^{21}$ Pound then writes the following lines twice: "Some minds take pleasure in counterpoint / pleasure in counterpoint" (79.49-50), a claim that builds on the initial aesthetic statement, "I like a certain number of shades in my landscape." His emphasis on the aesthetic emphasizes that dialogue, however voiced and specifically bodied, does not serve to characterize individuals but to affect sounds and images. "Counterpoint," then, describes the poet's method of collecting and arranging language in which contrast, incoherence, and disparity are prized, and race, for Pound, happens to be an incontrovertible indicator of the qualities that make counterpoint such a pleasure for his mind.

While Pound may not exactly be imagining the Africanist other, he does continue the age-old Western trend of appropriating other cultures, particularly those deemed "primitive" or "exotic," to make his art new. And yet, his commitment in The Pisan Cantos to immediacy and spontaneity in recreating his experience at Pisa compels questions of attention, accuracy, and methodology, especially as they pertain to pastoral discourse. How absorptive is Pound's attention as he gathers scraps of dialogue? In recreating the social space and physical location, what does Pound unwittingly observe? In the above-quoted passage, he miscounts the number of wires: to what extent is this error a performative gesture and to what extent can it be attributed to his traumatizing experience in prison? Michael North points to the seemingly spontaneous or improvised moments in The Pisan Cantos as "poetic contingency," explaining that in interrupting the flow of memory or turning his gaze outward to the

${ }^{21}$ Ibid. 
environment Pound "violates the boundaries between his poem and the outside world." 22 How this relates to my earlier proposal to read for a pastoral discourse beyond Pound's omnipresent biography lies in North's provocative yet convincing claim that the poet "gives himself up to chance" and thus "gives up the autonomy of his poetic form." The centrality of "overhearing," then, is quite striking, for it reveals a composition strategy in which dialogue is overheard, taken and reconstituted into the poem, and it enables Pound to perform his outsider status within the society of the DTC. He is not part of the conversation, only a detached, unintentional observer, and so the trainees become the makers of the poem, their overheard words unintentionally revealing truths. Pound's performance of overhearing draws on John Stuart Mill's definition of the lyric as speech overheard, in which "the poet's utter unconsciousness of a listener" makes the private accidentally public. ${ }^{23}$ In this formulation, the trainees are the poets, unconsciously uttering poetry, and the listener is Pound, simply recording what he overhears. But this is a new kind of poetry or, at least, a new kind of poet because Mill's definition of poetry as 'the nature of soliloquy" rests on a solitary speaker, and so Pound overhears a plurality, a collective of poets unaware that someone has caught their "feeling confessed" in a shared solitude. ${ }^{24}$ It is in his overhearing that Pound manages to leave his poem for the outside world that soldiers' dialogue represents. He may not be able to imagine the Africanist other, but he can enter their language as if it were a space, finding himself suddenly in a different America (an elsewhere?) than he has known.

While such a reading supports North's claims of Pound's contingency and implies the exciting possibility that The Pisan Cantos is a series of lyric accidents, it provides an

${ }^{22}$ North (1991), 184.

${ }^{23}$ Mill, 1048.

${ }^{24}$ Ibid. 
incomplete sense of both the composition process and final import of the poem. Pound would never relinquish that much authority and the accidents of the poem are if not performative, then symptomatic of larger cultural contexts. Thus, North enlists the concept of contingency to underscore the persistence of Pound's fascism in the face of what many critics have identified as hints of contrition in these cantos. However, the accidents of overhearing could also generate productive inquiries into what Pound could not see or recognize in the external world. If he could not fully harness his poem to his chosen aesthetic program, that a poem containing history might also include such accidents of context and contemporaneity, then investigating the disruptions, mistakes, stray voices, and stolen glances that make The Pisan Cantos so magisterially incoherent leads us beyond the minutiae of aesthetics and the poet's mind to the world that informs both. The American cultural landscape that results from the sequence results despite Pound's fascist politics and despite his ambitious scheme for The Cantos.

\section{Writing from the Outskirts}

In 1917, the poet observed in an essay that the duel dangers of provincialism were ignorance and social conformism, the first breeding "excessive particularity, insularity and localism" while the second was myopically “concerned with excessive uniformity." 25 Pound's rejection of provincialism served to defend modernism. Decades later, he would reverse his position as his fervent support of Fascism and Mussolini's regime began to inform his art. This historical irony warrants a re-examination of the essay, for despite the alarming contradictions, it anticipates the two-mindedness we often see at play in The Pisan Cantos.

${ }^{25}$ The essay in question, "Provincialism the Enemy" was reprinted in Ezra Pound's Selected Prose 1909-1951, ed. William Cookson (New York: New Directions, 1973), 189-204 and first appeared in The New Age in 12 July 1917. See North (1991), 129-31 for a study of how the early essay anticipated the poet's later politics. 
Pound associated provincialism, as North asserts, "with the outskirts, which insist on their ignorance that they are in fact the center but also the smug intolerance of the center, which denies the outskirts their individual character."26 North's use of the word "outskirts" invokes various forms of displacement and self-imposed marginalization in Pound's later life. In 1925, in dire financial straits, he relocated to Rapallo, a small town on the Italian Riviera hours away from any major city. Here, his literary reputation diminished as he struggle to complete The Cantos and make himself and the "backwater" of Rapallo culturally relevant to the greater world. ${ }^{27}$ Throughout the interwar years, Pound lived in the geographical and professional outskirts. But “outskirts” also resonates with Raymond Williams's call to modernist studies scholars to look beyond the metropolis and toward the "hinterlands," which hardly remained untouched by modernity. ${ }^{28}$

While pastoral has historically walked a line between worldliness and tradition, Pound's use of it reflects how his poetics tends to look forward and backward, alternately drawing from his vast cultural knowledge and alighting on the profane:

Pisa, in the $23^{\text {rd }}$ year of the effort in sight of the tower and was hung yesterday for murder and rape with trimmings plus Cholkis plus mythology, thought he was Zeus ram or another one Hey Snag wots in the bibl'? wot are the books ov the bible? Name 'em, don't bullshit ME.

\section{Or TIs}

a man on whom the sun has gone down the ewe, he said had such a pretty look in her eyes; and the nymph of the Hagoromo came to me, as a corona of angels (74.170-180)

\footnotetext{
${ }^{26}$ North (1991), 129.

${ }^{27}$ Torrey, 126.

${ }^{28}$ Williams (1989), 47.
} 
These lines are distinctive for how specifically they announce the immediate place and time of their writing. The " $23 \mathrm{~d}$ year of the effort" refers to the Italian Fascist calendar: it is July 3, 1945, the day after the DTC saw the execution of Private Louis Till, an African-American trainee and father of the young Emmett Till who would be lynched in Mississippi ten years later. But Pound quickly shifts from the brute facts of his present to the Greek mythology, alluding to the story of Jason and the Argonauts, before returning back again to the DTC with three lines of overheard dialogue. And the process of mixing cultures continues: a Chinese ideogram is placed beside an equivalent phrase in Greek, then falls a conventional pastoral scene of a shepherd and his ewe, and then a nymph from a Japanese Noh play, all of which is collectively recast as "a corona of angels." As North explains, "Pound is quite capable... of identifying civilization with difference and uniformity almost simultaneously," and what the poet creates in lines 170 to 180 is an environment that is as complete as it is necessarily incoherent. The differences may be irrevocable, but they coexist in time and in the spaces of the page and the DTC. Pound's mythological turn elevates Till's execution and the soldiers' conversation, connecting Pound's erudite citations to the social scene and suggesting a pastoral that mediates numerous distances. Choklis, mythology, and the Zeus ram stand in close proximity but also elaborate a moment, and how Pound shifts from his present to cultural past rehearses the pastoral convention of retreat even as he invites comparisons between the marginalized lives of the DTC inmates and the shepherds and nymphs of classical mythology.

Further, that Pound is equally attentive and distracted conveys a certain abandon in his already heterogeneous poetics. Whether or not he intends the vernacular speech of the black soldiers to be an ironic ornament, the poet absorbs their language, demonstrating, as Michael Coyle indicates, how he uses race as "an enabling discourse" for viewing history and 
himself within it. ${ }^{29}$ The conversation with Snag about the Bible orients the mythology but also announces the imperative of authenticity, the real: “don't bullshit ME.” Whoever speaks these words wants the truth, and although the capitalization of "ME" expresses a vocalized emphasis, the typography's objectification of the word offers another reading. The speaker demands an authentic, unrehearsed self. Moreover, the soldiers' Bible conversation, as an utterance overheard, registers as a kind of lyric burst, and, without dialogue markers, it gets absorbed into other more conventionally lyric language.

Pound also submerges the discourse of race into the discourse of pastoral by invoking one of the earliest pastoral conventions, the singing contest, and he deftly insinuates the similarities between the soldiers' Bible conversation to the singing contests of shepherds. But who is the voice behind that final demand, "Name 'em, don't bullshit ME"? Is this a soldier or Pound parroting a soldier? In The Dialect of Modernism, Michael North charts a history of racial masquerade within the modernist avant-garde, noting in particular how Pound regarded "black speech" as "the most prominent challenge to the dominance of received linguistic forms." ${ }^{\text {’0 }}$ The soldiers' Bible conversation, then, reorients literary cultural pasts, making the space of pastoral more dynamic by opening up its discursive range. North reads the African-American presence at the DTC as a "symbol of resistance to the authorities, military and cultural, then holding Pound in jail," describing the soldiers as "living representatives of the African tradition [he] hoped to set against the traditions of Europe." Pound is also observing that, beyond its symbolic resonance, black speech is constituting and thus integral to a new pastoral discourse about American belonging and

\footnotetext{
${ }^{29}$ Coyle (2010), 416. For more on the role of race in Ezra Pound's work, see also Coyle (2001); DuPlessis, 1-28, 106-32; North (1994), 77-99; and Patterson (2008), 1-8.

${ }^{30}$ North (1994), 78.
} 
American alienation. ${ }^{31}$ The Bible conversation recurs again in Canto 76 and 78 , and each iteration, altered by typography and context, reveals Pound's preoccupation with a language that effectively identifies him as American and locates him as imprisoned. Lines 174-176 in Canto 74 therefore insert a perspective of otherness, thwarting the sweeping mythopoesis that has been building in Canto 74, and this perspective implies a more striking contrast than the cultural differences of, for example, ancient Greek and Chinese allusions. That the racial otherness is emphatically American reflects the congruities and incongruities between the poet and the soldiers: he shares their national identity, but not their racial one. The lack of quotation marks also suggests that Pound had yet to decide how to mediate the soldiers' voices, whether performed or documented, into his own language and he absorbs them into the very fabric of his text.

My argument rests on the subtlety with which difference is written and, consequently, read. Pound's attention to different languages in The Pisan Cantos focuses on language — its history, materiality, and semantic potential—and not on difference, and his voracious consumption of cultural knowledge is realized in an accumulative compositional process in The Cantos. For Pound, writing is a process of layering languages, disciplines, voices, cultures, environments, and histories. In Canto 76, Pound rewrites the Bible conversation, elevating the soldiers' speech into a refrain; however, the addition of commentary and punctuation makes the speakers and their racial difference far more apparent than when it appeared to be in Canto 74:

Criminals have no intellectual interests?

"Hey, Snag, wot are the books ov th' bibl"" "name 'em, etc.

"Latin? I studied latin" said the nigger murderer to his cage-mate (cdn't be sure which of the two was speaking)

\footnotetext{
${ }^{31}$ Ibid, 96 and 97.
} 
"c'mon, small fry," sd/the smaller black lad

to the larger.

"Just playin"" ante mortem no scortum

(that's progress, me yr' ' ' se/call it progress/)

Here, Pound conflates the soldiers' status as criminals with their blackness, and the quoted section begins with the prefatory question "Criminals have no intellectual interests?" that the dialogue answers, and then includes dialogue tag that renames the criminals, "said the nigger murderer to his cage-mate." The parenthetical asides that follow are in vernacular slang, like the dialogue, except the ironized authorial subjectivity they reveal is offensive, to say the least. ${ }^{32}$ Pound exhibits the dialogue through the lens of his racist perspective. Whereas the first iteration of the dialogue is anonymized and absorbed into the textual environment, in this replay Pound identifies the soldiers as "criminals," a "nigger murderer," and "his cagemate," though he himself is also a caged criminal like them, and mockingly describes the exchange between soldiers as "progress."

The differences between the dialogues reflect how pastoral gets deployed as discourse in The Pisan Cantos. In this second instance, the text is typographically presented as a dialogue between multiple speakers invoking the singing contests of classical and Renaissance pastoral while supplying new pastoralist figures. Like Corydon and Thyrsis in the seventh of Virgil's Eclogues, Pound's speakers compete to be the dominant voice, only the songs are measures of knowledge rather than celebrations of Arcadia. They are "just playin," but their play makes the poem, just as pastoral singing contests reveal through their singers "something about the composition of poetry, specifically, bucolic poetry." 33 This particular

${ }^{32}$ Although Pound's anti-Semitism is notorious and perhaps precedes his literary reputation, he also expressed racism against African Americans in the radio broadcasts that resulted in the treason charges, his subsequent imprisonment at the DTC and then St. Elizabeths, and finally the justifiable controversy over his winning the 1948 Bollingen Prize. See Torrey, 167. ${ }^{33}$ Fantazzi and Querbach, 355. 
contest implies that Pound's pastoral is a debate over knowledge, over whose voice and which knowledge can ultimately sustain a poetry of place or, conversely, provide a place for poetry. Latin or the Bible? Pound's knowledge or the inmates'?

Moreover, the repeated dialogue in these cantos stages the aggressions of and between the inmates that is harder to discern elsewhere in the poems, which, ironically, tend to mitigate the experience of captivity through other expressions of pastoral lyricism. That the repeated dialogue centers on a debate over Biblical knowledge further summons up discourses of punishment that originated with the Bible, particularly from the Old Testament. Pound and his fellow inmates' displacement is anxiously animated by this daily sense of criminality and adjudication: the repetition of this dialogue expresses the boredom of prison life but also underscores pasts and inborn knowledge that suggests they might be guiltless. Their crimes displace them all; knowing the books of the Bible and Latin offers them the possibility of returning home or to a place where their citizenship, their freest selves, can be restored. In Pound's keen attention to the dialogue and especially to Snag, the sole inmate to be named here, a resemblance becomes clear: both men are criminals with intellectual interests, and if Pound identifies with Snag, it is because both men have the capacity to field literary historical inquiry. The repeated dialogue, then, reflects how and where Pound fits into the social world of the DTC, his provisional homeland. His identification with Snag would seem to confirm, however faintly, a sense of belonging. The dialogue, in this second iteration, is also emphatically placeless, without stated context, and stands alone in a stanza that consists only of dialogue and dialogue tags. Pound's provisional homeland is therefore not an environment, but a discourse, and what locates him in this stanza of Canto 76 is the soldier's African-American vernacular speech, demonstrating how speech can stand in for place. 
The Bible conversation returns again in Canto 77 and, as in Canto 76, it is

typographically marked as dialogue:

—niggers comin' over the obstacle fence

as in the insets at the Schifanoja

(del Cossa) to scale, 10,000 gibbet-iform posts supporting

barbed wire

"St. Louis Till," as Green called him. Latin !

"I studied latin," said perhaps his smaller companion.

"Hey Snag, what's in the bibl'?

what are the books of the bibl'?

Name 'em! don't bullshit me!'

"Hobo Williams, the queen of them all"

"Hey / Crawford, come over here/"

Roma profugens Sabinorum in terras

"Sligo in heaven," murmured uncle William

when the mist finally settled down on Tigulluio (77.265-274)

Comprising two stanzas, this passage tucks the third iteration of the Bible dialogue into a

longer conversation and frames it with some context. Posts forming a perimeter around the

DTC also serve as gibbets, where inmates were executed by hanging, and Pound compares

them to the Italian Renaissance artist Francesco del Cossa's frescoes in the Schifanoja palace.

It was on one of these gibbets that Louis Till was hung, an ominous harbinger to the

population of the living, and his ironic canonization by Green echoes Pound's rendering of

the prison camp, in this instance, as a palace. Yeats's voice follows the inmates' conversation,

a murmur of the afterlife, "Sligo in Heaven." Pound's use of vastly disparate cultural

allusions and registers of language is nothing new, but this third iteration of the Bible

dialogue feels significantly different from the previous two. If these lines possess a lyric

quality that is almost atmospheric, it is because the openness of the form and lack of

punctuation come without an orienting perspective. Loosely layering texts and contexts,

Pound layers discourses to effect a more aesthetically complex pastoral than we've

previously examined. Each text and context is used like material, as if the poem were 
architectural, and the voices of the soldiers, scarcely differentiated by typography or other markers, represent only one material among many. North's claim that Pound "gives up the autonomy of his poetic form" ultimately directs us to recognize the contingencies "between his poem and the political realities outside it," which result from an improvisational, fragmentary, and associative technique. He allows the poem a porousness by writing so freely and without any need to unify or make coherent the heteroglossia in action here. In the dialogue as it first appears in lines 174-176 in Canto 74, Pound includes the soldiers' language into the poem and unwittingly racializes the American pastoral. By Canto 77, this racialization has become habituated into the process of Pound's lyric making, and the black soldiers' speech is one of many layers in the culture of the poem.

That this American pastoral also represents a reckoning of his own cultural identity begs the question of how race might figure into Pound's sense of himself as an American. Again, Morrison proves insightful, explaining: "Explicit or implicit, the Africanist presence informs in compelling and inescapable ways the texture of the American literature. It is a dark and abiding presence, there for the literary imagination as both a visible and an invisible mediating force." 34 If Pound does not contend directly with "the Africanist presence" beyond casual racist observations throughout The Cantos, notions of difference are nevertheless crucial to the poetics of The Pisan Cantos. Difference marks each layer, whether that difference is aesthetic (a Renaissance fresco), literary historical (Yeats), or racial (St. Louis Till and Snag). Recognizing differences becomes a means of orienting the reader in verse passages that can be exceedingly dense and occasionally unintelligible, so obscure and frequent are some allusions, and it is a means by which we see the composition process.

\footnotetext{
${ }^{34}$ Morrison, 46.
} 
The soldiers' names thus offer flashes of lucidity, signaling to the reader that they are back in the social world of the DTC, which we see in Canto 74, when the dialogue first appears:

under les six potences

Absouldre, que tous nous vueil absoudre

lay there Barabbas and two thieves lay beside him infantile synthesis in Barabbas minus Hemingway, minus Antheil, ebullient and by name Thos. Wilson Mr. K said nothing, foolish, the whole month nothing foolish: "if we weren't dumb, we wouldn't be here"

Butterflies, mint and Lesbia's sparrows, and the Lane gang. the voiceless with bum drum and banners, and the ideogram of the guard roosts el triste pesnier si volge (74.96-110)

This passage begins with a citation from fifteenth century poet François Villon's “Ballade des Pendus," before proceeding to name a character from the Bible (Barabbas) and then two of Pound's contemporaries, the American writer Ernest Hemingway and the French composer George Antheil. It is a quick succession of a diverse range of cultural allusions that would not necessarily have immediate import for even the most educated readers. However, the names of the trainees, as the prisoner soldiers were called, are no better known than their illustrious counterparts. Nevertheless, Thos. Wilson, Mr. K, and the Lane gang are familiar insofar as they are pitched in colloquial language, and their ordinariness seems illuminated against the denser lines that surround them. Their racial and linguistic difference is also clarifying. "Under les six potencies / Absoudre, que tous nous vueil absoudre" translates into English as "Under six gallows... Absolve, may you absolve us all.” Villon's merciful plea gets revised in Mr. K's no-nonsense quip, “if we weren't dumb, we wouldn't be here.” Although Mr. K does not seek forgiveness, his words make sense of his plight and express a commensurate forbearance with a touch of humor. Both the Villon and Mr. K reflect 
Pound's attempts to cope with his imprisonment and pending treason trial; the former reflects how he draws on poetic tradition and the latter, how he draws on his immediate environment.

Racial difference does not simply ornament the text, but constitutes it, offering a kind of impromptu exegesis through its relational contexts. Pound interrupts the soldier's speech with natural imagery and another name dropped-“Butterflies, mint, and Lesbia's sparrows - and thus adds more layers to the poem, more citations and associations. Lesbia returns us to literary tradition, but it also endows the lines that follow with greater lyric weight: "the voiceless with bum drum and banners / and the ideogram of the guard roosts." Pound creates an image of the DTC's environment as difficult to read. He describes the rituals of soldiers, "the voiceless" who intone a sound that he can only translate onomatopoetically, and then transforms the guard, "the ideogram," into a language that is neither English nor exactly modern. In these two lines, Pound seems to be struggling to understand the soldiers' racial difference, assigning them figurative language that mediates his incomprehension while attempting to delineate his environment. After all, these lines supply further context to the poem and the poet's situation: as Pound experiences it, home is defamiliarized and destabilizing, yet it is nevertheless his home. In trying to read the soldiers, he is trying to read his place in this social world, measuring the distance between himself and other and between what he knows and does not know. Displaced from a provincial America, estranged from literary culture and political power, Pound arrives in these two lines at a tender and articulable confusion. That his scrutiny remains unresolved confirms Morrison's claim that the "dark and abiding presence" of Otherness animates the literary imagination with "a visible and invisible mediating force." 
Earlier in Canto 74, the poet posed the question: "what whiteness will you add to this whiteness, / what candor?” (74.17-18). In The Pisan Cantos, Pound finds himself abruptly located in an elsewhere as he longs for an elsewhere that can no longer exist. "Whiteness," then, holds many potential referents: it could refer to the page and the material practice of Pound's expansive poetics. It could refer the clouds in the Italian sky, which Pound observed obsessively, confined as he was in a steel cage without cover from the weather and with little else to do. It could refer to the illegibility of his fate, an uncertainty that haunts The Pisan Cantos. But it could as likely refer to his own isolation as a white American in a space dominated by black Americans. According to military records, by December 31, 1945, a month after Pound left the DTC, there had been a cumulative 901,896 African Americans inducted into the U.S. Army and these soldiers accounted for eleven percent of the whole. ${ }^{35}$

For Pound's pastoral, Otherness is visual and auditory, and it contributes to his compositional process of accumulation. The poet makes repeated claims about that process as expressions of nature: "rain is also of the process," "the wind is also of the process,..." It is no coincidence that "and" and "also" are among Pound's most used words in The Cantos. If process as the central preoccupation of The Pisan Cantos highlights how, as Ellen Stauder explains, "poems stage the dynamic process of making," the poet performs process by accumulating eclecticisms and disparities and, thus, delaying the need to choose one word or allusion over another or, indeed, to finish the poem. ${ }^{36}$ Ironically, the byproduct of such a process_-accumulative, prodigious, amplifying — is inclusivity, and so Pound's poetics finally encourages the equivalence of contradictions, developing into a surprisingly pluralistic discourse.

\footnotetext{
35 Selected Service and Victory: The $4^{\text {th }}$ Report of the Director of Selective Service, 189.

${ }^{36}$ Stauder, 27.
} 
Morrison's claim that race, or the "Africanist presence," has an invisible mediating force is, like pastoral, a measure of distance and social dynamics. Race might figure visibly as a vernacular oddity or linguistic ornament, but, invisibly, it telegraphs Pound's fraught selfperception. His displacement, after all, also represents a kind of homecoming now that he is surrounded by Americans and on American territory; however, that identity has been altered by his circumstances as an inmate, a ward of the U. S. Army, and by a population of racial and ethnic minorities that he's scarcely had any contact with. Confronted with the soldiers' criminality, occasional kindnesses, and perpetual discoursing, he inevitably must confront their commonalities: shared identities and shared displacements. Thus, although he positions them at a social and cultural distance, confirming their roles as pastoralists, he stands with them, a pastoralist himself.

\section{Pastoral Locality}

How do we read The Pisan Cantos as pastoral that, through discourse, reimagines American cultural identity? In asserting that, for Pound, "the ultimate unit of composition is the arrangement, embracing component poems, ordering them," Hugh Kenner describes a poetics that prizes not invention but negotiation, appraisal, and curation, a poetics that hinges on how contexts and relations change as poetic components get moved around. ${ }^{37}$ Such a poetics is naturally focused on process and resonates with my previous reading of Williams's poetics as topographical, wherein his pastoral writing absorbs Rutherford's ongoing reconfiguration amidst periods of urbanization. As one would expect of discourse, Pound's pastoral evinces a social and cultural dynamic that constantly re-adjusts depending on the arrangements of speakers, contexts, and attention from line to line. He returns to

\footnotetext{
${ }^{37}$ Kenner (1971), 355.
} 
certain phrases, re-arranging their contexts, making slight alterations to language and typography - sometimes attentively, sometimes distractedly. Pound's use of language "constructs a different kind of world from that of realism." 38 This world creates a space for a pastoral that arises out of a discourse so responsive to the fluctuations of thought and weather and of society and culture that each fluctuation becomes an attempt at locating the self against the other. "Whose world, or mine or theirs / or is it of none?" Pound asks in Canto 81, reflecting on the unpredictability of constructing this world and the uncertainty of where he belongs in it.

Pound's pastoral work in The Pisan Cantos produces a locality, a "complex phenomenological quality, constituted by a series of links between the sense of social immediacy, the technologies of activity, and the relativity of contexts. ${ }^{\prime 39}$ Arjun Appadurai's conception of locality corresponds with the provisional American space that Pound describes and activates in The Pisan Cantos, and it is suggestive of how writing pastoral complements both literary modernism and global modernity. For, the discursive nature of Pound's pastoral parallels "locality as primarily relational and contextual," and the gestures toward a desired emplacement are realized through the process by which locality gets made. ${ }^{40}$ Like pastoral, the production of locality is an ongoing process wherein a place arises out of contingency and longing. Locality is a "quality," and though it can lead to the formation of a territory or neighborhood, it dwells on potentiality, responds to the social dynamics of space, and is never by itself topographically complete. To read Pound and his fellow inmates as pastoralist figures is to measure the distance from where they are to where they want to be, and this measurement expresses a locality. The inhabitants of the DTC form a collective of

\footnotetext{
${ }^{38}$ Gifford, 45.

${ }^{39}$ Appadurai, 178.

${ }^{40}$ Ibid.
} 
longing, standing in relation to each other and to the world outside of the DTC, the various elsewheres that each defines himself as displaced from and that ultimately catalyze a shared sense of displacements. It is within this collectivity of longing that a community, however provisional, forms.

The question "Whose world, or mine or theirs / or is it of none" sifts through pronouns before finally arriving at the bleak conclusion of "none." Pound overlooks the first person plural (ours) and the second person (you). Certainly, this choice inscribes his sense of isolation and his infamous combativeness, but it is not wholly accurate if we consider how his profligate citations invite collaboration with his poetic vision. Other voices join his voice, and the reader, too, participates by unearthing sources and making interpretive leaps and connections. The conflict embedded in the question is further counterbalanced by its placement in perhaps the most well-known passage in The Pisan Cantos, a passionate address to an other, "thou":

What thou lovest well remains, the rest is dross

What thou lov'st well shall not be reft from thee

What thou lov'st well is thy true heritage

Whose world, or mine or theirs or is it of none?

First came the seen, then thus the palpable

Elysium, though it were in the halls of hell

What thou lovest well is thy true heritage

What thou lov's well shall not be reft from thee (81.134-143)

The turn to "thou" here consoles the atmosphere of distress and vulnerability that has pervaded the sequence, and leads to a moment of clarity. Elysium appears, "seen” and "palpable," but to whom it belongs is open-ended, just as the question of whose world remains unanswered. Pound implores "thou" to engage in his world, to love well. He then makes another demand: "Learn of the green world what can be thy place," suggesting that locating oneself in the world becomes more important than claiming the world. I want to 
propose that the production of locality implicitly locates a "we," a community that necessarily stands in for country, and that it is the formation of this locality that pastoral discourse ultimately builds toward. In other words, locality as "a structure of feeling, a property of social life, and an ideology of situated community" aligns with the pastoral discourse that compels us to read The Pisan Cantos as an American inquiry for a global age. ${ }^{41}$ In her groundbreaking study of pastoral ideology throughout western literature, Annabel Patterson argues that embedded in pastoral is a desire for social engagement, observing that "If $I$ is normally the index of subjectivity, and you the audience who permits its expression, we is the sign of community, of some common communicative ground." 42 Patterson discerns in pastoral an implicit potential for connection, a ground in which society and culture are reimagined through the very distances that pastoral traces and hopes to somehow bridge. Pound often intensifies his subjectivity when, turning to pastoral, he draws on natural imagery in order to reflect in solitude. And yet, he expresses in these moments a desire for "some common communicative ground." Placing varying texts in conversation, he demonstrates how a "we" might be possible. However, it is his participation in this conversation that makes a call for community explicit. The following passage begins with lines from Dante and Froissart, in Italian and French respectively, and then continues in his voice:

$\mathrm{ma}$

così discesi per l'aer maligno on doit le temps ainsi prendre qu'il vient or to write dialog because there is no one to converse with to take the sheep out to pasture to bring your g. r. to the nutriment gentle reader to the gist of the discourse to sort out the animals (80.233-41)

\footnotetext{
${ }^{41}$ Appadurai, 189.

${ }^{42}$ Patterson (1987), 2.
} 
Dante's and Froissart's lines are translated into the English as: "But / thus I descended through the malignant air" and "One must take the weather [or time] as it comes." ${ }^{43}$ Both quotations describe the weather as an experience of forbearance and reflect on Pound's struggle to endure his Pisan captivity and the uncertain future. He then pivots from these lines into a series of infinitive phrases: "to write," "to take, "to bring," and "to sort out." Each phrase extrapolates from his reading of Dante and Froissart and indicates an ordering of the social world rather than a solitary world. The dialogue Pound has written-between Dante, Froissart, and himself-models connection where "there is no one to converse with." The parallelism in subsequent lines_- "to bring your g. r. [gentle reader] to nutriment / gentle reader to the gist of the discourse"—equates "the gist of the discourse" to "nutriment." Discourse is the sustenance for the community, between the gentle reader(s) and the writer.

Negative connotations warrant consideration, though, as Pound clearly associates the gentle reader with the sheep and the animals, mindless creatures that need to be lead to pasture and sorted out. Readers of Pound must necessarily grapple with these frustrating and ugly contradictions. Writing from a desire for community, for "discourse," he can shed neither his sense of intellectual superiority nor his antipathy towards difference. His experience at the DTC should have offered ample evidence that he was wrong to perceive the world with these prejudices. Upon seeing the poet's mental collapse, one African American soldier secretly made a writing desk for him and a refrain in The Pisan Cantos honors the memory of this generosity. Reports of Pound's congeniality exist as well: he volunteered as typist and editor to soldiers who needed help when composing letters home and he provided the "nutriment" of his discourse in the form of lectures on economics to

${ }^{43}$ Pound (2003), 146. 
willing ears. Years later, he would remember his time at the DTC as a paradise. Even as I argue that The Pisan Cantos performs a productive political contingency that pastoral writing makes possible, it would be a mistake to idealize the poet's engagement with and perspective on the social world of the DTC (as represented on the page and in the historical record). It was, after all, a prison camp, housing some 4,000 inmates, and, to reiterate, it stands for a complicated and deeply flawed America, shaped by war, criminal behavior, and historical systemic prejudices. Steele emphasized in his 1978 interview with Michael King that black inmates were often misunderstood by outside observers: "We had a large percentage of Negro soldiers, and there were those who thought that these people had a greater tendency to commit offenses; but, our finding, on the contrary, was that it was people with little education — and consequently low self-image and inability to adjust that was the distinguishing characteristic." 44 Some of Pound's depictions of black inmates in The Pisan Cantos imply that he may very well have recognized their vulnerability as not dissimilar from his own. Certainly, his frequent retreat into the memory and his tendency to extract conversations from their context express a sensitivity to an environment aimed at training men for, in Steele's words, "more war." 45

The contradictions I'm noting here, about Pound's prejudices and the poem's communitarian ambitions, confirm North and Morrison's invaluable observations that white canonical writers unwittingly intimate structures of power. These structures of power, which I've identified throughout this dissertation as "distances," constitute, and arguably necessitate, pastoral as a literary form with sociocultural designs. As a form that defines identity in relation to place, projects future spaces of belonging, and imagines elsewhere into here, pastoral has the capacity to absorb and cultivate our collective desires for national

\footnotetext{
${ }^{44}$ King, 54 .

${ }^{45}$ Ibid, 52.
} 
belonging. In this sense, Pound's turn to the infinitive looks beyond himself, beyond his time and what he currently knows. Despite everything, Pound has written a future space of belonging for himself and his fellow inmates, and it is an American space, demonstrating once again that "[p]astoral authors are inescapably of their own culture and its preoccupations." "46 Further, I would posit that "to write dialog," "to take the sheep out to pasture," "to bring the g. r. to nutriment," and "to sort out the animals" articulates a theory of pastoral, connecting the historical "shepherding" to a project of cultural modernity.

Pound consequently finds a provisional unity in the incongruities of the natural environment and his social situation at the DTC:

mint springs up again in spite of Jones's rodents

as had the clover by the gorilla cage with a four-leaf

When the mind swings by a grass-blade an ant's forefoot shall save you the clover leaf smells and tastes as its flower (83.140-6)

Between the labor of the ant and the filth of Jones's rodents, mint and clover grow and the pastoralist's mind springs into action, “swings," from an emplaced perspective. Pound's description highlights an essential interconnectivity, an ecology of human-animal relations. To observe the world at ant-level, as he did to an almost obsessive degree at the DTC, is to see that the gorilla cage necessarily coexists with the clover, the rodents, the ants. Ants are present throughout The Pisan Cantos as a testament to the almost invisible effort of placemaking, and suggest how easily the production of locality might be overlooked if one does not pay attention:

And now the ants seem to stagger as the dawn sun has trapped their shadows this breath wholly covers the mountains

${ }^{46}$ Gifford, 82 
it shines and divides

it nourishes by its rectitude

does no injury

overstanding the earth it fills the nine fields

to heaven

\section{Boon companion to equity \\ it joins with the process \\ lacking it, there is inanition (83.87-97)}

Here, the micro-adjustments made by ants become enormous in scale. Their shadows are met by "this breath," which encompasses both the poet pastoralist's intense attention on the ants and the breath that sustains a line of verse, and suddenly it "wholly covers the mountain." As the lines build toward joining "the process," the antecedent for "it" becomes potentially various - it could be this breath, the dawn sun, the mind, the expanding sceneand is finally identified as "[b]oon companion to equity." Like pastoral's process of placemaking, the process of determining what "it" is exercises an uncertainty that is productive rather than confusing and, in the end, invites inclusivity, proliferating meaning through discourse. Without this process, "there is inanition."

That place-making might also be a process of meaning-making suggests a beautiful vision of locality. The production of locality in The Pisan Cantos, though, is not exactly a production of place, as the provisional, contingent nature of locality means that it is not sitespecific even as it actively engages sociality and space. Which is to say, a locality is always in the process of being made. As such, Appadurai's conception of neighborhoods, which are born of localities and subsequently become situated and actual, has resonance:

neighborhoods are inherently what they are because they are opposed to something else and derive from other, already produced neighborhoods. In the practical consciousness of many human communities, this something else 
is often conceptualized ecologically as forest or wasteland, ocean or desert, swamp or river. ${ }^{47}$

Pound's portrayal of the DTC in The Pisan Cantos suggests a locality, not a neighborhood. However, Appadurai's observation that neighborhoods form in response to "something else" aptly describes how the DTC comes to be defined by Pound as what it is not. Over and over again, his memories cast the prison camp as not the London, not Paris, not Provence, not Rapallo, not the United States of his childhood, but a stark outpost where he finds himself locked into a network of surprising interdependences. "[S]omething else," like Pound's shape-shifting “it," is various, proliferating. Again, we might think of this uncertainty, or indeterminacy, as productive rather than confusing. The poet uncovers not one equity, not one antecedent, but many, and so Pound's observation of the ants in Canto 83 concludes: "When the equities are gathered together, as birds alighting up vital." What is vital is the various, "gathered together," into a net full of meanings. Even as the locality of the DTC fluctuates discursively and in social experience, the "something else" that defines it from moment to moment is also inconstant, culturally and topographically protean.

\section{Pound's Elsewhere: Counting Birds in Canto 79}

"[M] odernity is an elsewhere."48 Appadurai’s statement locates where we might find modernity within the global technological networks of the twenty-first century, in a traversable distance yet still intangible experience. In terms of pastoral, his statement evinces a figurative complexity to the concept of elsewhere, implying that elsewhere itself might be a modernity. In previous chapters, I've noted that "elsewhere" often indulges divergent

\footnotetext{
${ }^{47}$ Appadurai, 183

48 Appadurai, 9.
} 
connotations: McKay equated elsewhere with both his native Jamaica and an imagined future of racial equality in the United States, while Williams saw elsewhere as in the new topographies and demographic populations of Rutherford, New Jersey's urbanization. In the case of Pound, elsewhere is a fraught modernity. Even as he aspires in The Cantos to a future community, he turns perpetually to the past in art and in mind. Thus, Pound's modernity can frequently seem fleeting. Literary, historical, and biographical pasts reflect more a conventional elsewhere for which Pound would seem to long; however, the fleeting nature of modernity in The Pisan Cantos engages the external world by recalibrating the poet's attention away from the past and to the pastoral work of community re-imagining.

While writing The Pisan Cantos at the DTC, Pound would send completed typescripts to his daughter, which were subject to review by officers assigned to read outgoing mail. Because these base censors found his poetry "incomprehensible" and "obscure to the point of suspicion," the poet included a "NOTE TO BASE CENSORS" to "explain the purport of the poem" ${ }^{49}$ :

"the citations from Homer or Sophokles or Confucius are brief, and serve to remind the ready reader that we were not born yesterday.... The form of the poem and the main progress is conditioned by its own inner shape, but the life of the D.T.C. passing OUTSIDE the scheme cannot but impinge, or break the flow." 50

The note represents a de facto artistic statement for The Pisan Cantos, delineating the process by which he layers the poems and absorbs the physical and temporal reality of the DTC. The poem's "inner shape" contains the past, not only citations from touchstone authors but also a lifetime's worth of memories, and it is repeatedly impinged on and broken by what is

\footnotetext{
${ }^{49}$ King, 59.

${ }^{50}$ Pound (1962), 17.
} 
"passing OUTSIDE." Although the note indicates that Pound saw this "inner shape" as primary to the poem, it is endlessly permeable, vulnerable to the external world. That "OUTSIDE" so disrupts and fractures the poem's "inner shape" suggests that Pound permits the space and experience of the poem to be remade. But it also suggests that whatever is outside becomes an elsewhere. How are we to read for pastoral when "elsewhere" becomes so diffuse yet so pervasive? If elsewhere is the point by which we measure the distance and displacement that constitutes pastoral, then Pound's distance from where he longs to be is immeasurable and his displacement unspeakably severe. To this end, whenever the outside penetrates his inner life-where he retreats into the personal and historical pasts - he is brought closer to the reader and to the community promise embedded in pastoral. Pastoral thus provides a means of containing some of these moments of diffuseness, fracture, and disruptions, moments where Pound would seem to lose control of his poem and his sense of place.

An important recurring disruption takes the form of counting birds. In Canto 79, in particular, the counting of birds, compulsively repeated, interrupts the poet's equally compulsive remembering and, as such, figures as a real-time distraction. And yet, the birds' presence sharpens his attention and the reader's, breaking the poem open to what happens outside of the mind and outside of human society. Pound identifies these attention shifts as “counterpoint,” as I noted earlier, but counterpoint implies pattern, and to recognize the bird counts as distractions that interrupt and impede the poem's purposeful progress opens Canto 79 to an alternative thought and feeling that is disordering and disorderly. Distractions break the stream of narrative memory and then permit the possibility of another structure and another path for the imagination (the poet's and the reader's). Indeed, the bird count habitually redirects attention away from Pound's more virulent politics to the "OUTSIDE." 
The bird count therefore suggests a different narrative from the contemplative interiority of Canto 79, and this interiority, as the poem's opening lines indicates, reflects a preoccupation of whiteness: "Moon, cloud, tower, a patch of the battistero / all of a whiteness" (1-2). Pound lists what he sees from his vantage point at the DTC, gathering each sight into a totalizing vision of purity. For Pound, one of the attractions of Italian fascism was a perceived purity across disciplines as distinct as art and economics. Similarly, the parataxis employed in these first two lines leads us to see the cosmic (moon, cloud) and the constructed (tower, battistero) as equal in value, "all of a whiteness." What Pound sees, then, is not his confinement within an American territory, but the Italian landscape as metonymy for his fascist ideals. Which is to say, rather than perceive reality, he sees his environment as poetic material, tenors on which to invent vehicles for metaphor or mere literary cultural evocations. A "dirt pile" is next compared to the frescoes of del Cossa, and so the poet drifts further away into the realm of memory. The vision of whiteness invites him to think poetically, to not see the reality of his environment, and to retreat into art. Pound's "retreat" suggests the conventional route of pastoral. However, he retreats not to elsewhere, but to the landscape of the past in which memories are seamless, bounded by neither time nor place, easily retrieved. Some memories belong to Pound, but many belong to the historical record and their accessibility makes them seem proximate, indistinct from a broader claim that the past is a place where one can freely wander. If the past is an elsewhere, it is an elsewhere of privilege and power, an elsewhere that Pound sees "all of a whiteness."

Canto 79 stands out amidst The Pisan Cantos for its imaginative engagement with the natural world. After the cacophony of memories, Pound invokes the lynx, whose recurring presence honors Dionysius and a personal mythology he shared with Dorothy Pound. The 
birds counter the work of imagination in the poem because of their startling realism.

Consider these interruptions:

as the young horse whinnies against the tubas

in the contending for certain values

(Janequin per esmpio, and Orazio Vechii or Bronzino)

Greek rascality against Hagoromo

Kumasaka vs. vulgarity

no sooner out of Troas

than the damn fools attacked Ismaurs of the Cicones

4 birds on 3 wires, one bird on one

the imprint of the intaglio depends

in part on what is pressed under it

the mould must hold what is poured into it

in

discourse

what matters is

to get it across e poi basta

5 of 'em now on 2 ;

on $3 ; 7$ on 4

thus what's his name

and the change in writing the song books

5 on 3 aulentissima rosa fresca

so they have left the upper church at Assisi (79.59-79)

For the most part, Pound uses numbers instead of words, and so the typography of the bird count alerts the reader's eye to their textual-material difference. The numbers are

immediately intelligible, whereas the surrounding language, so dense with allusion, resists

comprehension. In this, the numbers function similarly to Pound's use of Chinese ideograms

and the Greek, emphasizing language as visual representation and as tangible objects. But the numbers do more than reinforce the plentiful discourse on modern poetry and visual art.

They orient the text, emplacing the poet-speaker while offering the reader a stronghold against his excessive obfuscation. Indeed, the above quotation comprises Renaissance Italians (Vechii, a composer, and Bronzino, a painter), plot points from two Noh plays, and a mingling of Chinese ideograms and Italian that translate as "Get the meaning across, and then enough." What the meaning is and whether Pound has gotten it across are unclear 
beyond further cultivating a landscape of the past, and this seem to matter less as the activity of the birds — which is to say, the activity of the DTC—-stands, in contrast, in sharper, more precise expression. The birds perform the arithmetic of living, departing from the wires and then returning, flaunting both an essential freedom and a sense of place.

Where would Pound like to be? Compared to the birds, Pound can wander to and from his perch in mind only, and his preoccupation with their movement - the ongoing addition and subtraction of the birds — mirrors his own imagined movement. In this sense, Pound is wherever he'd like to be, and his tent at the DTC, like the birds' telephone wires, represents a sort of home base. That he is, based on military law, on American soil suggests how his geographical dynamic (or dilemma) resonates with his long history of exile. As his geographical and temporal distance from the United States increased, his conception of home was increasingly complicated by memory and imagination. Wherever Pound was, he was elsewhere, and yet, wherever he was, home was elsewhere, too. This reflects a radical dissolution of place and emplacement. In fact, in The Pisan Cantos, Pound is nowhere, fixed as he is in the prison camp, bound by his alleged crime and his nationality, and, at the same time, displaced from (and disenfranchised by) his native country. If Pound's nowhere-ness reflects the modernity of elsewhere-or the elsewhere of modernity, it more significantly collapses the possibility of any homecoming by subordinating actual place to the expansive, yet diffuse place-sense the poet compulsively enacts. Stauder has explained that Pound, and the modernist poetics he inspired, recognized "works of art are the locus of the real" 51 Accordingly, Canto 79 might confirm that we can more readily find the locus of the real in the poem than in the physical location of the DTC.

\footnotetext{
${ }^{51}$ Stauder, 27.
} 
The risk of reading Pound as placeless, though, mitigates the fascist currents that run through The Pisan Cantos. The bird count is therefore a critical resistance to the potential placelessness of Canto 79, in particular, and The Pisan Cantos, in general. Each recurrence of the birds reasserts a contemporaneous place and time, affirming the poem's historical context and reason for being: the poet's alleged treason has led to his incarceration, and this is the where and why of the poem. Moreover, these incontrovertible facts return us to a claims Pound made in Canto 72. The cantos immediately preceding The Pisan Cantos, the controversial Cantos 72 and 73, written in Italian and published in the Fascist propaganda newspaper Marina Repubblicana, resurrect a recently dead F. T. Marinetti and extol Mussolini for restoring Italian culture. Pound depicts a dream world, speaking to the dead Marinetti and living Mussolini and then speaking as Guido Calvacanti, writhing between hell and Purgatory, the fantastical is matched with condemnation of American presidents, usurers, and Jews. Alongside the radio transcripts, the Italian Cantos would seem to justify the treason charges; however, Pound's hateful ravings roam back and forth between exuberant language to rampant prejudice. In Canto 72 , birds arise as interruption, a gesture of music and calm: "I heard then / The voices mixed, their phrases broken, / And many birds in counterpoint." ${ }^{52}$ Given what follows, these lines are almost prophetic. Pound references Clement Jannequin's Chanson des Oiseux, the score of which becomes Canto 75, but these lines describe the interplay of human and animal, positioning "mixed" and "broken" language against bird music. The birds reflect contrast, contributing to the soundscape by casting in relief the incoherence of human voices. The birds represent an interruption and, it would follow, a momentary silencing of the "voices mixed, their phrases broken." Thus, the

\footnotetext{
${ }^{52}$ Bacigalupo, 9-19.
} 
birds reflect a wholly other perceptual way to experience within the poem, and that experience is material, tangible, and real.

On the one hand, my claim contradicts the notion that the work of art is "the locus of the real." For, noting the birds as counterpoint does not merely assign them to a theory of music, nor a prosody; the birds enforce a notion of reality that undermines the poet's efforts to supplant the real with his poem. Which is to say, the real must once again be found outside the poem. On the other hand, the birds are metonymy for music and Olga Rudge, who re-introduced the music of Jannequin to twentieth century audiences, and their presence here anticipates Canto 75, which signifies, like the bird counts of Canto 79, that the poem by itself is insufficient. In lieu of Pound's poetic imagination are a transcription of a song for birds and the birds that occupy the telephone wires hanging over him. The turn to the real, to birds and to musical composition, is a turn to the social, wherein Pound engages with what is outside himself as he does not elsewhere in the text, and to this extent, it suggests the argument that pastoral modernism gestures to throughout my dissertation, that writing pastoral might be more than an abeyance to literary historical tradition but an attempt to write into existence new forms of American cultural identity.

Counting birds represents the most explicit form of measurement in The Pisan Cantos, and in this sense, a demography. One imagines, for Pound the prisoner, keeping track of birds was a way of keeping track of reality, to test his sanity against numbing boredom, the endless loop of his memories, and the mounting uncertainty of his legal fate. Counting birds is also observing nature at its most basic level, noting what's seen, and it is the work, too, of a naturalist. The bird count begins to articulate an ecosystem, the fowl demographics, and it portrays this particular locality as balanced between the human and non-human. Consequently, the lack of subject and syntax in lines where counting takes place effectively 
subsumes the poet into the act of observing and his absent presence intimates his integrality to his place. The environment absorbs him so fully that he is more a part of it than he is himself. His observations of the human are observed with a similar detachment, and while no doubt Pound directs what we see, his naturalist's compilation of "data" bears the glint of objectivity.

But the demography extends beyond bird counts. Indeed, it would be a mistake to read The Pisan Cantos as nature poetry, and even in his ecological turn, Pound's principal investment lies in the formation of new cultures. Scraps of American vernacular mingle with the birds and underscore that pastoral, as a social form, focuses on the interactions between people within places. The fragments of dialogue that appear throughout The Pisan Cantos can also be read collectively as an accounting of people, often reflecting the racial and ethnic makeup of the DTC. ${ }^{53}$ One of the more surprising dialogue fragments, and surprisingly unexamined in the critical literature, appears in Canto 74 and is repeated in Canto 79:

Says the Japanese sentry: Paakk yu djeep over there, some of the best soldiers we have says the captain Dai Nippon Banzai from the Philippines remembering Kagekiyo : "how stiff the shaft of your neck is." an they went off each his own way (74.595-599)

The "Japanese sentry" represents one of estimated 30,000 American soldiers of Japanese descent who served in the military during and immediately after World War II. ${ }^{54}$ That his presence receives qualification from Captain Steele here indicates that the soldier is not an inmate but staffs DTC, and Pound's chosen bit of dialogue spotlights the solider as

\footnotetext{
${ }^{53}$ In his introduction to The Pisan Cantos, Richard Sieburth notes the 3,600 military prison population at the DTC was "mostly African-American" [Pound (2003), xii]. ${ }^{54}$ Commission on Wartime Relocation and Internment of Civilians, 253-54.
} 
cooperative, exceptional for his exemplary duty. He not only reveals the diversity of the DTC demographics, but his rendering of the Asian American population anticipates the politically fraught assignation of one race as a model minority. The phrase returns as a voice that interrupts Pound's reflections on the Goncourt's denunciation of the French Revolution in Canto 79: "paak you djeep oveh there" (82). The line is taken out of context and is played for comic effect, a random aside that either calls for a shift in subject matter or tells Pound to shut up. However, the line also functions like the interruptions of the bird counts because it redirects attention to the immediacy of the DTC, reaffirming the social environment and the contemporaneity of the poet's odd containment in his odd American space.

Pound's interest in the Japanese-American soldier is not exactly fleeting, but it also is not especially attentive. Like the birds, they afford an opportunity for poetic invention, disrupting the poem's "inner shape" of memory and historical reflection by letting the outer world "break the flow." Significantly, this composition strategy mirrors transnational phenomena of migration, immigration, and war that altered the demographic make-up of the United States, globalizing localities as simultaneously precise and arbitrary as an American prison camp in Italy. That the poems of The Pisan Cantos get interrupted, distracted, and broken is because of the poems' consistent attention to its place. Or, put another way, Pound's consciousness shifts and is repeatedly broken because even when deep in thought (and in poetry) he is acutely aware of his social-environmental emplacement. If counting the birds performs a demography, it does so, in part, to reinforce the inherent pastoralism of The Pisan Cantos. 


\section{Pastoral Modernism as an Argument Against Provincialism}

Pound was not the only modernist so preoccupied by provincialism that he felt the need to write about it. In his 1922 essay “The Three Provincialities,” Eliot equated provincialism with a too simplistic conception of nationalism, claiming that "literature is not primarily a matter of nationality, but of language; the traditions of the language, not the traditions of the nation or the race, are what first concern the writer... It is immaterial, from my point of view, whether English literature be written in London, in New York, in Dublin, in Indianapolis, or in Trieste." ${ }^{55}$ What is it about the specter of provincialism that Pound and Eliot found so vexing that they sought to erase the rigid parameters of place from their poems? Provincialism for American modernist writers was not only a problem resolved through exile or migration, but through discourse: literature unbound by nation and race, Eliot implies, affords new opportunities for language. Eliot's claim that a nation's literature is not place-bound but absorbs the peripatetic and promiscuous imaginations of language reflects the intrinsic transnationalism of literary culture in particular and suggests how modernity's porous borders might launch aesthetic experimentation. In this, Eliot was acutely observant of that watershed year, which saw the publications of The Waste Land, Ulysses, and Harlem Shadows, and he was prescient of the social and cultural consequences of war, migration, and global remapping on everyday life. Freed from the constraints of nation, the flux of people precipitated the flux of cultural forms. As Pound writes in his essay on provincialism, "Humanity is a collection of individuals, not a whole divided into segments or units. The only things that matter are the things which make individual life more interesting." 56

\footnotetext{
${ }^{55}$ Eliot, 391.

${ }^{56}$ Pound (1973), 200.
} 
The discourse of pastoral in The Pisan Cantos reflects these arguments against provincialism and, ironically, it is language that supplants place that ultimately enables new conceptions of nation. While the vernacular speech of black soldiers and his fellow inmates locates Pound, it meaningfully troubles what he has understood as an American cultural identity. It is within this "collection of individuals" that he comes to share an understanding of nation as racialized and not "whole." The distances pastoral inscribes measure what distinguishes one from another - Pound from Snag, for example. These distances also express an America that necessarily absorbs racial and ethnic difference, disparities of thought and method, and human conflict. It is what makes America suddenly so interesting to Pound. Which is to say, rather than using pastoral as a mode for environmental description, he realizes in The Pisan Cantos how pastoral reframes his distance from others as a measurement of connection and, moreover, as a dynamic rendering of place as conversations between people and history and the natural world.

Once place becomes incidental as a marker of nation and culture, the possibilities for writing and reading pastoral broaden. While pastoral cannot exactly change the world, the work of imagining a new or different world is, as Benedict Anderson has shown, the work of nation: "What the eye is to the lover - that particular ordinary eye he or she is born with language -whatever language history has made his or her mother-tongue - is to the patriot." ${ }^{, 57}$ The poetic synesthesia of Anderson's observation here is evocative of Pound's attentions to language in The Pisan Cantos, which repeatedly stages encounters with American speech. These encounters then effectively transform his depiction of not only the physical environment of the DTC but also the poem's cultural and rhetorical landscape. In this sense, the world of these poems is a dream world.

${ }^{57}$ Anderson, 154. 
After Pisa, after his 12-year confinement at St. Elizabeths, after his return to Rapallo, often living in self-enforced silence, Pound would lament his failure to achieve what he intended in writing The Cantos:

\author{
I have tried to write Paradise \\ Do not move \\ Let the wind speak \\ that is paradise. \\ Let the Gods forgive what I \\ have made \\ Let those I love try to forgive \\ what I have made. ${ }^{58}$
}

Devastating as this fragment seems, it reaffirms, years later, Pound's passionate commitment to process: "I have tried," he begins as an effort towards concluding. If The Cantos did not cohere in the end, it nevertheless augurs a discourse that remains ongoing. After all, as the discourse of The Pisan Cantos demonstrates, the poet's voice gets subsumed by so many others, and it is through such divergent discourses that we imagine ourselves both here and elsewhere - a paradise that ushers in a heteroglossic modernity, a paradise that is always in the process of being made. Pound himself resisted resolution, explaining in another final fragment, "These lines are for the /ultimate CANTO // whatever I may write / in the interim." Perhaps it is in the interim, in the space of writing, that modernist pastoral best imagines a nation where all of us will one day belong.

${ }^{58}$ Pound (1950), 822. 


\section{WORKS CITED}

Adorno, Theodor W. "Lyric Poetry and Society." Notes to Literature, Volume One. Ed. Rolf

Tiedemann. Trans. Shierry Webber Nicholson. New York: Columbia University Press, 1991. $37-54$.

Allen, Robert L. “The Cage.” Esquire 49 (1958): 22-26.

Alpers, Paul. What is Pastoral? Chicago, IL: University of Chicago Press, 1996.

Alter, Robert. The Art of Biblical Poetry. New York, NY: Basic Books, 1985.

Altieri, Charles. "Whose America is Our America?: On Walter Benn Michaels's Characterization of Modernity." Modernism/Modernity 3.3 (1996): 107-113.

Anderson, Benedict. Imagined Communities: Reflections on the Origin and Spread of Nationalism, Revised Edition. London: Verso, 2006.

Appadurai, Arjun. Modernity at Large: Cultural Dimensions of Globalization. Minneapolis: University of Minnesota Press, 1996.

Bacigalupo, Massimo. “Ezra Pound’s Cantos 72 and 73.” Paideuma 20 (1991): 9-19.

Barrell, John and John Bull, eds. The Penguin Book of English Pastoral Verse. London: Penguin, 1974.

Beasley, Rebecca. Theorists of Modernist Poetry: T. S. Eliot, T. E. Hulme, Ezra Pound. London: Routledge, 2007.

Bhabha, Homi. Foreword. The Wretched of the Earth. By Frantz Fanon. Trans. Richard Philcox. New York: Grove Press, 2004.

Blau, Rachel du Plessis, Genders, Races, and Religious Cultures in Modern American Poetry, 1908-1934. Cambridge, UK: Cambridge University Press, 2001.

Bone, Robert. Down Home: A History of Afro-American Short Fiction from Its Beginnings to the End of the Harlem Renaissance. New York: Putnam, 1975. 
Bourne, Randolph B. "The Social Order in an American Town." The Atlantic Monthly February 1913: $227-36$.

---. "Trans-national America." War and the Intellectuals: Essays by Randolph Bourne, 1915-1919. Ed. Carl Resek. New York: Harper \& Row, 1964. 107-23.

Brathwaite, Edward Kamau. History of the Voice: The Development of Nation Language in Anglophone Caribbean Poetry. London: New Beacon Books, 1984.

Breslin, James. William Carlos Williams: An American Artist. New York, NY: Oxford University Press, 1970.

Bruce, Jr., Dickson D. “W. E. B. Du Bois and the Idea of Double Consciousness.” American Literature: A Journal of History, Criticism, and Bibliography 64.2 (June 1992): 299-309

Buell, Lawrence, The Future of Environmental Criticism: Environmental Crisis and Literary Imagination (Malden, MA: Blackwell Publishing, 2005).

Burt, Stephen. "Scenic, or Topographic Poetry." Companion to Poetic Genre. Ed. Erik Martiny. Malden, MA: Blackwell, 2012. 598-613.

Bush, Ronald. "Pound, Emerson, and Thoreau: The Pisan Cantos and the Politics of American Pastoral.” Paideuma Vol. 34, Issue 2 \& \# (2005): 271-92.

---. "Quiet, Not Scornful?: The Composition of The Pisan Cantos,” A Poem Containing History: Textual Studies in The Cantos, ed. Lawrence Rainey. Ann Arbor: University of Michigan Press, 1996), 169-211.

Carew, Jan. Fulcrums of Change: Origins of Racism in America and Other Essays. Trenton, NJ: Africa World Press, 1988.

Clifford, James. The Predicament of Culture: Twentieth Century Ethnography, Literature, and Art. Cambridge, MA: Harvard University Press, 1988.

Commission on Wartime Relocation and Internment of Civilians. Personal Justice Denied: Report of the 
Commission on Wartime Relocation and Internment of Civilians. Washington, D.C.: Government Printing Office, 1982.

Cooper, Wayne. Claude McKay: Rebel Sojourner in the Harlem Renaissance. Baton Rouge: Louisiana State University Press, 1987.

Coyle, Michael. Ezra Pound ad African American Modernism. Orono, ME: National Poetry Foundation, 2001.

---. "Race,” Eqra Pound in Context. Ed. Ira Nadel. Cambridge, UK: Cambridge University Press, 2010. 412-23.

Cullen, Countee. My Soul's High Song: The Collected Writings of Countee Cullen, Voice of the Harlem Renaissance. Ed. Gerald Early. New York: Anchor, 1991.

Cushman, Stephen. The Meaning of Measure. New Haven, CT: Yale University Press, 1985.

Daniels, Roger. Guarding the Golden Door: American Immigration Policy and Immigrants since 1882. New York: Hill and Wang, 2004.

Davies, Carole Boyce and Babacar M’Bow. “Towards African Diaspora Citizenship.” Black Geographies and the Politics of Place, eds. Katherine McKittrick and Clyde Woods. Cambridge, MA: South End Press, 2007. 14-45.

Department of Labor. Industrial Directory of New Jersey, 1915. Trenton, New Jersey: Bureau of Statistics, 1915.

Dijkstra, Bram. Cubism, Stieglitz, and the Early Poetry of William Carlos Williams. Princeton, NJ: Princeton University Press, 1969.

Dixon, Melvin. Ride out the Wilderness: Geography and Identity in Afro-American Literature. Urbana: University of Illinois Press, 1987.

Doyle, Laura and Laura Winkiel. Geomodernisms: Race, Modernism, Modernity. Bloomington: Indiana University Press. 
DuBois, W. E. B. The Souls of Black Folk. Eds. Henry Louis Gates, Jr. and Terri Hume Oliver. New York: Norton, 1999.

DuPless, Rachel Blau. Genders, Races and Religious Cultures in Modern American Poetry. Cambridge, UK: Cambridge University Press, 2001.

Edwards, Brent Hayes. The Practice of Diaspora: Literature, Translation, and the Rise of Black Internationalism. Cambridge, MA: Harvard University Press, 2003.

---. “Three Ways of Looking at the Harlem Renaissance." Temples for Tomorrow: Looking Back at the Harlem Renaissance. Eds. Geneviève Fabre and Michael Feith. Bloomington: Indiana University Press, 2001. 288-313.

Eliot. T. S., "The Three Provincialities." The Complete Prose of T. S. Eliot: The Critical Edition, Volume 1: The Perfect Critic, 1919-1926. Eds. Anthony Cuda and Ronald Schuchard. Baltimore, MD: The Johns Hopkins University Press, 2014. 390-93.

Emerson, Ralph Waldo. “The Poet,” The Selected Writings of Ralph W aldo Emerson. Ed. Brooks Atkinson. New York: The Modern Library, 1940. 319-41.

Empson, William. Some Versions of Pastoral. New York: New Directions, 1974.

Fantazzi, Charles and Carl W. Querbach. "Sound and Substance: A Reading of Virgil's Seventh Eclogue." Phoenix 39.4 (Winter 1985), 355-67.

Fowler, Alastair. Kinds of Literature: An Introduction to the Theory of Genres and Modes. Oxford, UK: Clarendon Press, 1982.

Frail, David. The Early Politics and Poetics of William Carlos Williams. Ann Arbor, MI: University of Michigan Press, 1987.

François, Anne-Lise. Open Secrets: The Literature of Uncounted Experience. Stanford, CA: Stanford University Press, 2008.

Friedman, Susan Stanford. Mappings: Feminism and the Cultural Geographies of Encounter. Princeton, NJ: 
Princeton University Press, 1998.

Gifford, Terry. Pastoral. London: Routledge, 1999.

Gikandi, Simon. Writing in Limbo: Modernism and Caribbean Literature. Ithaca, NY: Cornell University Press, 1992.

Giles, "The Deterritorialization of American Literature." Shades of the Planet: American Literature as World Literature. Eds. Wai Chee Dimock and Lawrence Buell. Princeton, NJ: Princeton University Press, 2007. 39-61.

Gilroy, Paul. The Black Atlantic: Modernity and Double Consciousness. Cambridge, MA: Harvard University Press, 1993.

Glissant, Edouard. Caribbean Discourse: Selected Essays. Trans. J. Michael Dash. Charlottesville: University of Virginia Press 1989.

---. Poetics of Relation. Trans. Betsy Wing. Ann Arbor: University of Michigan, 1997.

Halperin, David. Before Pastoral: Theocritus an the Ancient Tradition of Bucolic Poetry. New Haven, CT: Yale University Press, 1983.

Hatlen, Burton. "From the Transcendental to the Immanent Sublime: The Poetry of William Carlos Williams, 1913-1917." Paiedeuma: Studies in American and British Modernist Poetry (2003), 123-55.

Hulme, T. E. The Collected Writings of T. E. Hulme. Ed. Karen Csengeri. Oxford, UK: Clarendon Press, 1994.

Jacobs, Jane. The Death and Life of Great American Cities. New York: Vintage, 1992.

Joyce, James. Ulysses. New York: Vintage, 1990.

Kenner, Hugh. A Homemade World: The American Modernist Writers. Baltimore, MD: Johns Hopkins University Press, 1989.

---. The Pound Era. Berkeley: University of California Press, 1971.

King, Michael. "Ezra Pound at Pisa: Interview with John L. Steele.” Texas Quarterly 49 (1978): 49-61. 
Lewis, David Levering, ed. The Harlem Renaissance Reader. New York: Viking, 1994.

---. When Harlem W as in Vogue. New York: Knopf, 1979.

Locke, Alain, ed. The New Negro. New York: Simon \& Schuster, 1992.

Longenbach, James. "The End of the Line.” The Resistance to Poetry. Chicago, IL: University of Chicago Press, 2004.

---. Modernist Poetics of History: Pound, Eliot, and the Sense of the Past. Princeton, NJ: Princeton University Press, 1987.

Mao, Douglas and Rebecca Walkowitz. Bad Modernisms. Durham, NC: Duke University Press, 2006.

Marshall, Margaret. “Notes on Jamaica.” The Nation (April 26, 1947): 476-77.

Marx, Leo. "Afterword: The Machine in the Garden," The Massachusetts Review. 40.4 (1999/2000): 483496.

---. The Machine in the Garden: Technology and the Pastoral Ideal in America. New York: Oxford University Press, 1964.

---. "Pastoralism in America." Ideology and Classic American Literature. Eds. Sacvan Bercovitch and Myra Jehlen. Cambridge, UK: Cambridge University Press, 1986. 36-69.

McKay, Claude. A Long Way from Home. Ed. Gene Andrew Jarrett. New Brunswick, NJ: Rutgers University Press, 2007.

---. Complete Poems: Claude McKay. Ed. William J. Maxwell. Urbana: University of Illinois Press, 2008.

---. Constab Ballads. London: Watts, 1912

---. Letter to Editor of The Nation. 23 May 1947. Claude McKay Collection. Letters and Manuscripts. Box 1, Item 4. Schomburg Center for Research in Black Culture. New York, NY.

---. Negroes in America. Trans. Robert J. Winter. Port Washington, NY: National University Publications, 1979.

---. "The New Negro in Paris." The New Negro: Readings on Race, Representation, and African American 
Culture, 1892-1938. Eds. Henry Louis Gates, Jr. and Gene Andrew Jarrett. Princeton, NJ:

Princeton University Press, 2007. 141-44.

---. The Passion of Claude McKay: Selected Poetry and Prose, 1912-1948. Ed. Wayne Cooper. New York:

Schocken Books, 1973.

---. “Report on the Negro Question.” International Press Correspondence Vol. 3 (January 5, 1923), 16-17.

---. Spring in New Hampshire. London: Grant Richards, 1920.

Michaels, Walter Benn. Our America: Nativism, Modernism, Pluralism. Durham, NC: Duke University Press, 1995.

Mill, John Stuart. "What is Poetry?" The Norton Anthology of English Literature, Volume E: The Victorian Ages. Eds. Carol T. Christ and Catherine Robson. New York: Norton, 2006. 1044-51

Miki, Roy. The Prepoetics of William Carlos Williams: Kora in Hell. Ann Arbor: University of Michigan Press, 1983.

Mitchell, W. J. T., ed. Landscape and Power, Second Edition. Chicago, IL: University of Chicago Press 2002.

Moody, A. David. Eqra Pound: Poet, a Portrait of a Man and His Work, Volume 1: The Young Genius, 1885-1920. Oxford, UK: Oxford University Press, 2007.

Morrison, Toni. Playing in the Dark: Whiteness and the Literary Imagination. New York: Vintage, 1993.

Neumann, William. Rutherford: A Brief History. Charleston SC: The History Press, 2008.

Newberry, Lida, ed. New Jersey: A Guide to Its Present and Past, New Revised Edition. New York, NY: Hastings House, 1977.

New Jersey Writers' Program. Bergen County Panorama. Hackensack, NJ: Bergen County Board of Chosen Freeholders, 1941.

New York Historical Society. Web. <http://www.nyhistory.org>

North, Michael. The Dialect of Modernism: Race, Language and Twentieth Century Literature. Oxford: 
Oxford University Press, 1994.

---. The Political Aesthetics of Yeats, Eliot, and Pound. Cambridge, UK: Cambridge University Press, 1991.

Parker, Kunal M. Making Foreigners: Immigration and Citizenship Law in America, 1600-2000. New York, NY: Cambridge University Press, 2015.

Patterson, Annabel. Pastoral and Ideology: Virgil to Valéry. Berkeley: University of California Press, 1987.

Patterson, Anita. Race, American Literature and Transnational Modernisms. Cambridge, UK: Cambridge University Press, 2008.

Pedersen, Carl. “The Tropics in New York: Claude McKay and the New Negro Movement.” Temples for Tomorrow: Looking Back at the Harlem Renaissance. Eds., Geneviève Fabre and Michael Feith. Bloomington: Indiana University Press, 2001, 259-69.

Peppis, Paul. Sciences of Modernism: Ethnography, Sexology, and Psychology. New York: Cambridge University Press, 2015.

Perloff, Marjorie. The Dance of the Intellect: Studies in the Poetry of the Pound Tradition. Evanston, IL: Northwestern University Press, 1996.

---. The Poetics of Indeterminacy. Evanston, IL: Northwestern University Press, 1981.

Phillips, Dana. The Truth of Ecology: Nature, Culture, and Literature in America. Oxford, UK: Oxford University Press, 2003.

Plotz, John. The Crowd: British Literature and Public Politics. Berkeley: University of California Press, 2000.

Posmentier, Sonya. "The Provision Ground in New York: Claude McKay and the Form of Memory." American Literature 84.2 (2012): 273-300.

---. “The Slave in the Great House: 'The Star Apple-Kingdom,' Property, and the Plantation.” Race and Real Estate. Eds. Adrienne Brown and Valerie Smith. Oxford, UK: University of Oxford 
Press, 2016. 294-312.

Pound, Ezra. “Art of Poetry No. 5.” Interview by Donald Hall. The Paris Review 28. (1962): n. pag.

Web. <http://www.theparisreview.org/interviews>.

---. The Cantos of Eqra Pound. New York: New Directions, 1950.

---. Literary Essays. Ed. T. S. Eliot. New York: New Directions, 1954.

---. The Pisan Cantos. Ed. Richard Sieburth. New York: New Directions, 2003.

---. "Provincialism the Enemy," Selected Prose, 1909-1951. Ed. William Cookson. New York: New Directions, 1973. 189-204.

---. The Spirit of Romance. New York: New Directions, 1968.

---. Letter to William Carlos Williams. 6 November 1946. MS William Carlos Williams Collection.

Poetry Collection. State University of New York Buffalo. Buffalo, NY.

Rabaté, Jean-Michel. 1913: The Cradle of Modernism. Malden, MA: Blackwell, 2007.

Ramazani, Jahan. A Transnational Poetics. Chicago, IL: University of Chicago Press, 2009.

Redfield, Marc. The Politics of Aesthetics: Nationalism, Gender, Romanticism. Stanford, CA: Stanford University Press, 2003.

Said, Edward. Culture and Imperialism. New York: Vintage, 1994.

Selected Service and Victory: The $4^{\text {th }}$ Report of the Director of Selective Service. Washington, DC: Government Printing Office, 1948.

Simmel, Georg. On Individuality and Social Forms. Ed. Donald N. Levine. Chicago, IL: University of Chicago Press, 1971.

Stauder, Ellen. "Poetics," Pound in Context. Ed. Ira Nadel. Cambridge, UK: Cambridge University Press, 2010, 23-32.

Stephens, Michelle Ann. Black Empire: The Masculine Global Empire of Caribbean Intellectuals in the United States, 1914-1962. Durham, NC: Duke University Press, 2005. 
Stevens, Wallace. Collected Poetry and Prose. Eds. Frank Kermode and Joan Richardson. New York: Penguin, 1997.

Taylor, Dorceta. The Environment and the People American Cities, 1600s-1900s: Disorder, Inequality, and Social Change. Durham, NC: Duke University Press, 2009.

Thoreau, Henry David. "Walking," Wlalden and Other Writings, ed. Brooks Atkinson. New York: The Modern Library, 2000. 625-63.

Tillery, Tyrone. Claude McKay: A Black Poet's Struggle for Identity. Amherst: University of Massachusetts Press, 1992.

Toomer, Jean. The Wayward and the Seeking: A Collection of Writings by Jean Toomer. Ed. Darwin T. Turner. Washington, DC: Howard University Press, 1980.

Torrey, E. Fuller. Roots of Treason: Exra Pound and the Secret of St. Elizabeths. Bethesda, MD: Lucas Books, 1992.

von Hallberg, Robert. “The Politics of Description: W. C. Williams in the Thirties.” ELH 45.1 (1978), 131-151.

Wagner-Martin, Linda, ed. Interviews with William Carlos Williams. New York: New Directions, 1976. Wallaert, Josh. “The Ecopoetics of Perfection: William Carlos Williams and Nature in Spring and All." Interdisciplinary Studies in Literature and the Environment 12.1 (2005): 79-98.

Whitman, Walt. Leaves of Grass. New York: Bantam, 2004.

Wilkerson, Isabel. The Warmth of Other Suns: The Epic Story of America's Great Migration. New York: Vintage, 2010.

Raymond Williams. The Country and the City. Oxford: Oxford University Press, 1973.

---. Politics of Modernism: Against the New Conformists. London: Verso, 1989.

William Carlos Williams. “America, Whitman, and the Art of Poetry.” Poetry Journal (1917): 27-36.

---. “A Pastoral.” undated. MS/TS A237. William Carlos Williams Collection. University at Buffalo 
Libraries Special Collection. Buffalo, NY.

---. The Autobiography of William Carlos Williams. New York: New Directions, 1951.

---. The Collected Poems of William Carlos Williams, Volume I: 1909-1939, eds. A. Walton Litz and Christopher MacGowan (New York: New Directions, 1986.

---. The Early Poetry of William Carlos Williams. Ed. Red Townley. Ithaca, NY: Cornell University Press, 1975.

---. Kora in Hell: Improvisations. San Francisco, CA: City Lights, 1967.

---. I W anted to Write a Poem, ed. Edith Heal. Boston, MA: Beacon Press, 1958.

---. Paterson, ed. Christopher Gowan. New York: New Directions, 1992).

---. Selected Essays of William Carlos Williams. New York: New Directions, 1969.

---. The Selected Letters of William Carlos Williams. Ed. John Thirlwall. New York, NY: McDowell, Obolensky Inc., 1957.

---. Spring and All. New York: New Directions, 2011.

Williams, William Eric. “The Doctor,” William Carlos Williams Review 9.102 (Fall 1983): 35-42.

Williamson, Karina. "From Arcadia to Bunyah': Mutation and Diversity in the Pastoral Mode.” Companion to Poetic Genre. Ed. Erik Martiny. Malden, MA: Blackwell, 2012. 568-83.

Witemeyer, Hugh, ed. Pound/Williams: Selected Letters of Ezra Pound and William Carlos Williams. New York: New Directions, 1996. 